\section{Obtención de hidrógeno por descomposición de metano empleando catalizadores de Rh y Pt soportados en y-alúmina, dopada con $\mathrm{Nd}$.}

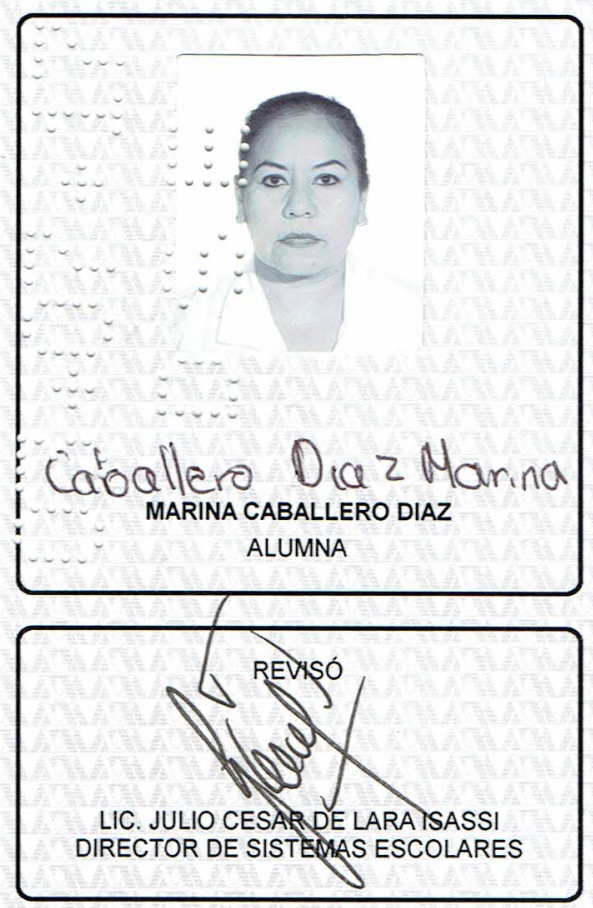

En la Ciudad de México, se presentaron a las 9:00 horas del día 28 del mes de junio del año 2017 en la Unidad Iztapalapa de la Universidad Autónoma Metropolitana, los suscritos miembros del jurado:

DR. JOSE RICARDO GOMEZ ROMERO

DRA. GLORIA ALICIA DEL ANGEL MONTES

DR. SALVADOR CASTILLO CERVANTES

DR. MAXIMILIANO JOEL ASOMOZA PAIACIOS

Bajo la Presidencia del primero y con carácter de Secretario el último, se reunieron a la presentación de la Disertación Pública cuya denominación aparece al margen, para la obtención del grado de:

DOCTORA EN CIENCIAS (QUIMICA)

DE: MARINA CABALLERO DIAZ

y de acuerdo con el artículo 78 fracción IV del Reglamento de Estudios Superiores de la Universidad Autónoma Metropolitana, los miembros del jurado resolvieron:

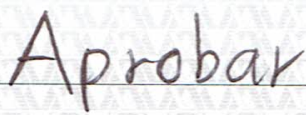

Acto continuo, el presidente del jurado comunicó a la interesada el resultado de la evaluación $y$, en caso aprobatorio, le fue tomada la protesta.
DIRECTOR DE LA DIVISIÓN DE CBI

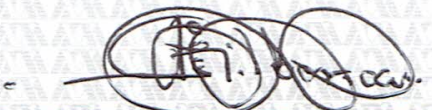

DR. JOSE GILBERTOCORDOBA HERRERA

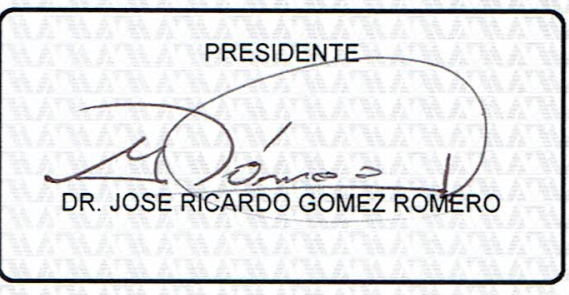

VOCAL

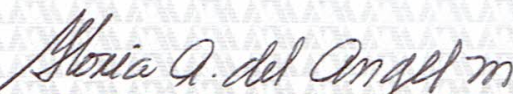
DRA. GLORIAALICIA DELANGEL MONTES
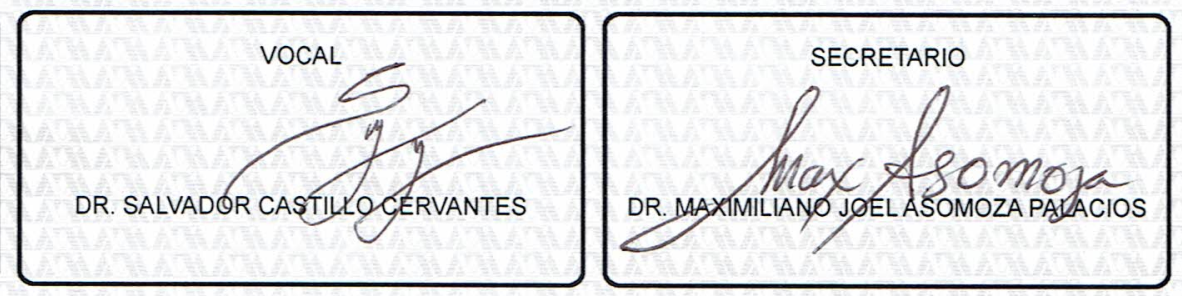


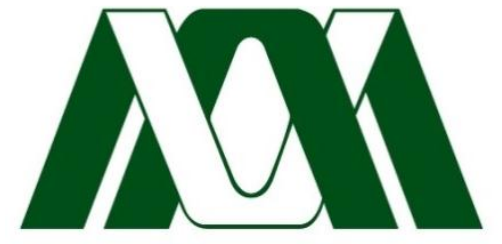

Casa abierta al tiempo

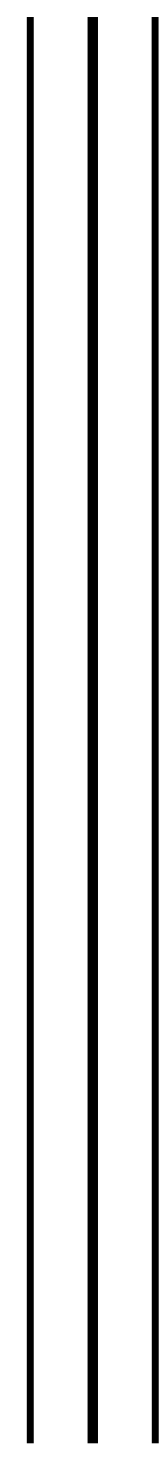

UNIVERSIDAD AUTÓNOMA METROPOLITANA

\author{
DIVISIÓN DE CIENCIAS BÁSICAS E INGENIERÍA \\ UNIDAD IZTAPALAPA \\ POSGRADO EN CIENCIAS (QUÍMICA)
}

TITULO DE LA TESIS

Obtención de hidrógeno por descomposición de metano empleando catalizadores de Rh y Pt soportados en $\gamma$-alúmina, dopada con $\mathrm{Nd}$.

PARA OBTENER EL GRADO DE DOCTORA EN CIENCIAS (QUIMICA)

PRESENTA:

M. en C. Marina Caballero Diaz

NOMBRE DEL ASESOR(A):

Dra. Gloria Alicia del Ángel Montes

FECHA 28 DE JUNIO DEL 2017. 


\title{
Agradecimientos
}

A Dios porque él me ha dado todo lo que tengo

A mi hija Miranda Nicole Caballero Diaz, no sabía que existía un amor tan perfecto hasta que ella llegó a mi vida

\author{
A mis Padres \\ Beatriz Diaz Martínez y Amador Caballero Gálvez
}

Por su amor, apoyo, cariño, tolerancia y comprensión incondicional, los quiero mucho.

Sin su ayuda no hubiera sido posible el desarrollo de ningún proyecto en mi vida.

A mis Hermanos

César, Ymelda y Bilma

Por su tolerancia y apoyo en todo momento, los quiero mucho, si Dios no me los hubiera dado como hermanos, yo los hubiera elegido.

A mi Asesora de tesis la Dra. Gloria Alicia Del Ángel por su entrega, paciencia e interés constante. Gracias por su experiencia compartida y por su ejemplo a seguir, es una gran profesionista, pero sobre todo un gran ser humano.

Agradezco a mis Sinodales, Dr. José Ricardo Gómez Romero por sus apreciados y relevantes conocimientos, comentarios y sugerencias para el desarrollo y culminación de este proyecto.

Dr. Maximiliano Asomoza Palacios por compartirme sus valiosos conocimientos y su ayuda para la conclusión del presente trabajo

Dr. Salvador Castillo Cervantes por sus invaluables comentarios y su ayuda para la conclusión del presente trabajo

Agradezco a la Dra. Virineya Sonia Bertín Mardel por su ayuda no sólo en sentido académico, sino humano y amigable. 
Agradezco el apoyo y el cariño en todo momento de mis grandes amigos que fueron mis profesores de la licenciatura Dr. Roberto Mendoza Serna, I. Q. Eduardo Vázquez Zamora, Físico Carlos Javier Martínez.

A mis amigos Dr. Ángel Zamorano, Víctor Corvera, Erick de los Santos.

Al Consejo Nacional de Ciencia y Tecnología (CONACYT) por la Beca otorgada para la realización de mis estudios de Doctorado 


\section{ÍNDICE}

RESUMEN

INTRODUCCIÓN

JUSTIFICACIÓN

ANTECEDENTES

HIPÓTESIS

OBJETIVOS

CAPÍTULO 1

Síntesis y técnicas de caracterización de Soportes y catalizadores

CAPÍTULO 2

Soportes resultados y discusión

CAPÍTULO 3

Catalizadores de rodio, resultados y discusión

CAPÍTULO 4

Catalizadores de platino, resultados y discusión

PERSPECTIVAS

BIBLIOGRAFÍA 


\section{ÍNDICE DE TABLAS}

Tabla 1. Tamaño de cristal de la y-alúmina.

Tabla 2. Áreas y tamaño promedio de poro de los soportes A, ANd1 y ANd10.

Tabla 3. Acidez de los soportes A y ANdX.

Tabla 4. Tamaño de cristal de la y-alúmina en los catalizadores RhA y RhANdX.

Tabla 5. Características de los catalizadores de Rh.

Tabla 6. Energía de enlace de $\mathrm{Rh} 3 \mathrm{~d}_{5 / 2}$ y abundancia relativa de las diferentes 46 especies de Rh a partir de datos EFRX en catalizadores RhA y RhANdX.

Tabla 8. Conversión, selectividad y TOF para la deshidrogenación del metano sobre 52 catalizadores de $\operatorname{RhANd} X$ a $400^{\circ} \mathrm{C}$.

Tabla 9. Conversión, selectividad y TOF para la deshidrogenación del metano sobre 55 catalizadores de $\operatorname{RhANd} X$ a 700 and $750^{\circ} \mathrm{C}$.

Tabla 10. Tamaño de cristalito para los catalizadores de Rh: fresco y usado en la 59 descomposición del metano.

Tabla 11. Cantidad total de carbón en los catalizadores RhA, RhANd1 y RhANd10 66 después de reacción. 
Table 12. Datos experimentales usados para determinar el pseudo-orden de 68 reacción.

Tabla 13. Energía de activación, valor del factor preexponencial y Ecuación de 72 Arrhenius

Tabla 14. Tamaño de Cristalito de $\gamma^{-}-\mathrm{Al}_{2} \mathrm{O}_{3}$ en los catalizadores de platino.

Tabla 15. Áreas BET, volumen y diámetro de poro de los catalizadores.

Tabla 16. Energías de unión (eV) de Pt4d $\mathrm{d}_{5 / 2}$, Nd 4 $\mathrm{p}_{3 / 2}$ y Nd $4 \mathrm{p}_{1 / 2}$ en los catalizadores de PtA, PtANd1 y PtANd10.

Tabla 17. Conversión, TOF, selectividad y rendimiento para la deshidrogenación del 90 metano sobre los catalizadores de $\operatorname{PtANd} X$ a $750^{\circ} \mathrm{C}$.

Tabla 18. Características de los catalizadores de Pt.

Tabla 19. Cantidad total de carbón en los catalizadores PtA, PtANd1 y PtANd10 94 después de reacción.

Tabla 20. Datos experimentales usados para determinar el pseudo-orden de 96 reacción.

Tabla 21. Energía de activación, valor del factor preexponencial y ecuación de 100 Arrhenius. 


\section{ÍNDICE DE FIGURAS}

Figura 1. Diagrama del proceso experimental.

Figura 2. DRX de los soportes A, ANd1 y ANd10.

Figura 3. Isotermas de adsorción-desorción de los soportes A, ANd1 y ANd10.

Figura 4. Distribución de diámetro de poro de los soportes A, ANd1 y ANd10.

Figura 5. Espectros de IRTF de Piridina adsorbida sobre los soportes A y $\operatorname{ANd} X$.

Figura 6. DRX de los catalizadores RhA y RhANdX.

Figura 7. Isotermas de adsorción-desorción de los catalizadores RhA, RhANd1 y 42 RhANd10.

Figura 8. Distribución de diámetro de poro de los catalizadores RhA, RhANd1 y 42 RhANd10.

Figura 9. Histograma del catalizador RhANd10 fresco.

Figura 10. Perfiles de reducción de los catalizadores de rodio.

Figura 11. Espectros EFRX de Rh 3d para los RhA, RhANd1 y RhANd10.

Figura 12. Espectros de IRTF de CO adsorbido sobre los catalizadores de RhA y 49 $\operatorname{RhANdX.}$ 
Figura 13. Espectros de IRTF de Piridina adsorbida sobre los catalizadores RhA y 50 $\operatorname{RhANd} X$.

Figura 14. Conversión de la descomposición de metano como función de la 52 temperatura para los catalizadores de Rh.

Figura 15. Representación del comportamiento de la descomposición del metano en 56 partículas metálicas Rh para: a) RhA y b) RhANd10.

Figura 16. Estabilidad del catalizador RhANd10 durante 600 min.

Figura 17. Selectividad a la producción de hidrógeno en función de la temperatura 57 para la descomposición del metano sobre catalizadores de $\mathrm{Rh}$ soportados en alúmina-neodimio.

Figura 18. Histograma del catalizador RhANd10 después de reacción.

Figura 19. Patrones de difracción de rayos X para todos los catalizadores de Rh 61 usados.

Figura 20. Análisis de mapeo de puntos MEB-EDERX para el catalizador RhANd10. 62

Figura 21. Imágenes METAR del catalizador RhANd10 después de reacción, a), b), c) 63 y d) corresponden a TF de las áreas escaneadas.

Figura 22. Perfiles de OTP de los catalizadores RhA, RhANd1 y RhANd10 después de 65 reacción.

Figuras 23 a, b y c. Pseudo orden de reacción a T y vo constantes y masa del 68 catalizador variable para los catalizadores de $\mathrm{Rh}$.

Figuras 23 d, e y f Pseudo orden de reacción a T y masa del catalizador constantes y 70 vo variable para los catalizadores de Rh. 
Figura 24. Gráfico de Arrhenius ln k vs. (1/T).

Figura 25. Patrones de difracción de rayos X para todos los catalizadores de Pt.

Figura. 26. Isotermas de adsorción-desorción de los catalizadores PtA y PtANdX

75

Figura. 27. Distribución del tamaño de poro de los catalizadores PtA y PtANdX.

Figura 28. Perfiles RTP- $\mathrm{H}_{2}$ de los catalizadores PtA y PtANd1 y PtANd10 77 promovidos por neodimio.

Figure 29. EFRX de Pt core levels $4 d_{5 / 2}$, (a) y $N d 4 p_{3 / 2}$ and $N d 4 p_{1 / 2}$ core levels (b), 79 catalizadores de PtANdX.

Figura 30. Imágenes MET e histogramas de distribución de tamaño de partículas 82 metálicas para PtA y PtANd1 y PtANd10.

Figura 31. Imágenes HRTEM del catalizador PtANd10 con a), b), c) y d) 83 correspondientes a FFT de las áreas escaneadas.

Figura 32. Análisis de mapeo de puntos MEB-EDERX para el catalizador PtANd10. 84

Figura 33. Análisis de mapeo de puntos MEB-EDERX para el catalizador 84 PtANd10_DRx.

Figura 34. Deconvolución de los espectros infrarrojos de CO de catalizadores 86 monometálicos de Pt soportados en $\gamma \mathrm{Al}_{2} \mathrm{O}_{3}$ y $\gamma-\mathrm{Al}_{2} \mathrm{O}_{3}$ modificado con neodimio $1 \mathrm{y}$ 10\% en peso, a) PtA, b) PtANd1 y c) PtANd10.

Figura 35. Espectros de IRTF de piridina adsorbida sobre catalizadores PtA, PtANd1 87 y PtANd10.

Figura 36. Perfiles de conversión de metano en función de la temperatura. 
Figura 37. Producción de $\mathrm{H}_{2}$ (milimoles de $\mathrm{H}_{2} /$ min* $^{*}$ gcat) en función de la 89 temperatura.

Figura 38. Perfiles de OTP de los catalizadores PtA, PtANd1 y PtANd10 después de 93 reacción.

Figura 39. Velocidad de descomposición del metano contra la temperatura.

Figuras 40 a, b, c. Pseudo orden de reacción a T y vo constantes y masa del 97 catalizador variable para los catalizadores de Pt.

Figuras 40 d, e, f. Pseudo orden de reacción a T y masa del catalizador constantes y 98 vo variable para los catalizadores de Pt.

Figura 41. Gráfico de Arrhenius ln k vs. (1/T).

\section{LISTA DE SIGLAS}

DRX

Difracción de Rayos-X, (XRD, por sus siglas en inglés).

RS

Reformado en Seco

GEI

Gases Efecto Invernadero

AOP

Adsorción con Oscilación de Presión

DGAI

Desplazamiento Gas de Agua Inversa

$\boldsymbol{A}$

$\gamma-\mathrm{Al}_{2} \mathrm{O}_{3}$

ANd1

$\gamma-\mathrm{Al}_{2} \mathrm{O}_{3}-\mathrm{Nd} 1 \%$

ANd10

$\gamma-\mathrm{Al}_{2} \mathrm{O}_{3}-\mathrm{Nd} 10 \%$

$\operatorname{Rh} A$

$\mathrm{Rh} / \gamma-\mathrm{Al}_{2} \mathrm{O}_{3}$

RhANd1

$\mathrm{Rh} / \gamma-\mathrm{Al}_{2} \mathrm{O}_{3}-\mathrm{Nd} 1 \%$

RhANd10

$\mathrm{Rh} / \gamma-\mathrm{Al}_{2} \mathrm{O}_{3}-\mathrm{Nd} 10 \%$

PtA

$\mathrm{Pt} / \gamma-\mathrm{Al}_{2} \mathrm{O}_{3}$ 
PtANd1

PtANd10

PtANd10_DRx

MET

METAR

RTP

OTP

IRTF-CO

IRTF-Piridina

DCT

DIF

BET

AAACO-MBET

EFRX

MEB

CONTRAST Z

EDERX
$\mathrm{Pt} / \gamma-\mathrm{Al}_{2} \mathrm{O}_{3}-\mathrm{Nd} 1 \%$

$\mathrm{Pt} / \gamma-\mathrm{Al}_{2} \mathrm{O}_{3}-\mathrm{Nd} 10 \%$

$\mathrm{Pt} / \gamma-\mathrm{Al}_{2} \mathrm{O}_{3}-\mathrm{Nd} 10 \%$ después de Reacción

Microscopía Electrónica de Transmisión, (TEM, por sus siglas en inglés`

Microscopía Electrónica de Trasmisión de Alta Resolución, (HRTEM, por sus siglas en inglés)

Reducción a Temperatura Programada, (TPR, por sus siglas en inglés).

Oxidación a Temperatura Programada, (TPO, por sus siglas en inglés).

Infrarrojo con Trasformada de Fourier-monóxido de carbono, (FT-IR of $\mathrm{CO}$, por sus siglas en inglés).

Infrarrojo con Trasformada de Fourier-Piridina, (FT-IR of pyridine, por sus siglas en inglés).

Detector de Conductividad Térmica, (TCD, por sus siglas en inglés).

Detector de Ionización de Flama, (FID, por sus siglas en inglés).

Brunauer-Emmett-Teller

Detector Anular de Alto Ángulo de Campo Obscuro-Microscopía de Barrido Electrónico

Espectroscopia de Fotoelectrones de Rayos X, (XPS, por sus siglas en inglés).

Microscopía electrónica de barrido (SEM, por sus siglas en inglés).

Contraste $\mathrm{Z}$

Espectrometría de Dispersión de Energía de Rayos X, (EDS, por sus siglas en inglés). 


\section{RESUMEN}

Este trabajo presenta los resultados de la descomposición catalítica de metano utilizando catalizadores de $\mathrm{M} / \gamma-\mathrm{Al}_{2} \mathrm{O}_{3}(\mathrm{~A})$ y $\mathrm{M} / \gamma-\mathrm{Al}_{2} \mathrm{O}_{3}-\mathrm{Nd}_{2} \mathrm{O}_{3}$ (ANd) para producir hidrógeno, donde (M=Rh y Pt). Todos los óxidos mixtos $\gamma-\mathrm{Al}_{2} \mathrm{O}_{3}-\mathrm{Nd}_{2} \mathrm{O}_{3}$ y los catalizadores $\mathrm{M} / \gamma-\mathrm{Al}_{2} \mathrm{O}_{3}-\mathrm{Nd}_{2} \mathrm{O}_{3}$ se sintetizaron por impregnación húmeda utilizando $\mathrm{Nd}\left(\mathrm{NO}_{3}\right)_{3} \cdot 6 \mathrm{H}_{2} \mathrm{O}, \mathrm{RhCl}_{3} \cdot 3 \mathrm{H}_{2} \mathrm{O}$ y $\mathrm{H}_{2} \mathrm{PtCl}_{6} \cdot 6 \mathrm{H}_{2} \mathrm{O}$ como sales precursoras. Las concentraciones para los catalizadores fueron de $1 \%$ en peso para $\mathrm{M}$, y para $\mathrm{Nd} 1$ y $10 \%$ en peso. La reacción se llevó a cabo de 400 a $750^{\circ}$ C.

Todos los catalizadores redujeron la temperatura de descomposición del metano de 400$750^{\circ} \mathrm{C}$ con respecto a la descomposición térmica no catalítica, la cual se lleva a cabo aproximadamente a $1300^{\circ} \mathrm{C}$.

Los catalizadores de rodio mostraron alta actividad y selectividad a $700{ }^{\circ} \mathrm{C}$, con conversiones alrededor del 74-79\% vol. La actividad por sitio (TOF) fue mayor en los catalizadores con el tamaño de las partículas de $\mathrm{Rh} \geq 2.1 \mathrm{~nm}$. El catalizador $\mathrm{Rh}$ con una concentración de neodimio al 10\% en peso fue altamente selectivo para hidrógeno, (100\%). Este comportamiento se explicó por la mayor interacción entre el Rh y el soporte $\gamma-\mathrm{Al}_{2} \mathrm{O}_{3}$ $\mathrm{Nd}_{2} \mathrm{O}_{3}$. Los catalizadores $\mathrm{RhA}$ y RhANd con $1 \%$ en peso de $\mathrm{Nd}$ mostraron selectividades de 89 y $65 \%$ a $700{ }^{\circ} \mathrm{C}$ respectivamente y productos de etano y etileno; estos productos provinieron de la movilidad de las especies CHx en la superficie del Rh durante la reacción, el carbón producido se depositó principalmente sobre el soporte.

Mientras que los catalizadores de Pt soportados sobre $\gamma$-alúmina-dopada con neodimio exhibieron mayor actividad que el Pt soportado solo sobre alúmina. Todos los catalizadores mostraron alta actividad y selectividad a $750{ }^{\circ} \mathrm{C}$, con conversiones alrededor del 57-80\% Vol. y producciones de hidrógeno de más de 20,000, 15,000 y 14,000 ppm para PtANd10, PtANd1 y PtA respectivamente, también se observaron en la salida de la corriente de metano no convertido, pequeñas cantidades de $\mathrm{C}_{2} \mathrm{H}_{4}$ y $\mathrm{C}_{2} \mathrm{H}_{6}$ (menos del 1\%).

La última etapa del trabajo incluye un estudio cinético del rompimiento del metano, para este propósito se realizaron dos experimentos, el primero consistió en variar la cantidad de catalizador (25, 50, 75 y $100 \mathrm{mg}$ ), manteniendo el flujo de alimentación constante (2 $\mathrm{ml} / \mathrm{min}$ ), en el segundo experimento se varió el flujo del metano (2, 4, 6 y $8 \mathrm{ml} / \mathrm{min}$ ), 
manteniendo la masa del catalizador constante $(50 \mathrm{mg})$. La energía de activación de la descomposición del metano se estimó en 39.2, 40.4 y 38.9 kJ/mol para los catalizadores RhA, RhANd1 y RhANd10, respectivamente y 35.5, 37.9 y $33 \mathrm{~kJ} / \mathrm{mol}$ para los catalizadores PtA, PtANd1 y PtANd10, respectivamente. La caracterización se realizó mediante DRX (XRD, por sus siglas en inglés), adsorción-desorción de $\mathrm{N}_{2}$, MET (TEM, por sus siglas en inglés), MEB (SEM, por sus siglas en inglés), RTP- $\mathrm{H}_{2}$ (TPR- $\mathrm{H}_{2}$, por sus siglas en inglés), IRTF de CO (FT-IR of CO, por sus siglas en inglés), IRTF de Piridina (FT-IR of pyridine, por sus siglas en inglés), EFRX (XPS, por sus siglas en inglés), METAR (HRTEM, por sus siglas en inglés) y análisis de OTP (TPO, por sus siglas en inglés) después de la reacción.

El objetivo del presente estudio fue investigar la influencia del neodimio en los catalizadores $\mathrm{Rh}$ y Pt soportados en $\gamma-\mathrm{Al}_{2} \mathrm{O}_{3}$ dopados con $\mathrm{Nd}_{2} \mathrm{O}_{3}$ en la actividad, selectividad y estabilidad para la descomposición de $\mathrm{CH}_{4}$. Dos concentraciones de $\mathrm{Nd}$ (1 y $10 \%$ en peso) en los catalizadores $\mathrm{Rh}$ y $\mathrm{Pt}$ se evaluaron en la descomposición de $\mathrm{CH}_{4}$ para producir hidrógeno. 


\section{INTRODUCCIÓN}

La necesidad actual de energía es suministrada por la combustión de fuentes de energía no renovables, es decir, los combustibles fósiles, y se asocia con la liberación de grandes cantidades de gases de efecto invernadero (GEI), especialmente el dióxido de carbono $\left(\mathrm{CO}_{2}\right)$ y otros gases nocivos lanzados a la atmósfera. Es posible que algún día el hidrógeno sustituya a los combustibles fósiles en varias aplicaciones como en automóviles y centrales eléctricas [1]. Sin embargo, el hidrógeno en la actualidad se produce principalmente a través de la reforma de combustibles fósiles y se espera que los combustibles fósiles sigan siendo una fuente importante de hidrógeno a largo plazo [2]. En la actualidad, el hidrógeno encuentra aplicación como un compuesto químico en lugar de un combustible en las operaciones comerciales, pero sí se utiliza hidrógeno para sustituir a los combustibles existentes, deben ser desarrollados métodos adecuados para su producción a gran escala.

El hidrógeno no se produce por sí mismo en la naturaleza, sino que se encuentra combinado con otros elementos tales como oxígeno y carbono, es decir, agua o hidrocarburos, por lo que estas sustancias deben descomponerse/reformarse para obtener $\mathrm{H}_{2}$ [3]. Para liberar el hidrógeno, se puede aplicar calor a los hidrocarburos, y para descomponer las moléculas de agua se pueden utilizar procesos termo-químicos, por carga eléctrica (electrólisis) o un proceso fotolítico. Algunos procesos de separación combinan calor y electricidad (electrólisis de vapor). Las bacterias y las algas también se pueden utilizar para producir $\mathrm{H}_{2}$ a partir de biomasa.

Actualmente, el proceso principal para la producción de hidrógeno es el reformado de gas natural con vapor, reacción (1), el cual se lleva a cabo en varias etapas, la primera es el reformado catalítico de metano que es altamente endotérmica, la segunda es el desplazamiento de gas de agua (DGA) reacción (2) que en realidad produce más hidrógeno y la tercera etapa es la separación de la mezcla de $\mathrm{H}_{2}-\mathrm{CO}_{2}$ utilizando adsorción con oscilación de presión (AOP)

$\mathrm{CH}_{4}+\mathrm{H}_{2} \mathrm{O} \leftrightarrow \mathrm{CO}+3 \mathrm{H}_{2}$

$$
\Delta \mathrm{H}^{\circ}=206 \mathrm{KJ} / \mathrm{mol}
$$

$\mathrm{CO}+\mathrm{H}_{2} \mathrm{O} \leftrightarrow \mathrm{CO}_{2}+\mathrm{H}_{2}$

$$
\Delta \mathrm{H}^{\circ}=-41.1 \mathrm{KJ} / \mathrm{mol}
$$

Durante muchos años, la reacción de dióxido de carbono o reformado seco (RS) [4-9] ha sido considerada como una alternativa posible, con la característica atractiva de utilizar un 
gas de efecto invernadero problemático, reacción (3). Sin embargo, la tecnología RS sufre de un talón de Aquiles, que se ha mantenido en gran parte desconocida. El problema dominante es el desplazamiento de gas de agua inversa (DGAI) reacción (4), que consume el hidrógeno que se produce en la reacción para formar agua. El problema no ha de ser reconocido por los investigadores que estudian la reacción RS debido a que la mayoría de los estudios han utilizado la presión atmosférica, y el agua producida es pequeña, pero tan pronto como la presión se eleva 5 atm, el DGAI comienza a dominar la reacción RS. Esto es debido a que el reactivo $\mathrm{CO}_{2}$ prefiere para reaccionar por la reacción (4) que por la reacción (3) debido a la alta estabilidad del $\mathrm{CH}_{4}$.

$\mathrm{CH}_{4}+\mathrm{CO}_{2} \leftrightarrow 2 \mathrm{CO}+2 \mathrm{H}_{2}$

$$
\begin{aligned}
\Delta \mathrm{H}^{\circ} & =247 \mathrm{KJ} / \mathrm{mol} \\
\Delta \mathrm{H}^{\circ} & =41.1 \mathrm{KJ} / \mathrm{mol}
\end{aligned}
$$

Además del reformado con vapor, la oxidación parcial reacción (5) también se utiliza para generar hidrógeno a partir de combustibles fósiles [10], pero el hidrógeno producido todavía está mezclado con $\mathrm{CO}$ y $\mathrm{CO}_{2}$, que a su vez necesita un proceso de separación complicado como en el caso de reformado con vapor.

$\mathrm{CH}_{4}+1 / 2 \mathrm{O}_{2} \leftrightarrow 2 \mathrm{H}_{2}+\mathrm{CO} \quad \Delta \mathrm{H}^{\circ}=-37 \mathrm{KJ} / \mathrm{mol}$

El aumento de la demanda de hidrógeno libre de CO ha aumentado el interés en la descomposición catalítica directa de gas natural [11,12], descrito por la reacción (6). Los dos productos de reacción son hidrógeno y carbono, siendo este último esencialmente en la forma de carbono filamentoso o nanotubos de carbono [13].

$\mathrm{CH}_{4} \leftrightarrow \mathrm{C}_{\mathrm{s}}+2 \mathrm{H}_{2} ; \quad \Delta \mathrm{H}^{\circ}{ }_{25}^{\circ} \mathrm{C}=74.8 \mathrm{~kJ} / \mathrm{mol}$

Como resultado de la descomposición del metano, sólo se produce hidrógeno como un producto gaseoso en una mezcla con el metano sin reaccionar. La separación de metano y el hidrógeno se puede conseguir fácilmente por absorción o membrana de separación para producir una corriente de 99\% en volumen de hidrógeno, que es mucho más simple que la necesidad de nuevos procedimientos de separación complicados que tienen que ver con $\mathrm{CO}_{2}$ o $\mathrm{CO}[2,10]$. Esto sería particularmente importante en el caso de aplicaciones de pilas de combustible de membrana de intercambio de protones, ya que el electrocatalizador a base de Pt es envenenado por CO [14]. Más específicamente, la concentración de CO en corrientes de hidrógeno utilizados como combustible para celdas debe ser inferior a 20 ppm con el fin de evitar la desactivación significativa [15]. Los nanotubos de carbono 
producidos como un producto sólido son un material de gran valor comercial; son útiles en muchas aplicaciones, especialmente en los procesos de adsorción y catálisis $[2,16]$.

La energía necesaria para la descomposición catalítica del metano es casi la mitad que se requiere para el reformado con vapor por mol de metano descompuesto $[2,12,17,18]$. Además de la menor demanda de energía para la descomposición catalítica del metano en comparación con el reformado con vapor, no hay necesidad de energía adicional para la generación de vapor de agua o de tratamiento de gas. El requisito de calor para la descomposición catalítica puede ser cubierto por la quema de $\sim 15-20 \%$ del hidrógeno producido, lo que reduce aún más las emisiones de $\mathrm{CO}_{2}$ [19].

La descomposición térmica de metano no es factible a temperaturas moderadas, para lograr un rendimiento razonable, es necesaria una temperatura superior a $1200{ }^{\circ} \mathrm{C}[3,20]$. Se requiere un catalizador activo para obtener una alta conversión del metano a temperaturas razonables: de 500 a $700^{\circ} \mathrm{C}$ para catalizadores a base de níquel, de 700 a $950^{\circ} \mathrm{C}$ para catalizadores basados en hierro, de 850 a $1100^{\circ} \mathrm{C}$ para catalizadores basados en carbono (carbón activado, negro de carbono, etc) y de 700 a $1000^{\circ} \mathrm{C}$ para los catalizadores basados en Co, Pd, Pt, Cr, Ru, Mo, W.

La demanda de hidrógeno puro está aumentando cada año, ya sea en cantidad o en número de aplicaciones que requieren hidrógeno libre de monóxido de carbono. Mejorar la economía de la descomposición catalítica del metano, requiere una amplia investigación para mejorar los diferentes parámetros del proceso. El uso de un catalizador muy activo y estable, la optimización de las condiciones de funcionamiento, y el desarrollo de reactores adecuados están entre las diferentes áreas que necesitan ser abordadas en la descomposición del metano [21].

Una economía energética basada en el hidrógeno podría aliviar las crecientes preocupaciones sobre el suministro de energía, la contaminación atmosférica y las emisiones de gases de efecto invernadero. Por lo tanto, la descomposición no-oxidativa directa de metano en hidrógeno y carbono es un método alternativo atractivo de la producción de hidrógeno que está libre de $\mathrm{CO}_{\text {y } \mathrm{CO}_{2}}$ [22-23]. 
Las características de este compuesto se presentan a continuación:

Formula Molecular $\mathrm{CH}_{4}$

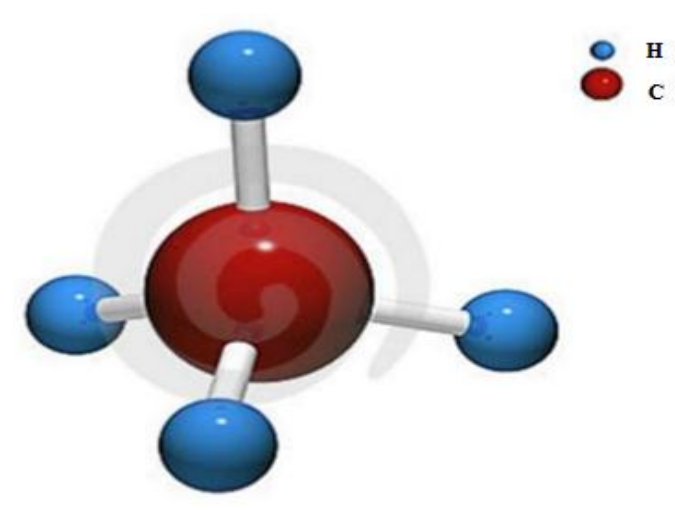

Estructura de la molécula de metano.

PROPIEDADES

- Punto de ebullición: $-161^{\circ} \mathrm{C}$

- Punto de fusión: $-183^{\circ} \mathrm{C}$

- Masa molar: $16.04 \mathrm{~g} / \mathrm{mol}$

- Solubilidad en agua, $\mathrm{ml} / 100 \mathrm{ml}$ a $20^{\circ} \mathrm{C}: 3.3$

- Densidad: $0.000717 \mathrm{~g} / \mathrm{cm}^{3}$

- Densidad relativa de vapor (aire = 1): 0.6

- Punto de inflamación: Gas inflamable

- Temperatura de auto ignición: $537^{\circ} \mathrm{C}$

- Límites de explosividad, \% en volumen en el aire: 5-15 


\section{JUSTIFICACIÓN.}

El hidrógeno utilizado como combustible, podría aliviar las crecientes preocupaciones sobre el suministro de energía, la contaminación atmosférica y las emisiones de gases de efecto invernadero. Por lo tanto, la descomposición no-oxidativa directa de hidrocarburos en hidrógeno y carbono es un método para la producción de hidrógeno libre de $\mathrm{CO}_{\text {y } \mathrm{CO}_{2}}$

Se utilizará metano ya que es el hidrocarburo más abundante, siendo el componente principal del gas natural, y la relación $\mathrm{H} / \mathrm{C}$ en el metano es la más alta entre todos los hidrocarburos.

La presencia de un metal es necesaria para la división C-C y C-H, y el platino es el metal de transición más eficaz para promover la deshidrogenación de alcanos, ya que estimula el rompimiento homolítico del enlace $\mathrm{C}-\mathrm{H}$, generando así átomos de hidrógeno y fragmentos de hidrocarburos adsorbidos en las partículas del metal.

Los metales nobles $\mathrm{Rh}, \mathrm{Ru}, \mathrm{Pt}$, y $\mathrm{Pd}$ son los más activos y una de las características principales de un catalizador para aplicarse en la reacción, es la resistencia al coque, es bien sabido que el depósito de coque necesita un número definido de átomos metálicos superficiales para proceder. Entre los metales de transición, los metales nobles se pueden clasificar según la energía necesaria para la disociación de metano: $\mathrm{Rh}>\mathrm{Ru}>\mathrm{Ir}>\mathrm{Pt}>\mathrm{Pd}$.

La $\gamma$-alúmina se seleccionó debido a su área específica, además, de que los cationes $\mathrm{Al}$ presentes en la superficie del soporte ayudan a estabilizar las partículas dispersas del metal contra el sinterizado, ya que en muchos catalizadores heterogéneos, la interacción de partículas metálicas con su soporte de óxido puede alterar las propiedades electrónicas del metal y puede jugar un papel crítico en la determinación de la morfología de las partículas y el mantenimiento de la dispersión.

El uso de óxidos de tierras raras ha sido descrito en la literatura como una de las mejores alternativas para la estabilización del soporte y la fase activa. 


\section{ANTECEDENTES}

En 1966, se introdujo el proceso HYPRO y fue el primer proceso comercial para la descomposición catalítica del metano e hidrocarburos gaseosos para la producción de hidrógeno, usando un catalizador de $\mathrm{Ni} / \mathrm{Al}_{2} \mathrm{O}_{3}$ [24]. El proceso HYPRO consistía en un lecho fluidizado circulante, que funcionaba a temperaturas de hasta $980^{\circ} \mathrm{C}$ a presión atmosférica. Rostrup-Nielsen [25] estudió el depósito de carbono en varios catalizadores de níquel durante la descomposición del metano y encontró una desviación de los datos de equilibrio al asumir que el carbono se depositaba como grafito. Atribuyeron la desviación, entre los datos experimentales y el cálculo de equilibrio tomando en consideración el grafito, al desorden superficial de la estructura de carbono formada y a la mayor energía superficial de los filamentos de carbono.

De Bokx et al. [26] también estudiaron la termodinámica de la descomposición del metano y se encontró una desviación entre los datos calculados y los datos de equilibrio asumiendo la formación de grafito para los catalizadores de hierro y níquel.

Steinberg y Cheng [27] compararon diferentes métodos para la producción de hidrógeno a escala industrial y concluyeron que la descomposición térmica del metano es el método más económico para la producción de hidrógeno seguido del reformado con vapor < Gasificación del carbón < Oxidación parcial < Electrolisis del vapor a alta temperatura < Gasificación Texaco $<$ Electrolisis del agua.

Algunas investigaciones se han centrado en mejorar el proceso de producción de hidrógeno por la descomposición de metano para formar hidrógeno y carbono elemental como una alternativa atractiva a la reforma de vapor [28], utilizando catalizadores de metal para una mayor conversión de metano y la estabilidad a largo plazo del catalizador [29-31]. También, se han estudiado diferentes catalizadores metálicos mono y bimetálicos en la producción de hidrógeno como $\mathrm{Fe}$ [32], $\mathrm{Ni}-\mathrm{Cu}-\mathrm{Fe} / \mathrm{Al}_{2} \mathrm{O}_{3}$ [33].

Para la producción simultánea de hidrógeno y nanopartículas de carbono, se han utilizado catalizadores a base de níquel. Sin embargo, el principal inconveniente en el caso de la descomposición en catalizadores metálicos ( $\mathrm{Ni}$, Co o Fe), es que el catalizador se desactiva rápidamente debido a los depósitos de carbono [34, 35]. En general, los metales nobles 
muestran una mejor actividad catalítica y resistencia a la desactivación, pero el uso de los catalizadores a base de Ni se debe a su menor costo [36].

Se publicó hace más de una década uno de los primeros trabajos que sugerían la posibilidad de emplear carbones como catalizadores en la reacción de descomposición de $\mathrm{CH}_{4}$ [37]. En un experimento de descomposición de $\mathrm{CH}_{4}$ sobre alúmina, demostró que el carbón que se depositaba sobre la superficie de la alúmina podía catalizar la propia reacción, el uso de estos materiales como catalizadores de la reacción de descomposición de metano evitaría la necesidad de regenerar el catalizador, e incluso, el carbono depositado podría emplearse como precursor del catalizador, dando lugar a un proceso auto-consistente [38,30].

La reacción sobre catalizadores de carbono, como el negro de carbón, el carbón activado, el carbono mesoporoso ordenado y el grafito, necesita una energía de activación alta (143-236 $\mathrm{kJ} / \mathrm{mol}$ ) y debe funcionar a temperaturas más altas $\left(800-1100{ }^{\circ} \mathrm{C}\right)$ que sobre catalizadores metálicos [39, 40-45]. Por lo tanto, la actividad es una función de la conformación de carbono [46-47], la superficie y la cantidad de defectos presentes en las capas de grafeno [48].

En los últimos años se ha estudiado el efecto del calentamiento con microondas sobre múltiples reacciones heterogéneas, como la descomposición de $\mathrm{CH}_{4}$ utilizando un catalizador de carbón activado [49-50]. La característica distintiva del calentamiento con microondas es su naturaleza volumétrica, es decir, idealmente todos los elementos infinitesimales que constituyen un volumen son calentados individualmente y a la misma velocidad.

Recientemente, se ha empezado a investigar el comportamiento de los dispositivos establecidos con recubrimientos en los que se mezcla un catalizador de metal noble con uno o más óxidos de elementos lantánidos [51], se asume que el componente de cerio tiene un papel crucial en el mantenimiento de la actividad catalítica del metal noble; en los metales preciosos, tales como $\mathrm{Rh}, \mathrm{Ru}, \mathrm{Pd}$, Pt, e Ir puede conducir a disminuir el depósito de carbono. Los catalizadores de cobalto no han sido un foco de atención hasta hace poco, se ha demostrado que $\mathrm{Co} / \mathrm{MgO}, \mathrm{Co} / \mathrm{Al}_{2} \mathrm{O}_{3}$ y $\mathrm{Co} / \mathrm{TiO}_{2}$ [51-52] muestran considerable actividad hacia la activación de $\mathrm{CH}_{4}$, lo que sugiere que el cobalto podría ser un metal adecuado. 
En trabajos previos, también han demostrado que los catalizadores binarios a escala nanométrica, basados en $\mathrm{Fe}\left[\left(4,5 \%\right.\right.$ en peso $\mathrm{Fe}-0,5 \%$ en peso de $\mathrm{M} / \mathrm{Al}_{2} \mathrm{O}_{3}$, donde $\mathrm{M}=\mathrm{Pd}$, $\mathrm{Mo}$ o Ni] son muy eficaces para la deshidrogenación catalítica de alcanos ligeros [53].

Hazzim F. Abbas et al. [54] estudiaron una serie de experimentos para determinar la cinética aparente, la desactivación del catalizador y el efecto de la difusión, usando carbón activado como catalizador en un reactor de lecho fijo. El experimento se llevó a cabo a presión atmosférica a $775-850{ }^{\circ} \mathrm{C}$ y diferentes tiempos de residencia de metano.

Otsuka et al. [55] utilizaron oxígeno para regenerar el carbono depositado en $\mathrm{Pd}-\mathrm{Ni} / \mathrm{SiO}_{2}, \mathrm{Ni}$ $/ \mathrm{TiO}_{2}$ y Ni/ $\mathrm{Al}_{2} \mathrm{O}_{3}$, e informaron que todos los catalizadores usados recuperaron su actividad después de la regeneración, durante 5 ciclos de craqueo/regeneración. El carbono depositado sobre el catalizador se oxidó a $480^{\circ} \mathrm{C}$ para estos ensayos, pero para la eliminación completa del carbono depositado se necesitó una temperatura superior a los $500^{\circ} \mathrm{C}$.

Bjørn Enger et al. [56] estudiaron las reacciones elementales que son relevantes para la producción de hidrógeno catalítico que se han evaluado en una amplia gama de metales de transición. El UBI-QEP se utilizó para estimar calores de quimisorción y energías de activación. Las reacciones se evaluaron sobre una superficie limpia con el propósito principal de ilustrar diferencias relativas de propiedades intrínsecas.

Los resultados apoyaron lo que se observa experimentalmente, en particular con respecto a la diferencia relativa entre catalizadores de combustión clásicos (Pt, Pd) y catalizadores de reformado (Ni, $\mathrm{Rh})$.

En los últimos años, se ha desarrollado la investigación del comportamiento de la adición de elementos lantánidos a catalizadores que contienen metales nobles [57, 58]. Manoj et al. [59] sintetizaron satisfactoriamente un conjunto de catalizadores de níquel soportados en ceria y lantano para la descomposición termocatalítica de metano no diluido; se obtuvo un rendimiento inicial máximo de hidrógeno de $62 \%$ y 58\% sobre catalizadores soportados con ceria y lantano, respectivamente, a $700^{\circ} \mathrm{C}$ y concluyeron que el rendimiento de hidrógeno y carbono aumentó significativamente con el aumento de la temperatura de reacción de $600^{\circ} \mathrm{C}$ a $700^{\circ} \mathrm{C}$.

Ahmed et al. [60] estudiaron la descomposición catalítica de metano en un reactor de lecho fijo, y se investigó el efecto de la promoción del Fe con Ce y Co y la temperatura de 
reducción. Los resultados revelaron que la adición de Ce mostró un impacto negativo sobre el rendimiento de $\mathrm{H}_{2}$ mientras que con la adición de Co se observó un efecto positivo sobre el rendimiento de $\mathrm{H}_{2}$ y la estabilidad del catalizador. Tang et al. [61] utilizaron $\mathrm{Fe} / \mathrm{CeO}_{2}$ para la descomposición de metano utilizando un reactor de lecho fijo a $750{ }^{\circ} \mathrm{C}$. La actividad óptima se observó con un catalizador compuesto de $60 \%$ en peso de $\mathrm{Fe}_{2} \mathrm{O}_{3}$ y $40 \%$ en peso de $\mathrm{CeO}_{2}$. El catalizador monometálico de Ce mostró una conversión de $\mathrm{CH}_{4}$ muy pequeña, mientras que el catalizador de Fe mostró una conversión del 60\% después de 25 min, y después de 50 min el catalizador se desactivó completamente. 


\section{HIPÓTESIS.}

Con la adición de Neodimio se espera mejorar la estabilidad catalítica, y el empleo de metales, tales como Rh y Pt conducirán a la disminución del depósito de carbono en la reacción de deshidrogenación del $\mathrm{CH}_{4}$.

Con la utilización de Rh y Pt como metal activo se promoverá el rompimiento del enlace C-H para facilitar la deshidrogenación del metano y aumentar la cantidad de $\mathrm{H}_{2}$ producido.

\section{OBJETIVO GENERAL.}

Determinar el efecto de la adición de $\mathrm{Nd}_{2} \mathrm{O}_{3}$ a los catalizadores monometálicos de rodio y platino soportados en $\gamma$-alúmina en la descomposición termocatalítica del metano.

\section{OBJETIVOS PARTICULARES.}

$>\quad$ Sintetizar los diferentes soportes de $\gamma-\mathrm{Al}_{2} \mathrm{O}_{3}$, y $\gamma-\mathrm{Al}_{2} \mathrm{O}_{3}-\mathrm{Nd}_{2} \mathrm{O}_{3}$, y catalizadores monometálicos de $\mathrm{Rh}$ y Pt al $1 \%$ en peso, soportados en $\gamma-\mathrm{Al}_{2} \mathrm{O}_{3}$, y $\gamma-\mathrm{Al}_{2} \mathrm{O}_{3}$ modificada con neodimio ( 1 y $10 \%$ en peso).

$>\quad$ Caracterizar los soportes y los catalizadores sintetizados empleando diferentes técnicas.

> Determinar las propiedades catalíticas y analizar el efecto del depósito de neodimio en los soportes y en los catalizadores sintetizados en la actividad y la selectividad a $\mathrm{H}_{2}$ en la reacción de deshidrogenación del metano. 


\section{A P Í T U L O 1}

\section{Síntesis y técnicas de}

\section{caracterización de Soportes y catalizadores}




\section{$>$ Síntesis de soportes}

El soporte $\gamma-\mathrm{Al}_{2} \mathrm{O}_{3}$ se preparó a partir de la Boehmita Catapal B (CONDEA, alta pureza del 99,999\%, 74\% AlOOH, 26\% de $\mathrm{H}_{2} \mathrm{O}$ ), secada a $120{ }^{\circ} \mathrm{C}$ durante 12 horas. Después del procedimiento de secado, el sólido se calcinó en flujo de aire de $60 \mathrm{~mL} / \mathrm{min}$ durante 24 horas empleando un programa de temperatura de $25{ }^{\circ} \mathrm{C}$ a $650{ }^{\circ} \mathrm{C}$ con una velocidad de 2 ${ }^{\circ} \mathrm{C} / \mathrm{min}$. Finalmente, se enfrió el sistema a temperatura ambiente con la misma velocidad de $2{ }^{\circ} \mathrm{C} / \mathrm{min}$, manteniendo el flujo de aire en $60 \mathrm{~mL} / \mathrm{min}$.

Los soportes $\gamma-\mathrm{Al}_{2} \mathrm{O}_{3}-\mathrm{Nd}_{2} \mathrm{O}_{3}$ se prepararon mediante la impregnación con la sal precursora de neodimio, estos se prepararan al 1.0 y 10 por ciento en peso de $\mathrm{Nd}$.

El método de impregnación consistió en añadir a la boehmita cierta cantidad de agua y agitar por algunos minutos. Por otro lado, la cantidad necesaria de la sal precursora $\mathrm{Nd}\left(\mathrm{NO}_{3}\right)_{3} 6 \mathrm{H}_{2} \mathrm{O}$ se disolvió con la cantidad mínima de agua, esta solución se agregó a la boehmita y se dejó en agitación durante 3 horas; pasando este tiempo se coloca en un rotavapor a $60^{\circ} \mathrm{C}$ y un vacío de 110 milibares, y el agua restante es evaporada con el vacío hasta sequedad. Posteriormente se secó en una estufa a $120{ }^{\circ} \mathrm{C}$ durante 12 horas. Los soportes así preparados fueron calcinados a $650^{\circ} \mathrm{C}$ en flujo de aire a una velocidad de 60 $\mathrm{mL} / \mathrm{min}$ durante $24 \mathrm{~h}$. De esta manera se obtuvo la fase $\gamma-\mathrm{Al}_{2} \mathrm{O}_{3}$ dopada con óxido de neodimio.

\section{Soportes sintetizados.}

\begin{tabular}{c|c|c}
\hline $\begin{array}{c}\text { Nomenclatura de los } \\
\text { soportes }\end{array}$ & $\begin{array}{c}\text { Gramos de } \mathbf{N d}\left(\mathrm{NO}_{3}\right)_{\mathbf{3}} \mathbf{6 H}_{2} \mathbf{O} \text { por } \\
\text { gramo de soporte. }\end{array}$ & $\begin{array}{c}\text { Contenido de } \mathbf{~ N d ~ ( \% ~} \\
\text { peso) }\end{array}$ \\
\hline$\gamma-\mathrm{Al}_{2} \mathrm{O}_{3}$ & 0.0 & --- \\
$\gamma-\mathrm{Al}_{2} \mathrm{O}_{3}-\mathrm{Nd} 1 \%$ & 0.03 & $1 \%$ peso $\mathrm{Nd}$ \\
$\gamma-\mathrm{Al}_{2} \mathrm{O}_{3}-\mathrm{Nd} 10 \%$ & 0.30 & $10 \%$ peso $\mathrm{Nd}$ \\
\hline
\end{tabular}




\section{$>$ Síntesis de catalizadores}

Los soportes $\gamma-\mathrm{Al}_{2} \mathrm{O}_{3}, \gamma-\mathrm{Al}_{2} \mathrm{O}_{3}-\mathrm{Nd}$ al 1 y $10 \%$ en peso fueron impregnados con una solución acuosa de $\mathrm{RhCl}_{3} \cdot 3 \mathrm{H}_{2} \mathrm{O}$ (99.9 \% de pureza, Strem Chemicals), con la cantidad adecuada para obtener 1\% en peso de Rh en cada catalizador. La mezcla se dejó en agitación por tres horas a $100 \mathrm{rpm}$ y posteriormente se evaporó toda el agua empleando un rotavapor a $60{ }^{\circ} \mathrm{C}$ y un vacío de 110 milibares, finalmente el sólido se secó a $120^{\circ} \mathrm{C}$ durante $12 \mathrm{~h}$. Después se calcinó a $500{ }^{\circ} \mathrm{C}$ durante $5 \mathrm{~h}$ en flujo de aire empleando un programa de calentamiento con una velocidad de $2^{\circ} \mathrm{C} / \mathrm{min}$ y posteriormente se sometió a una atmósfera reductora (hidrógeno, Praxair grado 5) a $500^{\circ} \mathrm{C}$ por $5 \mathrm{~h}$ empleando el mismo programa de calentamiento, ambos tratamientos se realizaron con una velocidad de flujo de $60 \mathrm{~mL} / \mathrm{min}$. Para obtener los catalizadores de platino, se utilizó la sal precursora de $\mathrm{H}_{2} \mathrm{PtCl}_{6} .6 \mathrm{H}_{2} \mathrm{O}(99.9$ \% de pureza, Aldrich), y se siguió el mismo procedimiento de síntesis.

\section{Catalizadores sintetizados.}

\begin{tabular}{c|c|c}
\hline $\begin{array}{c}\text { Nomenclatura de los } \\
\text { catalizadores }\end{array}$ & Contenido de Metal (\% peso) & $\begin{array}{c}\text { Contenido de Nd (\% } \\
\text { peso) }\end{array}$ \\
\hline RhA & 1 & --- \\
RhANd1 & 1 & $1 \%$ peso Nd \\
RhANd10 & 1 & $10 \%$ peso Nd \\
PtA & 1 & --- \\
PtANd1 & 1 & $1 \%$ peso $\mathrm{Nd}$ \\
PtANd10 & 1 & $10 \%$ peso Nd \\
\hline
\end{tabular}

\section{TÉCNICAS DE CARACTERIZACIÓN}

\section{Difracción de Rayos X}

Los patrones de difracción de rayos $\mathrm{X}$ de los soportes se obtuvieron usando un difractómetro Bruker D-8 Advance de rayos X de polvo equipado con un ánodo de radiación $\mathrm{Cu} \mathrm{K} \alpha$ en geometría Bragg-Brentano. La detección se llevó a cabo utilizando un detector Lynxeye, que es de tipo lineal. 
Esta técnica nos permite determinar las fases cristalinas presentes en nuestros soportes y catalizadores. La determinación de las fases se realiza a partir de la comparación de los patrones obtenidos con patrones de referencia.

Procedimiento: La muestra en polvo se colocó en un porta-muestras de vidrio. A la muestra se le hizo un barrido en un intervalo de $10^{\circ}$ a $70^{\circ}$ con una velocidad de paso de $0.02^{\circ}$ y un tiempo de $1 \mathrm{~s} /$ punto con $\lambda=1.54$. La determinación del compuesto se hizo con referencia a tarjetas 05-0685, 04-0802, 84-1439, 010-79-9858 y 056.0457 que corresponden al rodio, al platino, al óxido de platino $\left(\mathrm{PtO}_{2}\right)$, óxido de neodimio $\left(\mathrm{Nd}_{2} \mathrm{O}_{3}\right)$ y $\gamma$-alúmina, según archivo JCPDS.

\section{Áreas BET}

A partir de medidas de adsorción-desorción de $\mathrm{N}_{2}$, se determinó el área específica y la distribución de tamaños de poro de materiales sólidos. Las superficies específicas se calcularon con la ecuación de BET y el diámetro de poro por el método BJH.

El área superficial BET de los catalizadores se midió usando un analizador Quantachrome Multistation Autosorb 3B.

Procedimiento: Se utilizó nitrógeno como gas de medición a $-196{ }^{\circ} \mathrm{C}$. Antes de la adsorción, la muestra (100 mg) fue desgasificada a $300{ }^{\circ} \mathrm{C}$ bajo vacío $\left(10^{-3} \mathrm{Torr}\right)$ durante $24 \mathrm{~h}$ para eliminar la humedad y las impurezas físicamente adsorbidas sobre la superficie del sólido.

\section{Reducción a Temperatura Programada}

Esta técnica nos proporciona información sobre el grado de dificultad de la reducción de los cationes presentes en la superficie catalítica. Es importante aclarar que no todos los cationes presentes en la superficie catalítica son reducibles, en nuestro caso en particular el catión $\mathrm{Al}^{3+}$ perteneciente a la alúmina no se reduce, a diferencia del $\mathrm{Rh}^{\circ}$ y el $\mathrm{Pt}^{\circ}$.

Las determinaciones de RTP se llevaron a cabo en un aparato Chembet-3000 (Quantachrome Co) usando $0.2 \mathrm{~g}$ de catalizador.

Procedimiento: la muestra se calentó a $300^{\circ} \mathrm{C}$ bajo flujo de nitrógeno $\left(10 \mathrm{ml} \mathrm{min}^{-1}\right)$ durante 30 min. A continuación, la muestra se enfrió a temperatura ambiente y se le hizo pasar una mezcla ( $5 \%$ de $\mathrm{H}_{2} / 95 \% \mathrm{~N}_{2}$ ). Los perfiles de RTP se registraron calentando la muestra desde 
la temperatura ambiente hasta $600^{\circ} \mathrm{C}$ a una velocidad de $10^{\circ} \mathrm{C} \mathrm{min}^{-1}$ bajo la mezcla de gas de $10 \mathrm{ml} \mathrm{min}^{-1}$.

La variación en la concentración del $\mathrm{H}_{2}$ presente en la mezcla durante el proceso de reducción fue medido por un detector de conductividad térmica y registrado por una computadora.

\section{Análisis EFRX (XPS por sus siglas en inglés)}

El análisis EFRX se realizó en un ordenador espectrómetro fotoeléctrico Kratos con eje ULTRA de rayos X con un analizador de energía hemisférica de electrones de $165 \mathrm{~mm}$. La radiación incidente se produce a partir de rayos X monocromáticos de $\mathrm{Al}(1486,6 \mathrm{eV})$ a 225 W (15 kV, $15 \mathrm{~mA})$. El estudio (ampliado) se realizó en un analizador con una energía de paso de 160 eV y multiplex (estrecho) con exploraciones de alta resolución con energía de paso de $20 \mathrm{eV}$.

Procedimiento: El barrido se realizó con un intervalo de energía de unión 1200-0 eV en pasos de 1,0 eV y tiempo de permanencia de $100 \mathrm{~ms}$. Las exploraciones de alta resolución se realizaron con 0,05 eV y $250 \mathrm{~ms}$ de tiempo de permanencia. La presión base en la cámara de análisis fue 1,0 × $10^{-9}$ Torr durante el análisis de la muestra fue de 1,0 × $10^{-8}$ Torr. Los espectros XPS se ajustaron con el programa SDP v 4.1. [62].

\section{Microscopia Electrónica de Transmisión de Alta Resolución.}

Es una técnica para obtener imágenes mediante el microscopio electrónico de transmisión (MET) que permite la formación de imágenes de la estructura cristalográfica de una muestra en una escala atómica. Debido a su alta resolución es una valiosa herramienta ampliamente utilizada para el estudio de nanoestructuras de materiales cristalinos. El análisis se realizó en un JEOL METAR-2010F equipado con una fuente de emisión de campo y una aceleración de 200 kV.

Procedimiento: La muestra se trituró y se dispersó sobre una rejilla de carbón gruesa de 300 mallas, y las imágenes de alta resolución se obtuvieron a partir de la transmisión de electrones que pasaron por la muestra. La medida de los planos cristalográficos se realizó utilizando el programa Digital Micrograph el cual es una aplicación utilizada para adquirir, 
visualizar, analizar y procesar datos de imágenes digitales, principalmente dentro del contexto de la microscopía electrónica.

\section{Microscopía Electrónica de Transmisión (MET)}

Este estudio se realizó en un microscopio electrónico de emisión de campo que opera a 200 kV. El microscopio está equipado con un campo de cañón de emisión de tipo Schottky y una configuración de resolución ultra alta (UHR) $(\mathrm{Cs}=0,5 \mathrm{~mm}$, Cc $1,1 \mathrm{~mm}$, punto a punto de resolución, $0.19 \mathrm{~nm}$ ). Las muestras también se caracterizaron por un detector de ángulo anular alto de campo oscuro (AAACO), el microscopio se hizo operar en modo conocido como "contraste Z".

Procedimiento: Las muestras se pusieron en polvo en un mortero de ágata y se suspendieron en etanol a temperatura ambiente y se dispersaron en un baño de ultrasonidos durante dos minutos, después se depositó una gota de la solución sobre una rejilla de carbono-cobre. Es importante señalar que las muestras se transportaron en una bolsa de plástico llena de argón con el fin de evitar la contaminación de $\mathrm{O}_{2}$.

\section{Microscopia Electrónica de Transmisión (Contraste Z)}

La información que se genera sobre el tamaño de partícula usualmente se presenta en histogramas, el cual muestra un gráfico de números de partículas en rangos específicos de tamaños de partícula (60).

El tamaño promedio de partícula d, se determinó con la siguiente ecuación:

$\mathrm{ds}=\sum$ ni $\mathrm{di}^{3} / \sum$ ni di ${ }^{2}$

dónde:

di = es el diámetro de partícula

ni = es número de partículas con diámetro di

\section{Análisis MEB (SEM por sus siglas en inglés)}

Esta técnica utiliza un haz de electrones en lugar de un haz de luz para formar una imagen. Tiene una gran profundidad del campo, la cual permite que se enfoque a la vez una gran parte de la muestra. 
El análisis se realizó en un microscopio electrónico de barrido y emisión secundaria con control de rangos variables de vacío (presión variable) de la marca JEOL modelo JSM-5900 LV, con un espectrómetro EDERX acoplado marca Oxford.

Procedimiento. La preparación del catalizador fue realizada de la siguiente manera; fue utilizado un porta muestra de aluminio que fue lavado con alcohol para la eliminación de cualquier impureza, posteriormente se secó y fue depositado un trozo de cinta de carbono sobre el porta muestra para después depositar el catalizador en estudio, para que dicho catalizador no se desprenda de la cinta de carbono por el alto vacío se le deposita una monocapa de oro (material conductor).

\section{Espectroscopia infrarroja (IRTF de CO)}

En la región del infrarrojo (5000-200 $\mathrm{cm}^{-1}$ ), los estados de excitación que se producen son de vibración-rotación, que se refieren a las deformaciones que se producen en los enlaces de los átomos en la molécula.

Las diferentes combinaciones de masas atómicas y energías de enlace constituyen sistemas que vibran a diferentes frecuencias cuando la molécula absorbe radiación electromagnética. Además los diferentes movimientos vibracionales del átomo en la misma molécula producen absorción característica a diferentes números de onda.

El estudio por IRTF de la adsorción de CO se realizó con el fin de determinar la dispersión y tamaño de partícula metálicas del $\mathrm{Rh}$ y Pt en los catalizadores, para ello se usó un espectrofotómetro Nicolet modelo 170-SX, con una resolución de $2 \mathrm{~cm}^{-1}$.

Procedimiento: El catalizador se pulveriza en un mortero de ágata para hacer una pastilla (sin aglutinantes), la cual se coloca en una celda de vidrio Pirex, equipada con ventanas de $\mathrm{CAF}_{2}$, acoplada a sistema de vacío y líneas de gases. Las muestras se mantuvieron en vacío $\left(10^{-3}\right.$ Torr) a $400{ }^{\circ} \mathrm{C}$ durante $30 \mathrm{~min}$. Luego, se disminuye la temperatura a $25^{\circ} \mathrm{C}$ y se adiciona CO (Praxair UHP) a una presión de 20 Torr. El exceso de CO se evacuó durante 30 minutos, para después obtener los espectros de adsorción con CO. 


\section{Espectroscopia infrarroja (IRTF de adsorción de Piridina)}

La piridina es una molécula sonda ampliamente utilizada en espectroscopía de IR para establecer, mediante su adsorción, el tipo de sitios ácidos existentes en la superficie de un sólido. Su basicidad permite cubrir una amplia gama de fuerzas ácidas.

La termo-desorción de piridina, acoplada a la espectroscopia infrarroja, es una técnica que se utiliza para estudiar la acidez de la superficie de sólidos. La piridina al adsorberse en los sitios ácidos de Lewis presenta una serie de bandas características a 1450, 1580 y $1600 \mathrm{~cm}^{-}$ 1 , cuando la piridina se adsorbe en los sitios ácidos de tipo Bronsted presenta otras bandas en 1540 y $1640 \mathrm{~cm}^{-1}$ y una banda a $1490 \mathrm{~cm}^{-1}$ asignada a la acidez total.

La espectroscopia infrarroja es una técnica que se basa en las vibraciones de los átomos de una molécula. Comúnmente un espectro de infrarrojo se obtiene por el paso de una radiación de infrarrojo a través de una muestra y determinando la fracción de la radiación incidente que es adsorbida en un valor de energía particular. La energía en la cual un pico en un espectro aparece corresponde a la frecuencia de vibración de una parte de la molécula. Esta técnica se realizó a temperatura ambiente usando un aparato IRTF Nicolet 170-SX, con una resolución de $2 \mathrm{~cm}^{-1}$.

Procedimiento: El catalizador se pulverizó en un mortero de ágata para hacer una pastilla (sin aglutinantes), la cual se colocó en una celda, que está acoplada a líneas de vacío y líneas de gases. En seguida, es sometida a un tratamiento en vacío durante 30 min. (1x10-3 Torr) a $400{ }^{\circ} \mathrm{C}$. Luego, se disminuyó la temperatura a $25^{\circ} \mathrm{C}$ y se adicionó piridina a una presión de 20 Torr. Posteriormente, se evacua el exceso de piridina con vacío por 30 min para después obtener los espectros de IRTF.

\section{Oxidación a Temperatura Programada (TPO por sus siglas en inglés)}

El estudio de OTP después de la reacción se llevó a cabo en un aparato CHEMBET-3000 utilizando un detector de conductividad térmica (DCT) y $0.1 \mathrm{~g}$ de catalizador. En estos experimentos, la velocidad de flujo de la mezcla de $5 \%$ de $\mathrm{O}_{2} / 95 \%$ de He fue de $10 \mathrm{~mL} \mathrm{~min}^{-1}$ y la velocidad de calentamiento fue de $10{ }^{\circ} \mathrm{C} \mathrm{min}^{-1}$. Finalmente, los espectros se registraron desde la temperatura ambiente hasta $750{ }^{\circ} \mathrm{C}$ y se mantuvo a esta temperatura durante una hora. 


\section{Actividad catalítica}

Las determinaciones de actividad se llevaron a cabo en un micro reactor de cuarzo de lecho fijo $($ d. i. $=1.2 \mathrm{~cm}$ y longitud $=56 \mathrm{~cm}$ ) a presión atmosférica y carga de catalizador de $0.05 \mathrm{~g}$ (fig. 1). Las temperaturas de reacción variaron de 400 a $750^{\circ} \mathrm{C}$, con aumentos de $100{ }^{\circ} \mathrm{C}$ y solo el último fue de $50{ }^{\circ} \mathrm{C}$ con una velocidad de $5{ }^{\circ} \mathrm{C} \mathrm{min}{ }^{-1}$. Los experimentos consistieron en un tratamiento térmico previo a los catalizadores con flujo de nitrógeno durante 15 minutos a temperatura ambiente. A continuación, se alimentó al reactor un flujo de $\mathrm{CH}_{4}$ puro $(99,999 \%)$ (2 $\mathrm{ml} \mathrm{min}^{-1}$ ). Los efluentes de entrada y salida se monitorizaron en un cromatógrafo de gases, Shimadzu GC-2014 equipado con 6 columnas empacadas y detectores DCT y DIF. Lo que permite la medición de gases inorgánicos $\left(\mathrm{H}_{2}, \mathrm{CO}\right.$ y $\left.\mathrm{CO}_{2}\right)$ e hidrocarburos orgánicos como $\mathrm{CH}_{4}, \mathrm{C}_{2} \mathrm{H}_{4}$ y $\mathrm{C}_{2} \mathrm{H}_{6}$.

La identificación de los productos de reacción se llevó a cabo mediante la cuantificación de los mismos, mediante curvas de calibración. La conversión de metano se calculó como la cantidad de metano convertida a lo largo del experimento sobre la cantidad alimentada. La selectividad fue la cantidad de cada producto $\mathrm{H}_{2}, \mathrm{C}_{2} \mathrm{H}_{4} \mathrm{o}_{2} \mathrm{H}_{6}$ detectada en la salida del reactor sobre el metano convertido.

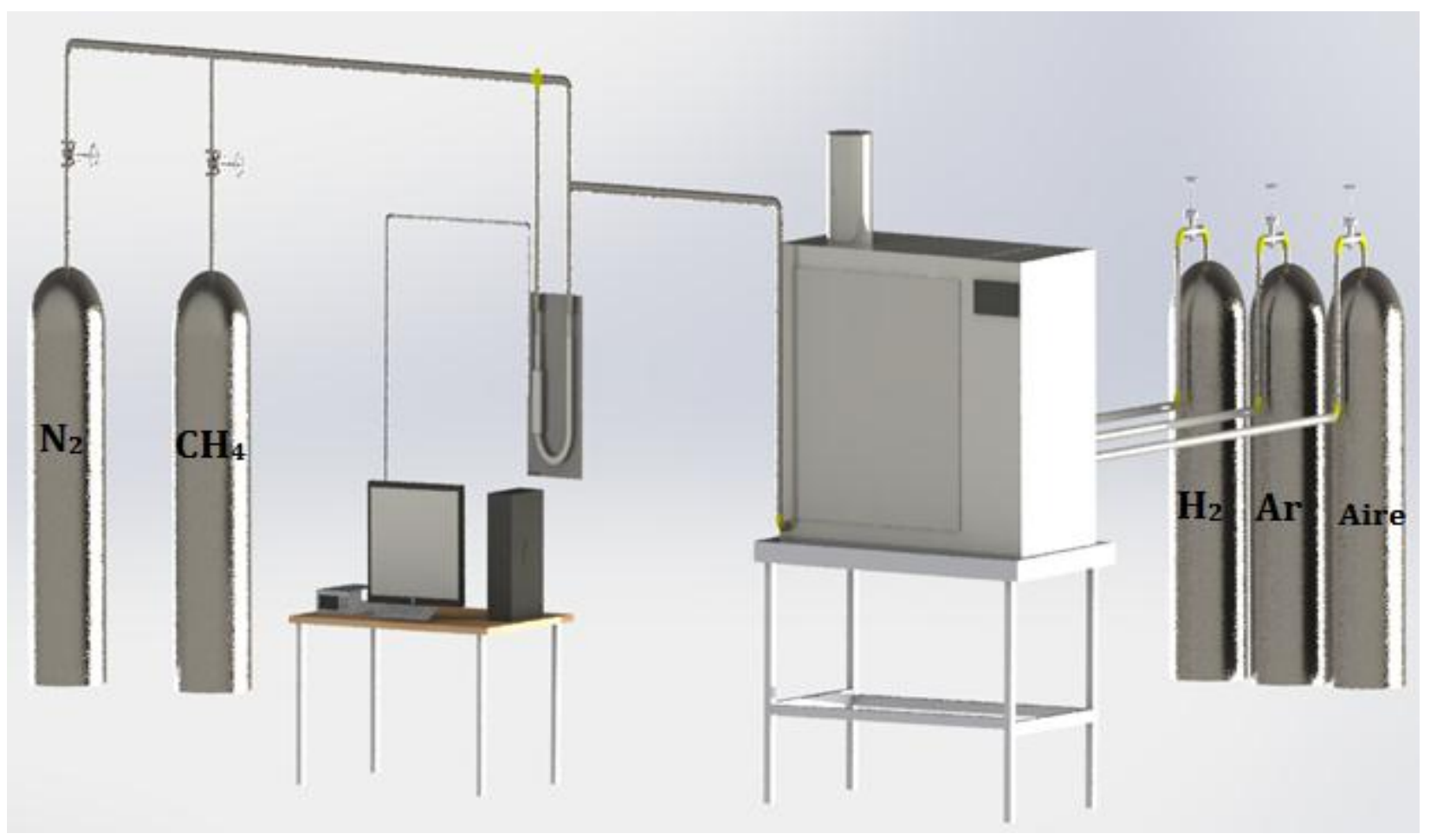

Figura 1. Diagrama del proceso experimental. 


\section{A P Í T U L O 2}

SOPORTES

\section{RESULTADOS Y DISCUSIÓN}


Los análisis de DRX se realizaron con el fin de identificar las diferentes fases presentes en los soportes y en los catalizadores y determinar el tamaño de cristal, los patrones de difracción de rayos $\mathrm{X}$ presentados en la figura 2 revelan que se formó la fase $\gamma-\mathrm{Al}_{2} \mathrm{O}_{3}$ después del tratamiento térmico a $650^{\circ} \mathrm{C}$ en flujo de aire de la Boehmita Catapal B. En el gráfico se presentan los picos característicos de la fase $\gamma-\mathrm{Al}_{2} \mathrm{O}_{3}$ (JCPDS PDF 056-0457 Calidad: Rietveld), se observa también que a contenidos de $1 \%$ de neodimio (ANd1) únicamente aparecen las señales correspondientes a $\gamma-\mathrm{Al}_{2} \mathrm{O}_{3}$, lo que indica que el $\mathrm{Nd}_{2} \mathrm{O}_{3}$ se encuentra muy disperso (fig. 2), Nd (JCPDS PDF 01-079-9858 Calidad: Star (*)) no muestra diferencia notable con respecto al difractograma del soporte A.

La presencia del $10 \%$ en peso de $\mathrm{Nd}$ en el soporte ANd10 conduce a una modificación del patrón de difracción. Se observa una menor intensidad de los picos de la alúmina, lo que indica una baja cristalinidad del sólido (tabla 1). La presencia de neodimio al 10\% en peso inhibe el crecimiento de los cristales de alúmina [63]. En la Fig. 2 se observan los picos de la alúmina que tienen máximos en torno a $67^{\circ}$ en $2 \theta$. El aumento en la anchura se relaciona

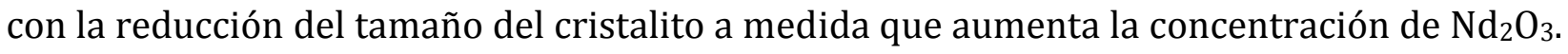
No se detectaron picos de $\mathrm{Nd}$ ( 1 y $10 \%$ en peso), debido probablemente a su alta dispersión en la superficie de la alúmina. Por otra parte la probable sustitución de los iones $\mathrm{Al}^{3+}$ por los iones $\mathrm{Nd}^{3+}$ dentro de la estructura de la alúmina no ha de ser totalmente producido ya que $\mathrm{Nd}^{3+}$ presenta radios iónicos de 1,08 $\AA$ con una estructura hexagonal, Mientras que $\mathrm{Al}^{3+}$ tiene una estructura cristalina fcc y un radio iónico de 0.5 Å. Los radios iónicos del neodimio son más grandes que el $\mathrm{Al}^{3+}$, lo que dificulta la sustitución atómica en la red de la estructura de la alúmina. Pero una integración probablemente pequeña causa una perturbación en la estructura cristalina de la alúmina que obstaculiza el crecimiento de las cristalitos (tabla 1 ) [63]. A mayor contenido de $\mathrm{Nd}$ se puede encontrar una probable segregación de este elemento en la superficie de la alúmina como óxido de neodimio, entonces se espera una superficie enriquecida con $\mathrm{Nd}_{2} \mathrm{O}_{3}$ en el soporte $\mathrm{ANd} 10$ [64]. 


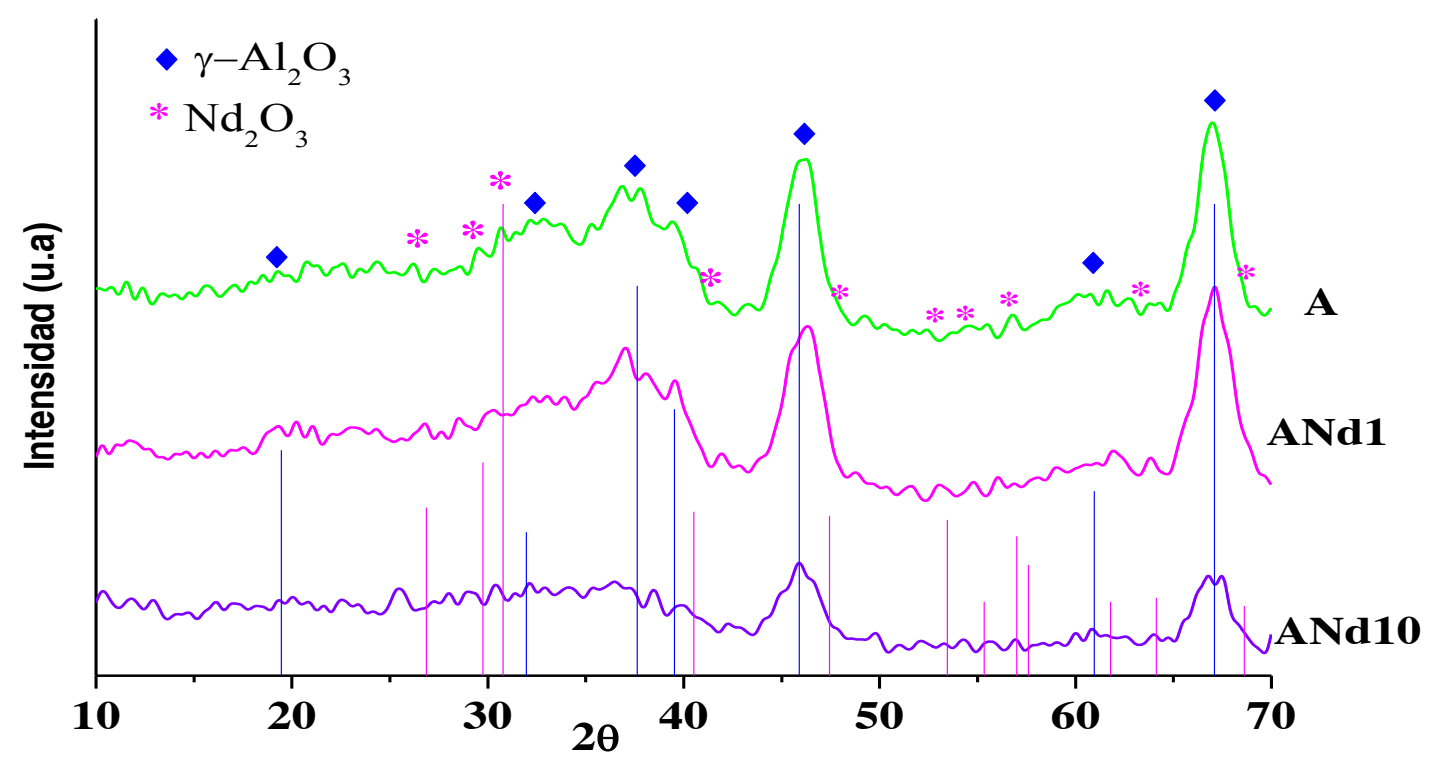

Figura 2. DRX de los soportes A, ANd1 y ANd10.

Para corroborar la reducción del tamaño de cristal, se realizó el calculó del tamaño del cristal empleando la ecuación de Scherrer.

$$
\tau=\frac{K \lambda}{\beta \cos \theta}
$$

dónde:

$\mathrm{K}=$ factor esférico, comúnmente empleado 0.9.

$\lambda=$ Longitud de onda (nm)

$\beta=$ altura media del pico característico (radianes).

$\theta=$ = ángulo de difracción (grados).

Tabla 1. Tamaño de cristal de la y-alúmina.

\begin{tabular}{c|c|c}
\hline Soportes & FWHM $\mathbf{2 \theta = 6 7 ^ { \circ }}$ & Tamaño de Cristalito $(\AA))$ \\
\hline A & 2.3 & 77 \\
ANd1 & 2.4 & 72 \\
ANd10 & 2.7 & 57 \\
\hline
\end{tabular}


El área de superficie específica y volumen de poro se calcularon aplicando el método BET y Barrett-Joyner-Halenda $(\mathrm{BJH})$ método de integración numérica, respectivamente. Modelo BJH de desorción se utilizó para calcular la distribución de tamaño de poro de las muestras. En el análisis textural de los soportes calcinados a $650{ }^{\circ} \mathrm{C}$, todas las muestras exhibieron Isotermas de adsorción tipo IV, características de mesoporos (fig. 3), según la clasificación propuesta por Brunauer, estas se caracterizan por presentar interacciones débiles entre el adsorbente y el adsorbato. La condensación de poro a mayor presión relativa indica la presencia de poros más grandes.

Se puede observar que se tiene el mismo tipo de poro debido a que todas las isotermas presentan histéresis de tipo H1, este ciclo de histéresis se caracteriza por tener una curva de adsorción y una curva de desorción prácticamente vertical y paralela. Se observa habitualmente en materiales mesoporosos con una distribución de tamaños de poro muy estrecha y en aglomerados de partículas esferoidales de tamaño uniforme.

El área específica fue afectada por la incorporación del 1\% de neodimio, no así con el 10\% de neodimio, donde las áreas permanecieron muy parecidas (tabla 2).

Exhiben una mayor cantidad adsorbida de nitrógeno las muestras A y ANd1.

El diámetro de poro fue afectado por el dopaje con neodimio (fig. 4). El volumen de poro presenta una tendencia decreciente con la cantidad creciente de $\mathrm{Nd}$ en el catalizador. Este comportamiento se debe al depósito de $\mathrm{Nd}_{2} \mathrm{O}_{3}$ en la boca de los poros de la alúmina, produciendo un poro pequeño pero con la disminución esperada en el área superficial. 


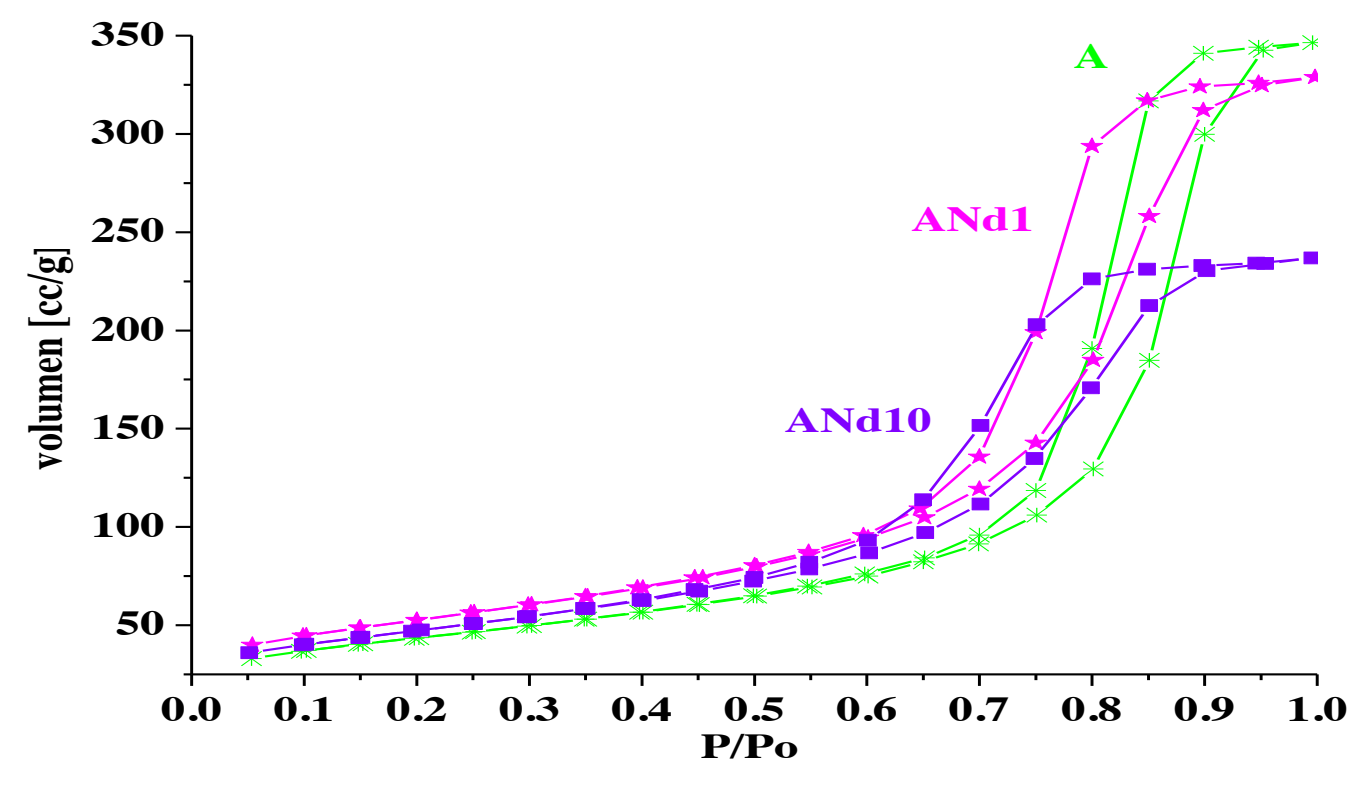

Figura. 3 Isotermas de adsorción-desorción de los soportes A, ANd1 y ANd10.

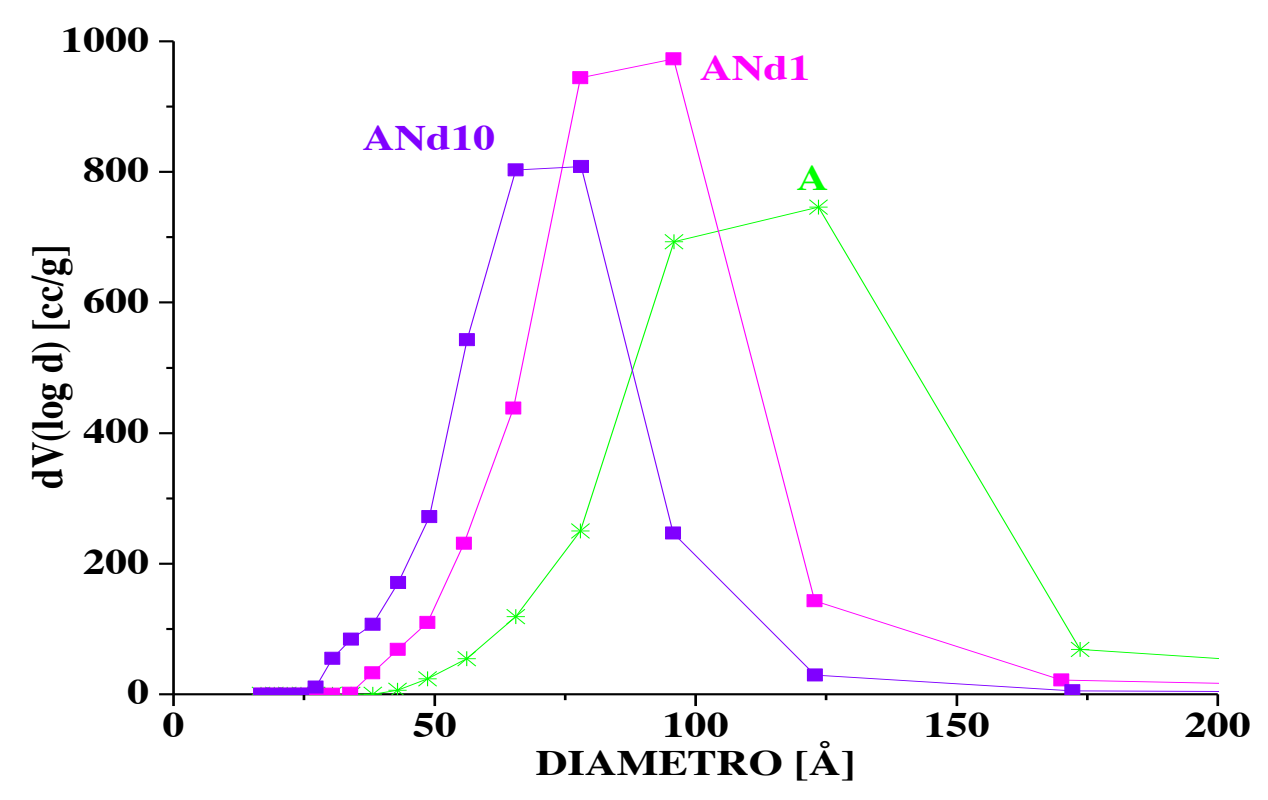

Figura 4. Distribución de diámetro de poro de los soportes A, ANd1 y ANd10. 
Tabla 2. Áreas y tamaño promedio de poro de los soportes A, ANd1 y ANd10.

\begin{tabular}{cccc}
\hline Soportes & Contenido de Nd (\% peso) & Área BET m ${ }^{2} \mathrm{~g}^{-1}$ & Tamaño de Poro \\
& & & $\AA$ \\
\hline A & 0 & 266 & 109 \\
ANd1 & 1 & 215 & 85 \\
ANd10 & 10 & 244 & 72 \\
\hline
\end{tabular}

La piridina se adsorbió en los sitios ácidos de Lewis presentando una serie de bandas características a 1449, 1581 y $1615 \mathrm{~cm}^{-1}$, y no presenta sitios ácidos de tipo Brönsted ya que no presenta bandas en 1540 y $1640 \mathrm{~cm}^{-1}$ y presenta una banda a $1495 \mathrm{~cm}^{-1}$ asignada a la acidez total. Al ir aumentando la cantidad de neodimio se aprecia una disminución en las intensidades de las bandas (fig. 5), mostrando así una disminución de la acidez en los soportes (tabla 3).

Teniendo en cuenta la alta basicidad del neodimio respecto a la alúmina, se puede inferir que la disminución de los sitios ácidos en los materiales con neodimio puede deberse a la alta dispersión de éste sobre la superficie del $\gamma-\mathrm{Al}_{2} \mathrm{O}_{3}$ bloqueando los sitios Ácidos.

En el caso de la $\mathrm{Al}_{2} \mathrm{O}_{3}$ dopado con $\mathrm{Nd}_{2} \mathrm{O}_{3}$, las intensidades de las bandas asociadas con la acidez de Lewis fueron mucho menores, este resultado indicó que $\mathrm{Nd}_{2} \mathrm{O}_{3}$ disminuyó el número de sitios ácidos de Lewis.

El hecho de que la acidez disminuya podría indicar que el aditivo (neodimio), selecciona sitios muy ácidos en el soporte a depositar como lo ha mencionado en su estudio Oudet y col. 


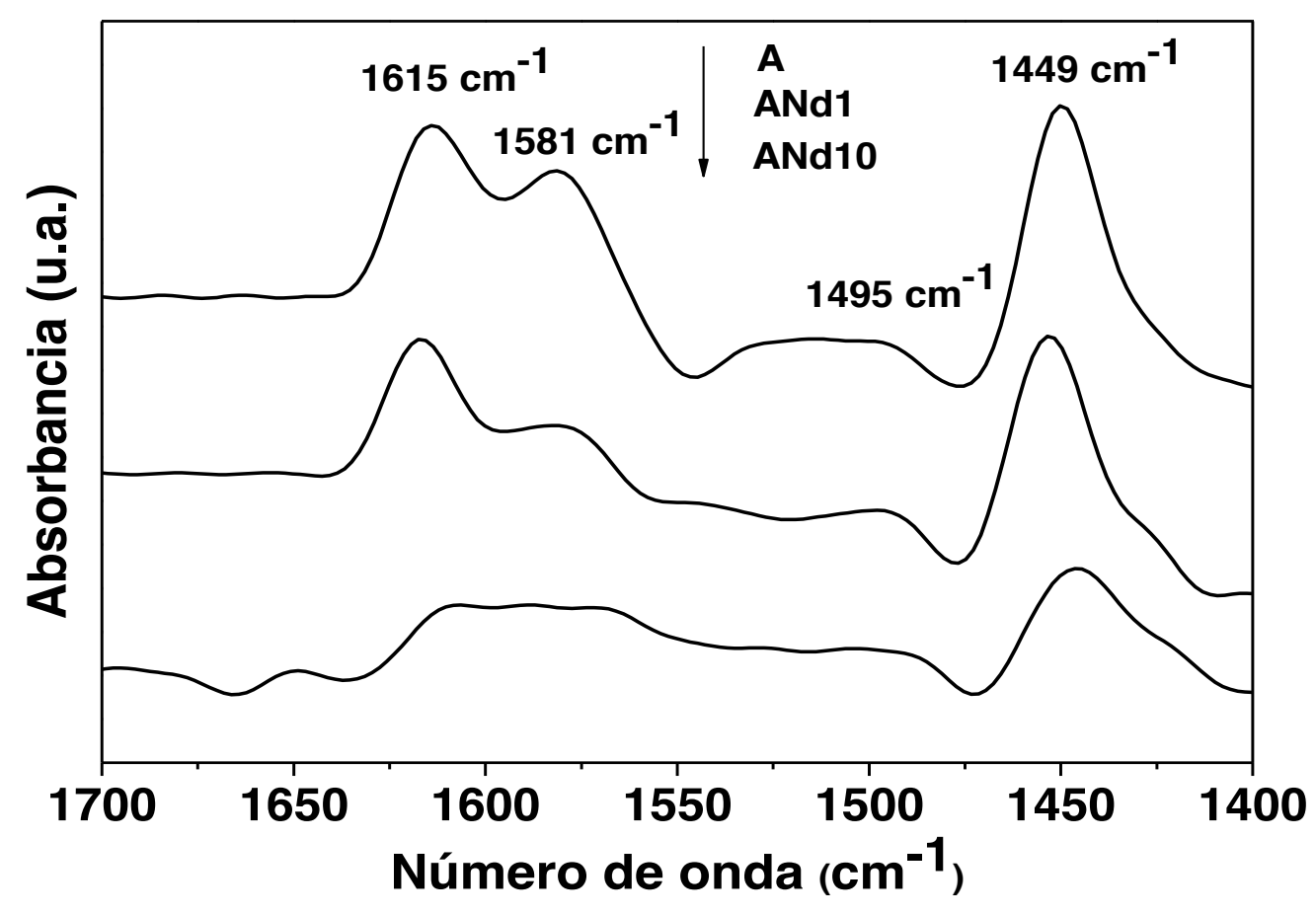

Figura 5. Espectros de IRTF de Piridina adsorbida sobre los soportes A y $\operatorname{ANd} X$.

Tabla 3. Acidez de los soportes A y ANdX.

\begin{tabular}{c|c}
\hline Catalizador & Acidez ( $\boldsymbol{\mu m o l} / \mathbf{g c a t})$ \\
\hline A & 85 \\
ANd1 & 72 \\
ANd10 & 54 \\
\hline
\end{tabular}




\section{A P Í T U L O 3}

\section{CATALIZADORES DE RODIO RESULTADOS Y DISCUSIÓN}


Después de los tratamientos térmicos de calcinación y reducción a los catalizadores de Rh, la estructura de los picos característicos de la $\gamma-\mathrm{Al}_{2} \mathrm{O}_{3}$ (JCPDS PDF 056-0457 Calidad: Rietveld) se presenta en todas las muestras; no obstante la intensidad de la difracción en las muestras disminuyó con el aumento en el contenido de neodimio (fig. 6); este efecto provenía de los soportes y se demostró que el tamaño de cristal disminuía.

No se detectaron picos de Nd (1 y 10\% en peso) ni de Rh (JCPDS PDF 05-0685 Calidad: Start $\left.{ }^{*}\right)(0,7-0,86 \%$ en peso), debido probablemente a la baja concentración, que no pudo ser detectada por el equipo o debido a su alta dispersión en la superficie de la alúmina.

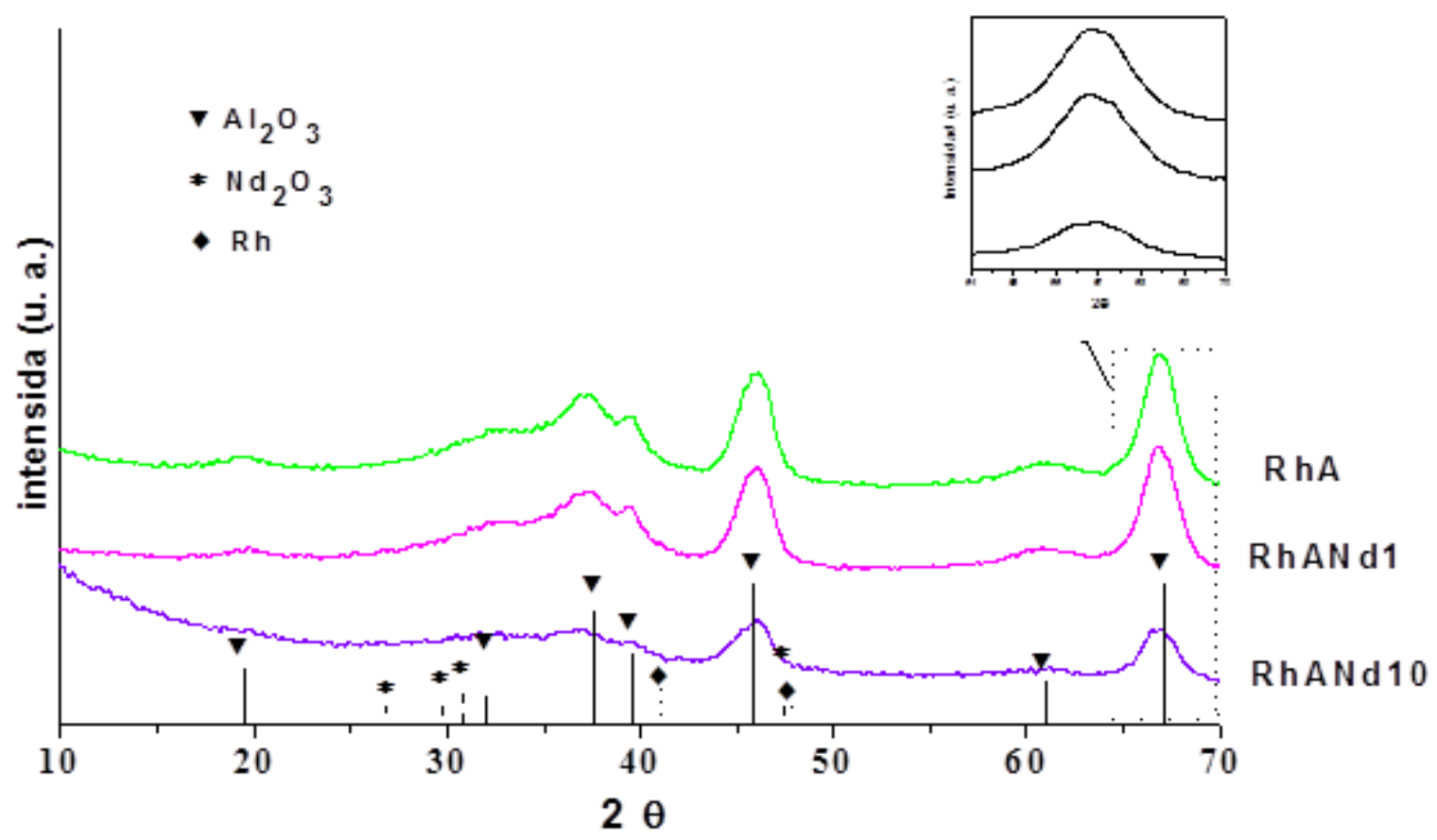

Figura 6. DRX de los catalizadores RhA y $\operatorname{RhANdX.~}$

Tabla 4. Tamaño de cristal de la y-alúmina en los catalizadores RhA y RhANdX.

\begin{tabular}{c|c|c}
\hline Catalizadores & FWHM $2 \theta=67^{\circ}$ & Tamaño de Cristalito $(\AA)$ de $\gamma-\mathrm{Al}_{2} \mathrm{O}_{3}$ \\
\hline RhA & 2.0 & 98 \\
RhANd1 & 2.1 & 97 \\
RhANd10 & 2.3 & 89 \\
\hline
\end{tabular}


Las superficies específicas BET de los catalizadores se indican en la tabla 5. El área de superficie BET para el soporte de alúmina (A) fue de $266 \mathrm{~m}^{2} \mathrm{~g}^{-1}$, y para el catalizador RhA, $284 \mathrm{~m}^{2} \mathrm{~g}^{-1}$. Los catalizadores que contienen neodimio RhANd1 y RhANd10 muestran una ligera disminución de la superficie (237 y $227 \mathrm{~m}^{2} \mathrm{~g}^{-1}$ ) con respecto a la observada en las referencias del soporte A y el catalizador RhA (tabla 5). En la Fig. 7 se representan las isotermas de adsorción-desorción del análisis textural de los catalizadores calcinados y reducidos, todas las muestras exhibieron Isotermas de adsorción tipo IV, características de mesoporos, exhibiendo una mayor cantidad adsorbida de nitrógeno con respecto a los soportes, en la figura 8 se muestra la distribución del tamaño de poro de los catalizadores de rodio, donde se muestra una distribución de tamaño de poro similar en RhA y RhANd1, con valores de tamaño promedio de poro de 48 y $49 \AA$ Å respectivamente. El catalizador RhANd10 presentó un perfil de distribución de tamaño de poro desplazado hacia valores más bajos dando un tamaño promedio de poro menor, $39 \AA$ A. Las concentraciones de Rh en los catalizadores se determinaron por absorción atómica y se indican en la Tabla 5. La concentración nominal de Rh fue de 1,0\% en peso, y las concentraciones reales fueron de $0,77,0.7$ y $0.86 \%$ en peso, y estos valores pueden considerarse válidos en el rango de error. 


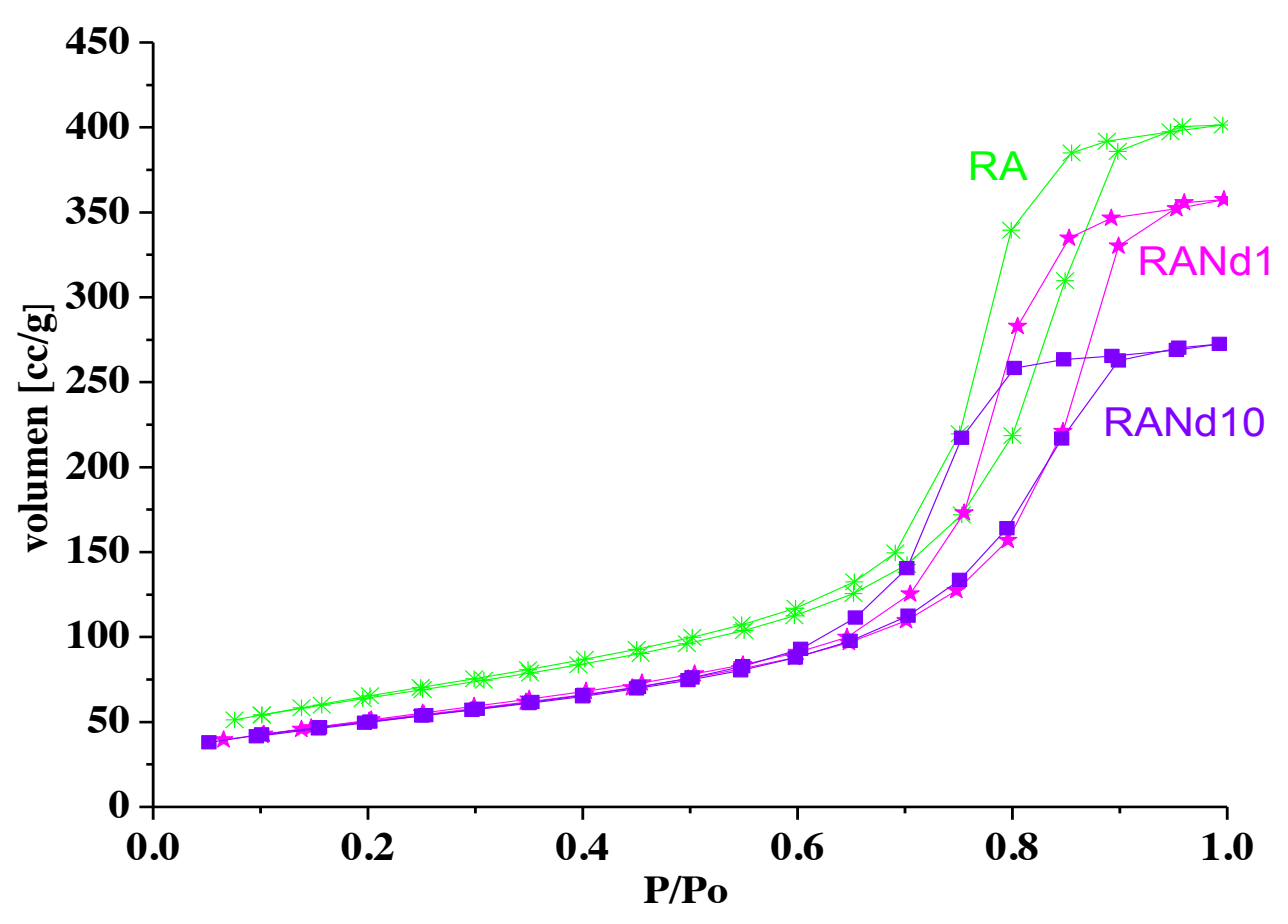

Figura 7. Isotermas de adsorción-desorción de los catalizadores RhA, RhANd1 y RhANd10.

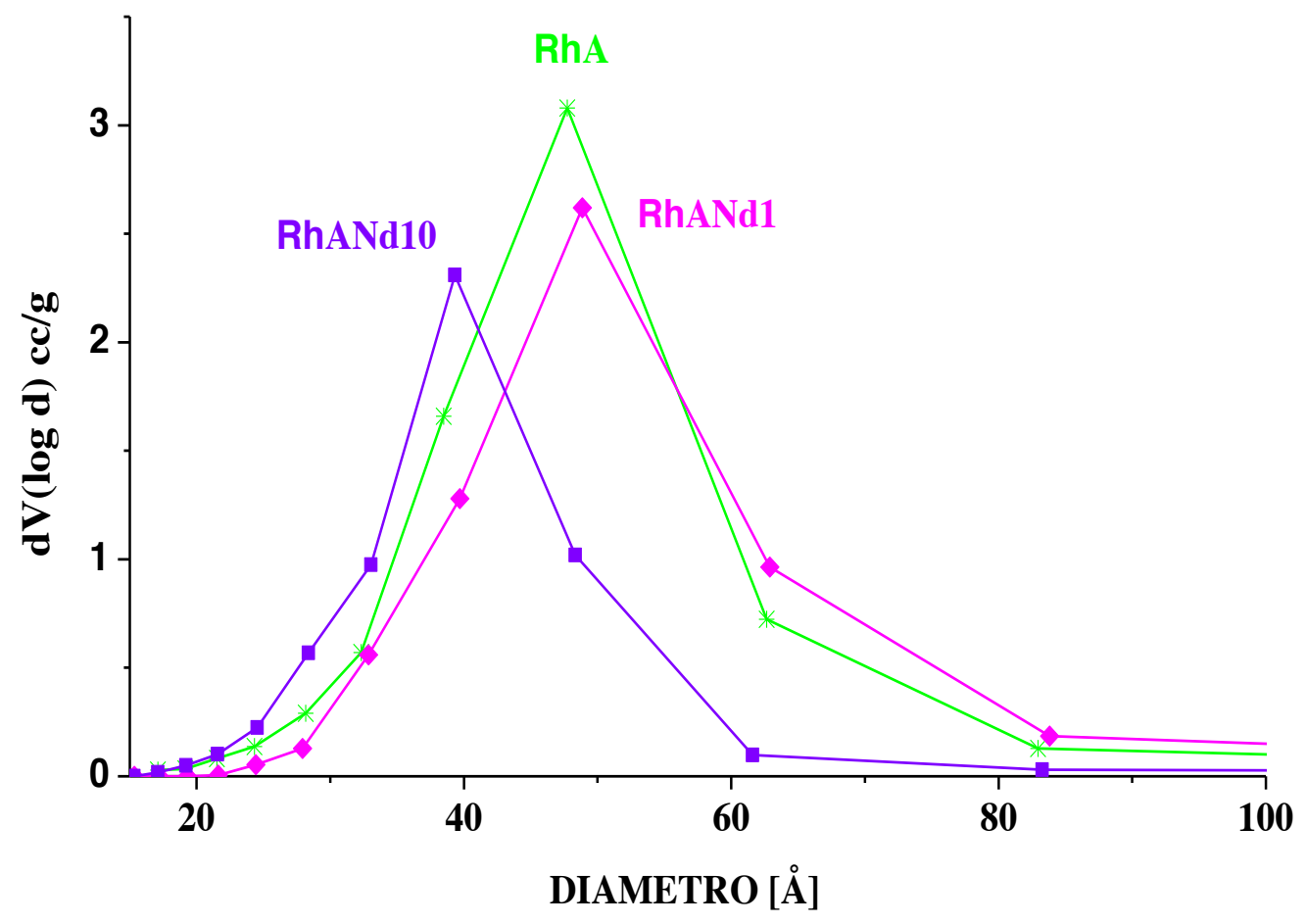

Figura 8. Distribución de diámetro de poro de los catalizadores RhA, RhANd1 y RhANd10. 
Tabla 5. Características de los catalizadores de Rh.

\begin{tabular}{|c|c|c|c|c|c|c|}
\hline${ }^{1}$ Catalizador & ${ }^{2} \mathrm{Rh}$ & $\begin{array}{c}\text { Tamaño medio } \\
\text { del cristal de } \\
\text { Rh }\end{array}$ & $\% \mathrm{D}^{3}$ & $\begin{array}{l}\text { Volumen } \\
\text { del poro }\end{array}$ & $\begin{array}{l}\text { Tamaño } \\
\text { de Poro }\end{array}$ & $\begin{array}{l}\text { Area } \\
\text { BET }\end{array}$ \\
\hline & (\% peso) & $(\mathrm{nm})$ & & $\operatorname{cc~g}^{-1}$ & $\AA$ & $m^{2} g^{-1}$ \\
\hline RhA & 0.77 & $1.0 \pm 0.30$ & 100 & 0.638 & 48 & $\begin{array}{c}{ }^{4}(266) \\
284\end{array}$ \\
\hline RhANd1 & 0.70 & $2.1 \pm 0.48$ & 52 & 0.575 & 49 & 237 \\
\hline RhANd10 & 0.86 & $3.3 \pm 0.72$ & 33 & 0.439 & 39 & 227 \\
\hline
\end{tabular}

${ }^{1}$ Catalizador fresco.

2Técnica de Absorción Atómica

3 (\%) Dispersión $=\left({ }^{\mathrm{a}} \mathrm{N}_{(\mathrm{S})} \mathrm{Rh} /{ }^{\mathrm{b}} \mathrm{N}_{(\mathrm{T})} \mathrm{Rh}\right) \times 100$

${ }^{a} N_{(S)} R h=$ Número de átomos activos de rodio activos disponibles para la reacción.

${ }^{\mathrm{b}} \mathrm{N}_{(\mathrm{T})} \mathrm{Rh}=$ Número total de átomos de rodio en el catalizador.

4 Superficie específica para el soporte de alúmina (A).

El tamaño promedio de los cristales de Rh fue determinado por MET (TEM por sus siglas en inglés), fue de 1,0, 2,1 y 3,3 nm para RhA, RhANd1 y RhANd10 para los catalizadores frescos respectivamente y se determinó mediante la ecuación ds $=\Sigma n_{\text {idi }} 3 / \mathrm{nidi}^{2}$, donde ds, es el tamaño promedio del cristalito de $\mathrm{Rh}$, ni es el diámetro de cristalino $\mathrm{Rh}$, di las medidas tomadas directamente sobre las micrografías, se contaron 150 partículas (Tabla 5). La micrografía y la distribución del tamaño de cristalito para el catalizador fresco de RhANd10 se representan en la Fig. 9, el análisis del histograma claramente sugiere una estrecha distribución de tamaño. La dispersión del Rh en los diferentes catalizadores, también se indica en la Tabla 5, calculada por $\mathrm{D}(\%)$ = Número de Átomos de Rh activos disponibles para la reacción/número total de átomos de Rh en el material de catalizador x100. 


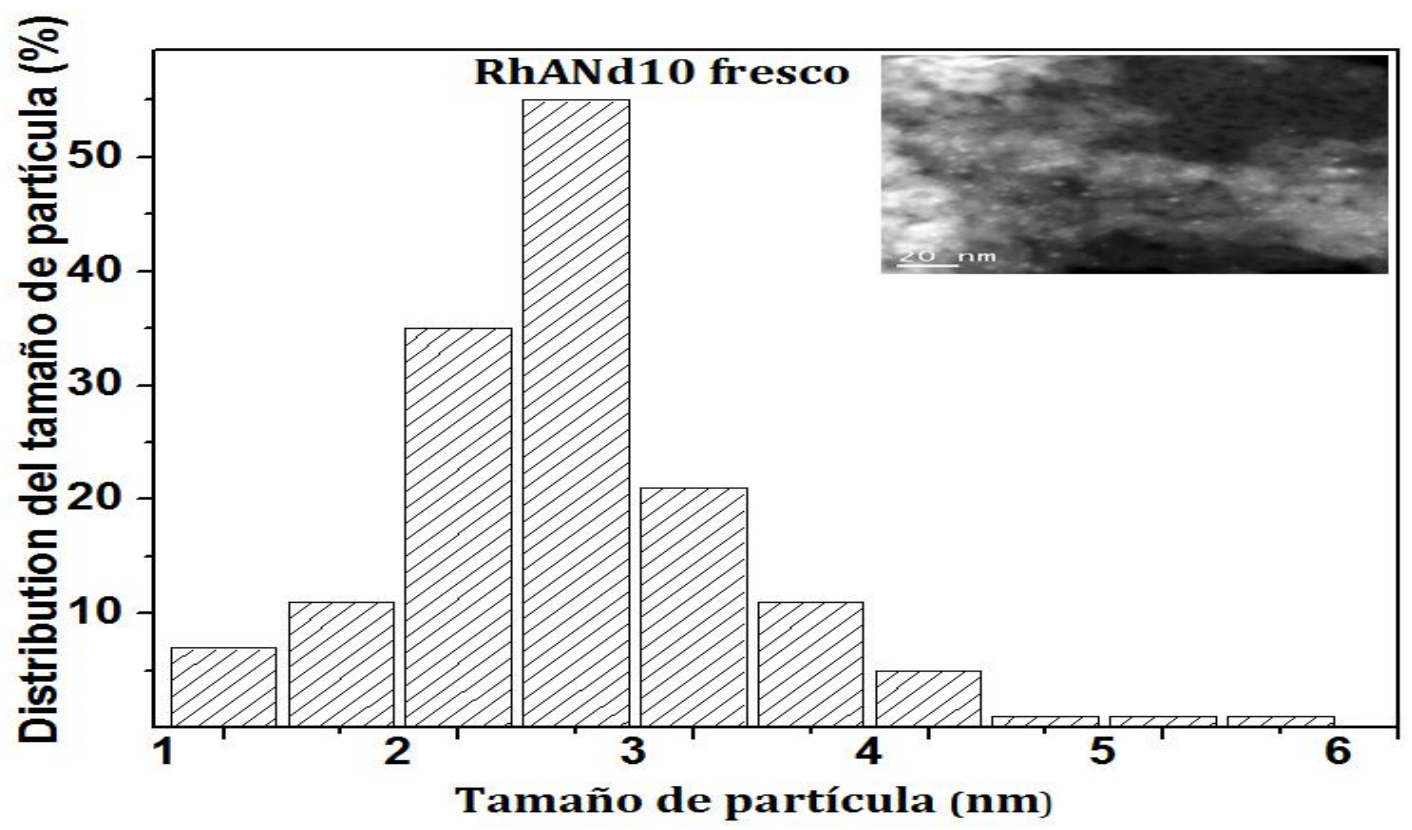

Figura 9. Histograma del catalizador RhANd10 fresco.

Los perfiles de reducción (RTP- $\mathrm{H}_{2}$ ) para los catalizadores RhA, RhANd1 y RhANd10 se muestran en la Fig. 10, se observaron dos picos de reducción en todas las muestras de Rh. Los catalizadores $\mathrm{RhA}$ y RhANd1 exhibieron un pico similar a 157 y $159{ }^{\circ} \mathrm{C}$ respectivamente, que se han atribuido a la reducción de cristales tridimensionales de $\mathrm{Rh}_{2} \mathrm{O}_{3}$ para dar el rodio metálico $[64,65]$. Esta especie de óxido de rodio está en estrecha interacción con la superficie de la alúmina $[66,67]$. En el catalizador de Rh con 1\% en peso de Nd como promotor (RhANd1) prácticamente no se modificó la temperatura de reducción de la especie $\mathrm{Rh}_{2} \mathrm{O}_{3}$, indicando una interacción similar de $\mathrm{Rh}$ con la superficie como en el catalizador RhA.

Para el catalizador RhANd10 el primer pico se desplaza hacia una temperatura más alta, el pico de reducción se centra a $174{ }^{\circ} \mathrm{C}$, lo que corresponde a la reducción de partículas tridimensionales de $\mathrm{Rh}_{2} \mathrm{O}_{3}$ para obtener $\mathrm{Rh}$ metálico [68], el cambio de la reducción de $\mathrm{Rh}$ a una mayor temperatura indica una mayor interacción entre el Rh y el óxido de neodimio originada en la atmósfera oxidante de los pretratamientos de calcinación [64], Burch et al. Propuso que cuando el $\mathrm{Rh}$ se calcina a $500^{\circ} \mathrm{C}$, un poco de óxido de Rh puede extenderse sobre el soporte y colocarse en los sitios de defectos de la alúmina y el Rh se vuelve 
difícilmente reducible. Algunos autores han informado que los compuestos $\mathrm{Rh}_{2} \mathrm{O}_{3}$ y $\mathrm{Nd}_{2} \mathrm{O}_{3}$ muestran una gran afinidad en una atmósfera oxidante, lo que hace que el $\mathrm{Rh}$ interactúe fuertemente con el $\mathrm{Nd}_{2} \mathrm{O}_{3}$ y provoca la formación de enlaces Rh-O-Nd [69]. Entonces, la interacción del $\mathrm{Rh}$ con el soporte con una capa superficial enriquecida con $\mathrm{Nd}_{2} \mathrm{O}_{3}$ en la muestra de RhNd10 es responsable del cambio de temperatura de reducción del Rh, ya que esta muestra tiene la mayor cantidad de $\mathrm{Nd}_{2} \mathrm{O}_{3}(10 \%$ en peso) y cuyo exceso se depositaría sobre la superficie de la alúmina con gran interacción con las partículas de Rh.

El segundo pico de reducción a la temperatura más alta muestra un máximo a $428{ }^{\circ} \mathrm{C}, 429$ ${ }^{\circ} \mathrm{C}$ y $410{ }^{\circ} \mathrm{C}$ para los catalizadores $\mathrm{RhA}$, RhANd1 y RhANd10 respectivamente, este pico se ha asociado a la reducción de una especie oxidada de rodio, $\mathrm{Rh}\left(\mathrm{AlO}_{3}\right)$, formada por difusión de los óxidos de $\mathrm{Rh}$ en las subcapas de la estructura de la $\gamma-\mathrm{Al}_{2} \mathrm{O}_{3}$ a altas temperaturas [66]. Aunque, otros autores han propuesto que este segundo pico está relacionado con la reducción de dos dimensiones de partículas de $\mathrm{Rh}_{2} \mathrm{O}_{3}[66]$.

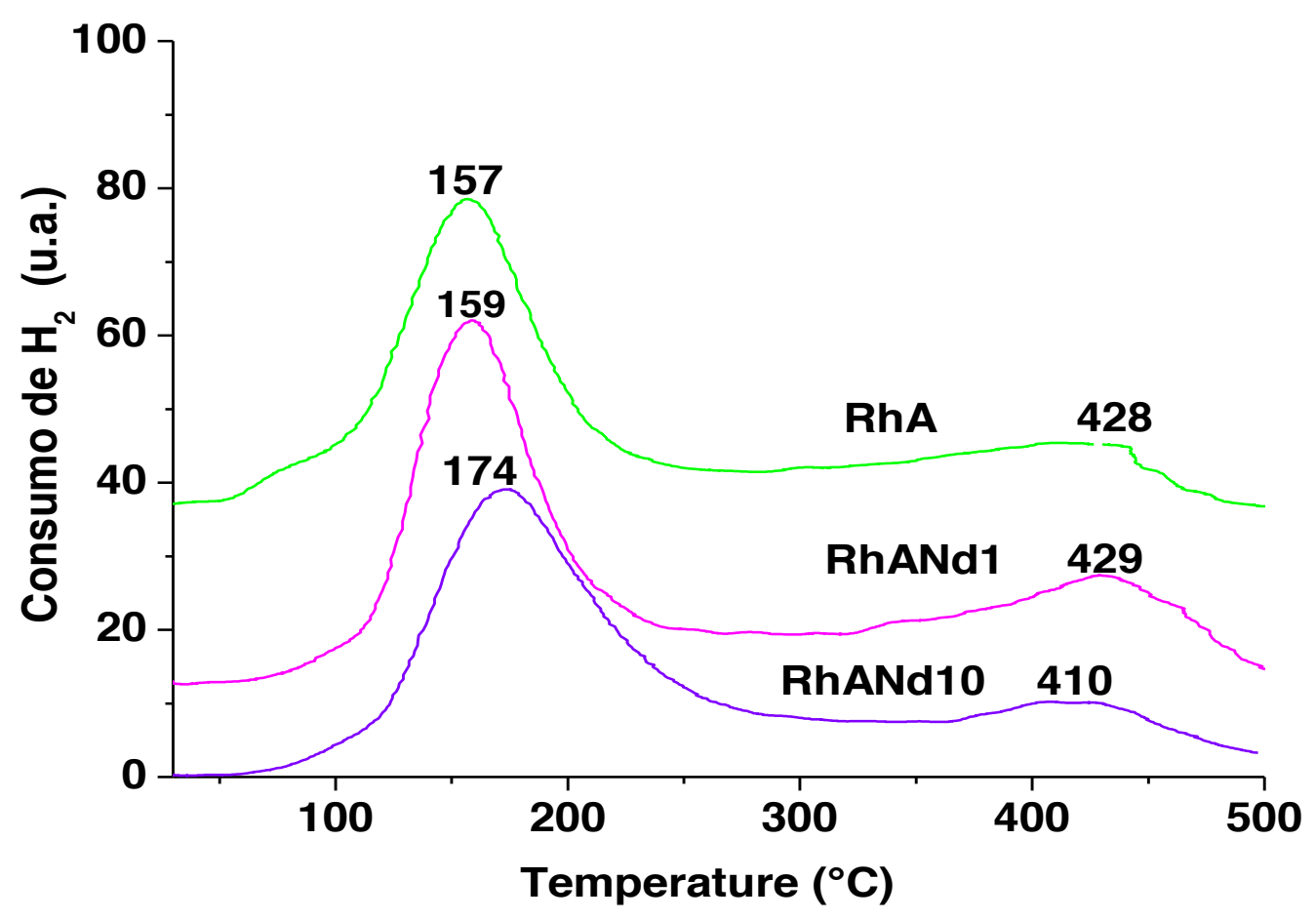

Figura 10. Perfiles de reducción de los catalizadores de rodio. 
Los resultados anteriores están de acuerdo con los obtenidos por espectroscopia de fotoelectrones de rayos X (XPS por sus siglas en inglés). Los datos de fotoelectrones de rayos X de la región $\mathrm{Rh} 3 \mathrm{~d}$ para catalizadores $\mathrm{Rh}$ se presentan en la Tabla 6 y los espectros EFRX se muestran en la Fig. 11. Las energías de enlace de Rh correspondientes al nivel del núcleo de $\mathrm{Rh} 3 \mathrm{~d}_{5 / 2}$ muestran 2 picos a $307.25 \mathrm{eV}$ y $308.45 \mathrm{eV}$ que se pueden atribuir a las especies $\mathrm{Rh}^{\circ}$ y $\mathrm{Rh}^{3+}$ para todos los catalizadores de $\mathrm{Rh}$, RhA, RhANd1 y RhANd10. La abundancia relativa de la especie reducida y oxidada se calculó a partir del área de los picos deconvolucionados. Para RhA, RhANd1 y RhANd10 (Tabla 6) la cantidad relativa de la especie $\mathrm{Rh}^{\circ}$ varía de 42,33 y $25 \%$, mientras que para las especies $\mathrm{Rh}^{3+}$ las cantidades son 58, 67 y 75\%, respectivamente. Se observó un aumento de la especie oxidada con el aumento del $\mathrm{Nd}_{2} \mathrm{O}_{3}$ en el catalizador, la presencia de $\mathrm{Nd}_{2} \mathrm{O}_{3}$ estabiliza la especie oxidada $\mathrm{Rh}^{3+}$. Estos resultados sugieren que la presencia de $\mathrm{Nd}_{2} \mathrm{O}_{3}$ en los catalizadores de $\mathrm{Rh}$ produce especies de $\mathrm{Rh}$ deficientes en electrones como resultado de la fuerte interacción de $\mathrm{Rh}$ con la capa superficial enriquecida con $\mathrm{Nd}_{2} \mathrm{O}_{3}$ en el catalizador $\mathrm{RhANd} 10$. Los resultados de EFRX confirman las sugerencias propuestas anteriormente de una interacción más fuerte metal-soporte sobre el catalizador con el contenido más alto de $\mathrm{Nd}_{2} \mathrm{O}_{3}$.

Tabla 6. Energía de enlace de $\mathrm{Rh} 3 \mathrm{~d}_{5 / 2}$ y abundancia relativa de las diferentes especies de $\mathrm{Rh}$ a partir de datos EFRX en catalizadores RhA y RhANdX.

\begin{tabular}{lcccc}
\hline Catalizador & \multicolumn{2}{c}{ Energía de enlace (eV) } & \multicolumn{2}{c}{ Abundancia (\%) } \\
& $\mathrm{Rh}^{\circ}$ & $\mathrm{Rh}^{3+}$ & $\mathrm{Rh}^{\circ}$ & $\mathrm{Rh}^{3+}$ \\
& & & & \\
\hline RhA & 307.25 & 308.45 & 42 & 58 \\
RhANd1 & 307.25 & 308.45 & 33 & 67 \\
RhANd10 & 307.25 & 308.45 & 25 & 75 \\
\hline
\end{tabular}



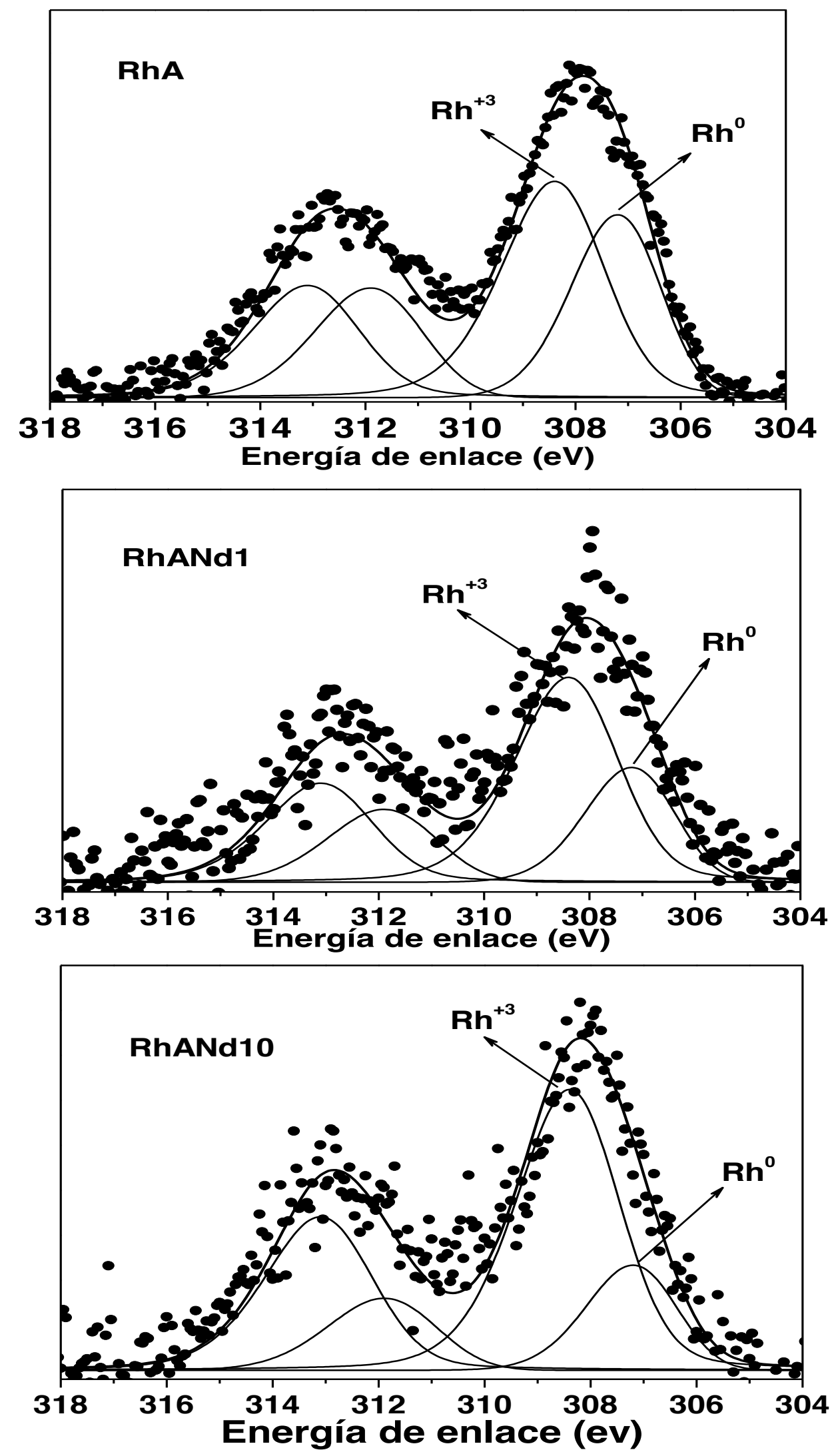

Figura 11. Espectros EFRX de Rh 3d para los RhA, RhANd1 y RhANd10. 
El IRTF de CO adsorbido en los catalizadores Rh promovidos y no promovidos se muestra en la Fig. 12. El catalizador de RhA muestra espectros similares reportados por otros autores [70]. Los dos únicos picos se representan en 2091 y $2019 \mathrm{~cm}^{-1}$ que están asociados a la vibración de estiramiento simétrico y asimétrico de las especies germinal-dicarbonil $\mathrm{Rh}^{+}(\mathrm{CO})_{2}$. La presencia de esta especie se explica por la ruptura oxidativa de los cristalitos de Rh que comprenden grupos hidroxilo del soporte [71, 72]. No se detectaron enlaces puenteados a las especies de CO $\left(1850 \mathrm{~cm}^{-1}\right)$ ni las especies CO unidas linealmente al $\mathrm{Rh}^{\circ}$ (2040-2070 $\mathrm{cm}^{-1}$ ), las especies se formaron en la superficie del Rh [71]. La presencia de especies gem-dicarbonilo en el espectro IRTF para el catalizador RhA debe interpretarse como la presencia de cristalitos de rodio muy pequeños que corresponden a una alta dispersión. Entonces, se puede asumir que el CO gem-dicarbonilo se adsorbe en sitios de baja coordinación. De la misma manera para los catalizadores RhANd1 y RhANd10 las bandas de las especies de dicarbonilo fueron las únicas bandas de adsorción de CO detectadas. Sin embargo, la tendencia observada en estas muestras es que con el aumento de la carga de Nd se produce una disminución de la intensidad de las bandas de CO. Este comportamiento fue más notable en la muestra con mayor cantidad de $\mathrm{Nd}$ ( $10 \%$ en peso). La disminución de la intensidad con la adición del promotor Nd podría estar relacionada con la diferencia de tamaño del cristalito Rh. Si el tamaño del cristalito de Rh aumenta, debe notarse la presencia de la banda de adsorción de CO lineal, sin embargo este no es el caso. Para la obtención de la adsorción lineal de CO sobre rodio metálico es necesario un tamaño de cristalito mayor que el obtenido en nuestros catalizadores. Por otra parte, es probable que la reducción de la intensidad de las bandas de IR se deba a una disminución del número de sitios de Rh de baja coordinación expuestos a la adsorción de CO por bloqueo progresivo por el óxido de neodimio [65]. 


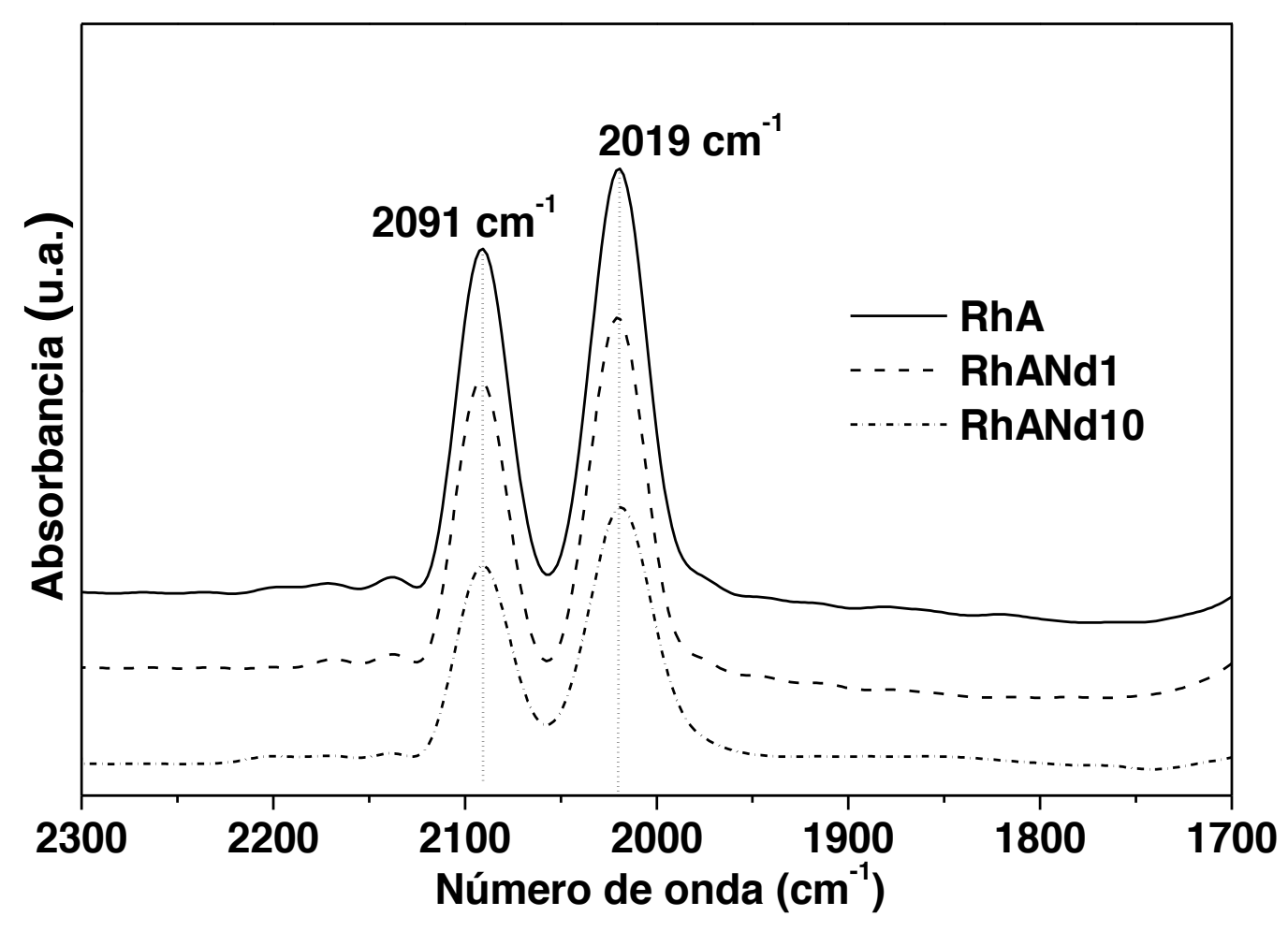

Figura 12. Espectros de IRTF de CO adsorbido sobre los catalizadores de RhA y $\operatorname{RhANd} X$.

El espectro IR de la piridina adsorbida sobre RhANdX (fig. 13) presenta cuatro bandas, a 1614, 1573, 1492 y $1448 \mathrm{~cm}^{-1}$, que se atribuyen a ser características de la piridina coordinada a los sitios ácidos de Lewis, se observa que con el aumento de la cantidad de neodimio en los catalizadores, dichas bandas disminuyen ligeramente en intensidad, y la banda débil observada en $1573 \mathrm{~cm}^{-1}$ desaparece, en este caso no se detectaron sitios ácidos de Brönsted, en la tabla 7 se presentan los valores de acidez de los catalizadores en $\mu \mathrm{mol} / \mathrm{gcat}$, notando una ligera disminución entre la acidez del RhA y RhANd1, mientras que hay una mayor disminución de la acidez del catalizador RhANd10. 


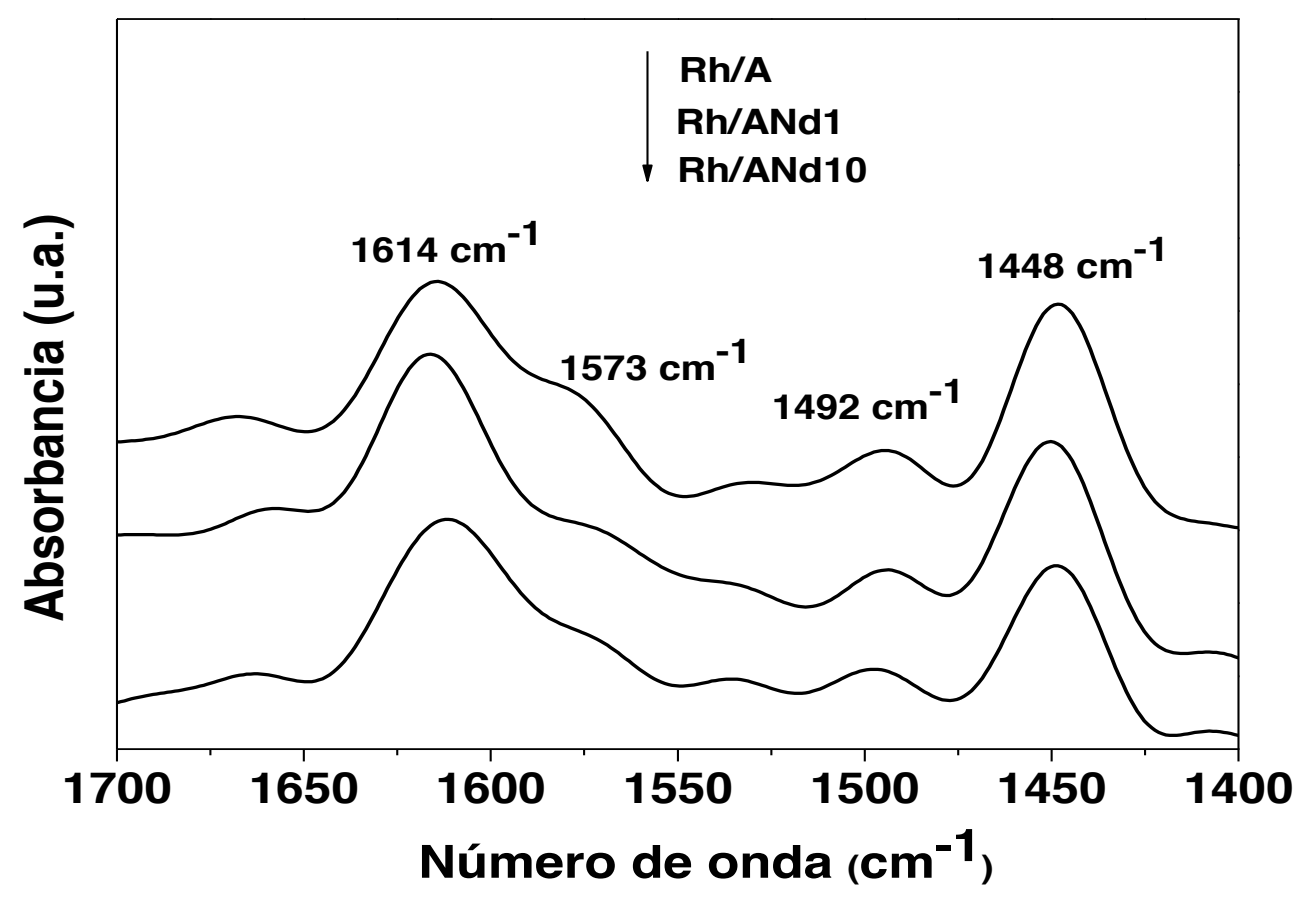

Figura 13. Espectros de IRTF de Piridina adsorbida sobre los catalizadores RhA y RhANdX.

Tabla 7. Acidez de los catalizadores de RhA y RhANdX

\begin{tabular}{c|c}
\hline Catalizador & Acidez $(\boldsymbol{\mu m o l} / \mathbf{g c a t})$ \\
\hline RhA & 123 \\
RhANd1 & 119 \\
RhANd10 & 96 \\
\hline
\end{tabular}




\section{Actividad, selectividad y carbono.}

La deshidrogenación de metano se llevó a cabo a temperaturas de 400, 500, 600, 700 y 750 ${ }^{\circ} \mathrm{C}$ con un flujo de metano sin diluir y una velocidad espacial de $6 \mathrm{~L} \mathrm{~h}^{-1} \mathrm{~g}^{-1}$. La figura 14 muestra los perfiles de conversión del metano en función de la temperatura. Se observa que la conversión de metano aumenta a medida que la temperatura aumenta de $400{ }^{\circ} \mathrm{C}$ a una conversión máxima a $700{ }^{\circ} \mathrm{C}$, y se observa una disminución a $750{ }^{\circ} \mathrm{C}$.

La deshidrogenación del metano para los diferentes catalizadores a $400{ }^{\circ} \mathrm{C}$ muestra una baja actividad mostrando conversiones de 20, 18 y 19 \% vol, correspondientes a RhA, RhANd1 y RhANd10, respectivamente (Tabla 8). Por otra parte, la actividad por sitio, TOF h${ }^{1}$ para la descomposición de metano, el catalizador RhANd10 mostró la mayor actividad (7.2 $\mathrm{h}^{-1}$ ) seguidos por el RhANd1 (5.3 $\left.\mathrm{h}^{-1}\right)$, y finalmente el RhA con $2.6 \mathrm{~h}^{-1}$ (Tabla 8). Como es bien conocido, la estructura de la partícula metálica puede influir en la actividad [73]. La muestra de RA con el tamaño de cristalito más bajo $(1.0 \mathrm{~nm})$ muestra también una baja actividad por sitio. Con un tamaño de partícula $\geq 2,0 \mathrm{~nm}$, la actividad es mayor, un tamaño de cristalito Rh más grande es más activo a $400{ }^{\circ} \mathrm{C}$ (Tabla 8).

Todos los catalizadores $\mathrm{Rh}$ exhiben el más alto rendimiento a $700{ }^{\circ} \mathrm{C}$ (Fig. 14). La conversión de la reacción aumentó rápidamente entre 600 y $700{ }^{\circ} \mathrm{C}$, esto puede explicarse por la reducción de los sitios de Rh más activos, utilizando el hidrógeno producido in situ, a $700^{\circ} \mathrm{C}[74,75]$. 


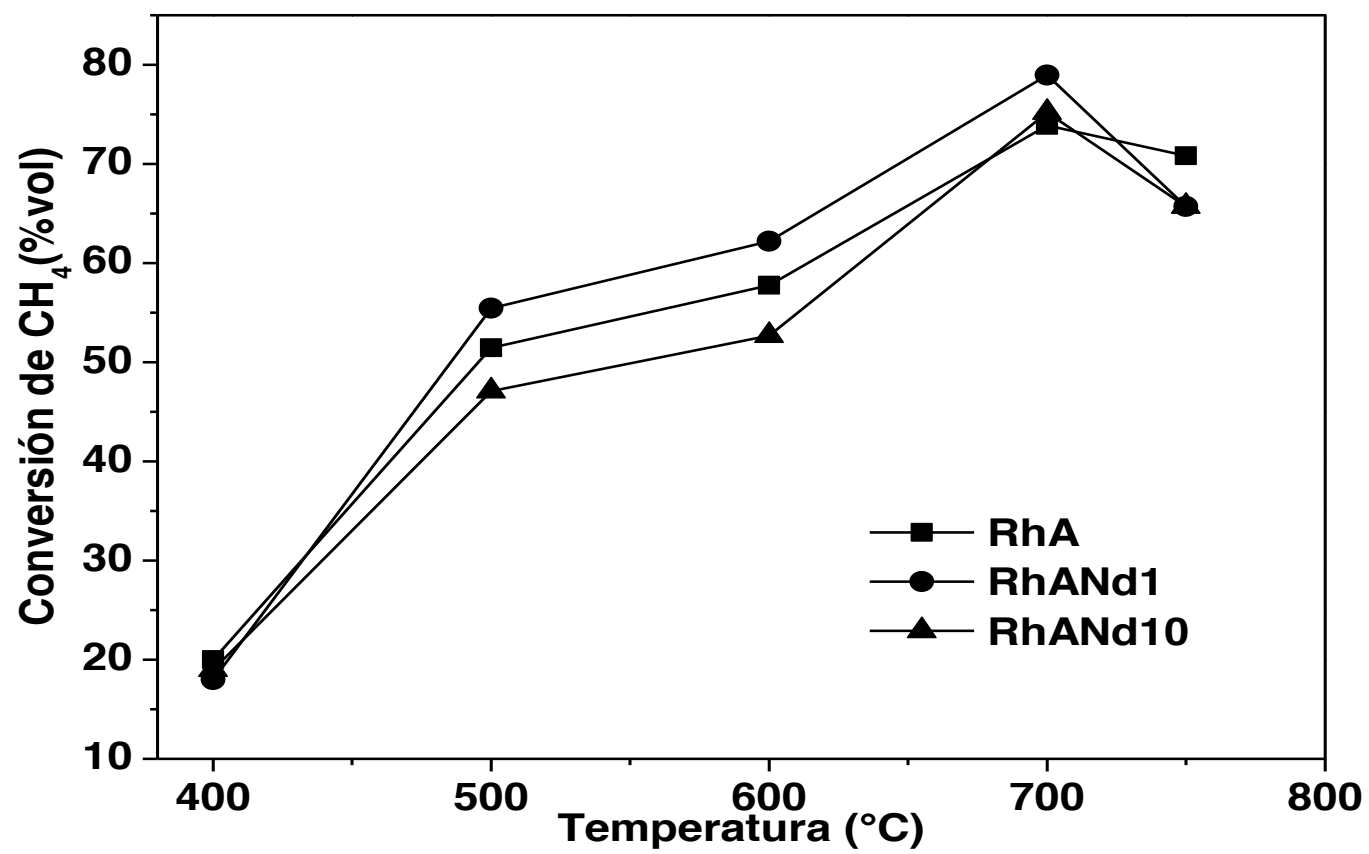

Figura 14. Conversión de la descomposición de metano como función de la temperatura para los catalizadores de Rh.

Tabla 8. Conversión, selectividad y TOF para la deshidrogenación del metano sobre catalizadores de $\operatorname{RhANd} X$ a $400{ }^{\circ} \mathrm{C}$.

\begin{tabular}{cccc} 
Catalizador & Conversión de $\mathrm{CH}_{4}$ & Selectividad a $\mathrm{H}_{2}$ & TOF \\
& $(\%)$ & $(\%)$ & $\mathrm{h}^{-1}$ \\
\hline RhA & 20 & 22 & 2.6 \\
RhANd1 & 18 & 17 & 5.3 \\
RhANd10 & 19 & 26 & 7.2 \\
\hline
\end{tabular}


La conversión máxima de la deshidrogenación de metano es de aproximadamente 74-79\% en volumen a $700{ }^{\circ} \mathrm{C}$ para todos los catalizadores Rh (Tabla 9). Sin embargo, la actividad por sitio activo (TOF) es mayor con la presencia de $\mathrm{Nd}$ en los catalizadores. La actividad TOF para los diferentes catalizadores es: $\operatorname{RhANd} 10 \sim \operatorname{RhANd} 1>\mathrm{RhA}$, a $700{ }^{\circ} \mathrm{C}$ (Tabla 9). Los catalizadores con mayor tamaño de cristalito $\geq 2,1 \mathrm{~nm}(\operatorname{RhANd} 1$ y RhANd10) son más activos que el catalizador RhA con partículas pequeñas $\sim 1,0 \mathrm{~nm}$ (Tabla 9]. Los pequeños cristalitos de rodio de la muestra de $\mathrm{RhA}$ altamente dispersados, muestran una baja actividad por sitio. Algunos autores estudiando la adición de Pd al Rh mostrando una disminución en TOF que se explicó por una reducción de sitios de Rh para la hidrogenación de anillos aromáticos [76]. Esta menor capacidad de los cristales pequeños de Rh fue consistente con los grupos inorgánicos mononucleares de Rh en catálisis homogénea. Las propiedades electrónicas de estas partículas muy pequeñas son muy diferentes a las partículas de metal en el bulk [77]. Por otra parte, las partículas de Rh más grandes podrían presentar sitios activos para la reacción, donde el metano podría adsorberse mostrando una actividad más alta. En los presentes catalizadores se podría considerar que RhANd1 y RhANd10 con mayor tamaño de cristalito tendrían sitios más accesibles. Cuando se aumentó la temperatura a $750{ }^{\circ} \mathrm{C}$ todos los catalizadores presentaron una disminución en la actividad (Fig.14), esta disminución en la conversión podría ser debido a una sinterización del tamaño de partícula o a un depósito de carbono sobre la superficie del catalizador. La mayor producción de hidrógeno se observó a $700{ }^{\circ} \mathrm{C}$ sobre el catalizador RhANd10 (mayor tamaño de partícula, $3.3 \mathrm{~nm}$ y mayor concentración de neodimio). Este catalizador presenta una selectividad a hidrógeno del 100\%. Los catalizadores con tamaños de partícula $\leq 2,1 \mathrm{~nm}$ mostraron selectividades inferiores a hidrógeno de 89 y $65 \%$ sobre $\mathrm{RhA}$ y RhANd1 respectivamente. Uno de los factores importantes que afectan el rendimiento del metal está relacionado con su estructura electrónica, y esto se asocia a la estructura del tamaño de la partícula [77]. Las partículas metálicas pequeñas presentan mayor número de sitios de baja coordinación como esquinas y bordes que son más electrodeficientes. Otro parámetro importante a considerar es el grado de interacción entre el metal y el soporte. La transferencia de carga entre las interfaces del soporte y del metal puede cambiar la densidad de la banda d de los estados y por lo tanto conducir a diferentes propiedades catalíticas [73]. Los estudios de RTP- $\mathrm{H}_{2}$ y EFRX mostraron que existe una alta interacción 
entre el $\mathrm{Rh}$ y el soporte de $\mathrm{y}-\mathrm{Al}_{2} \mathrm{O}_{3}-\mathrm{Nd}_{2} \mathrm{O}_{3}$ que depende de la cantidad de enriquecimiento superficial de neodimio sobre el catalizador. Una superficie de $\gamma^{-}-\mathrm{Al}_{2} \mathrm{O}_{3}$ rica en óxido de neodimio (10\% en peso) conduce a una interacción superficial fuerte entre el $\mathrm{Rh}$ y el soporte $\mathrm{Nd}_{2} \mathrm{O}_{3}-\mathrm{\gamma}^{-}-\mathrm{Al}_{2} \mathrm{O}_{3}$ [64]. El bajo contenido de $\mathrm{Nd}$ (1\% en peso) en la alúmina produce una interacción $\mathrm{Rh}$-soporte, similar a la mostrada en $\mathrm{\gamma}-\mathrm{Al}_{2} \mathrm{O}_{3}$. La diferencia en el grado de interacción de $\mathrm{Rh}$ con el soporte induce a cambios en la estructura electrónica, que afectan a la actividad y selectividad de la descomposición del metano.

De hecho, como se observa en la Tabla 9, el patrón de selectividad en el catalizador RhANd10 es diferente al observado en los catalizadores RhA y RhANd1. El $\mathrm{CH}_{4}$ se adsorbe disociativamente en partículas superficiales de Rh que producen especies $\mathrm{H}_{2}$ y $\mathrm{CHx}(\mathrm{x}=3-0)$. Si las especies $\mathrm{CHx}$ tienen alta movilidad en la superficie metálica, por lo tanto una recombinación con otra especie podría conducir a la formación de hidrocarburos superiores [78]. Se ha reportado que la principal especie observada en la descomposición de $\mathrm{CH}_{4}$ es el hidrocarburo $\mathrm{C}_{2}$ y depende de la naturaleza del soporte [73]. Como se puede ver en la Tabla 9, los productos detectados, además del hidrógeno, en los catalizadores RhA y RhANd1 son etano y etileno cuyas selectividades son 3 y 8\% para RhA y 12 y $23 \%$ para RhANd1, a $700{ }^{\circ} \mathrm{C}$. Estudios sobre la conversión de metano y las quimisorciones en las superficies metálicas mostraron que el $\mathrm{CH}_{3}$ es la principal especie disociada y el acoplamiento de $\mathrm{CH}_{3}$ puede producir etano [78].

La deshidrogenación adicional a $\mathrm{CH}_{2}$ y el acoplamiento conduce a la formación de etileno. Estos productos se favorecen en la superficie del Rh en los catalizadores RhA y RhANd1, ya que la fuerza de adsorción permite la migración de la especie CHx sobre la superficie. La fig. 15a) representa el comportamiento de los catalizadores RhA y RhANd1 donde la interacción con el soporte es muy similar, favoreciendo la migración de la especie CHx y formando el etano y el etileno. Por otra parte, en el catalizador RhANd10, las especies CHx son adsorbidas más fuertemente y son más estables en la superficie del Rh, la quimisorción disociativa de las especies de metano produce la evolución a $\mathrm{H}_{2}$, resultado de la asociación de átomos de hidrógeno, el único producto detectado en este catalizador, Fig. 15 b). No se detectaron otros productos debido a la fuerte adsorción de especies $\mathrm{CHx}$ en la superficie. 
Tabla 9. Conversión, selectividad y TOF para la deshidrogenación del metano sobre catalizadores de $\operatorname{RhANd} X$ a 700 and $750^{\circ} \mathrm{C}$.

\begin{tabular}{|c|c|c|c|c|c|c|}
\hline \multirow[t]{2}{*}{ Catalizador } & \multirow{2}{*}{$\begin{array}{c}\text { Temperatura } \\
\left({ }^{\circ} \mathrm{C}\right)\end{array}$} & \multirow{2}{*}{$\begin{array}{c}\text { Conversión } \\
\qquad \%)\end{array}$} & \multirow{2}{*}{$\begin{array}{l}\text { TOF } \\
\left(\mathrm{h}^{-1}\right)\end{array}$} & \multicolumn{3}{|c|}{ Selectividad (\%) } \\
\hline & & & & $\mathrm{H}_{2}$ & $\mathrm{C}_{2} \mathrm{H}_{4}$ & $\mathrm{C}_{2} \mathrm{H}_{6}$ \\
\hline \multirow[t]{2}{*}{ A } & 700 & 12.8 & - & 100 & 0 & 0 \\
\hline & 750 & 20 & - & 100 & 0 & 0 \\
\hline \multirow[t]{2}{*}{ ANd1 } & 700 & 27.7 & - & 100 & 0 & 0 \\
\hline & 750 & 27.8 & - & 100 & 0 & 0 \\
\hline \multirow[t]{2}{*}{ ANd10 } & 700 & 16.8 & - & 100 & 0 & 0 \\
\hline & 750 & 18.2 & - & 100 & 0 & 0 \\
\hline \multirow[t]{2}{*}{$\mathrm{RhA}$} & 700 & 74 & 9 & 89 & 8 & 3 \\
\hline & 750 & 71 & - & 85 & 8 & 7 \\
\hline \multirow[t]{2}{*}{ RhANd1 } & 700 & 79 & 20 & 65 & 23 & 12 \\
\hline & 750 & 68 & - & 63 & 12 & 25 \\
\hline \multirow[t]{2}{*}{ RhANd10 } & 700 & 75 & 26 & 100 & 0 & 0 \\
\hline & 750 & 66 & - & 100 & 0 & 0 \\
\hline
\end{tabular}




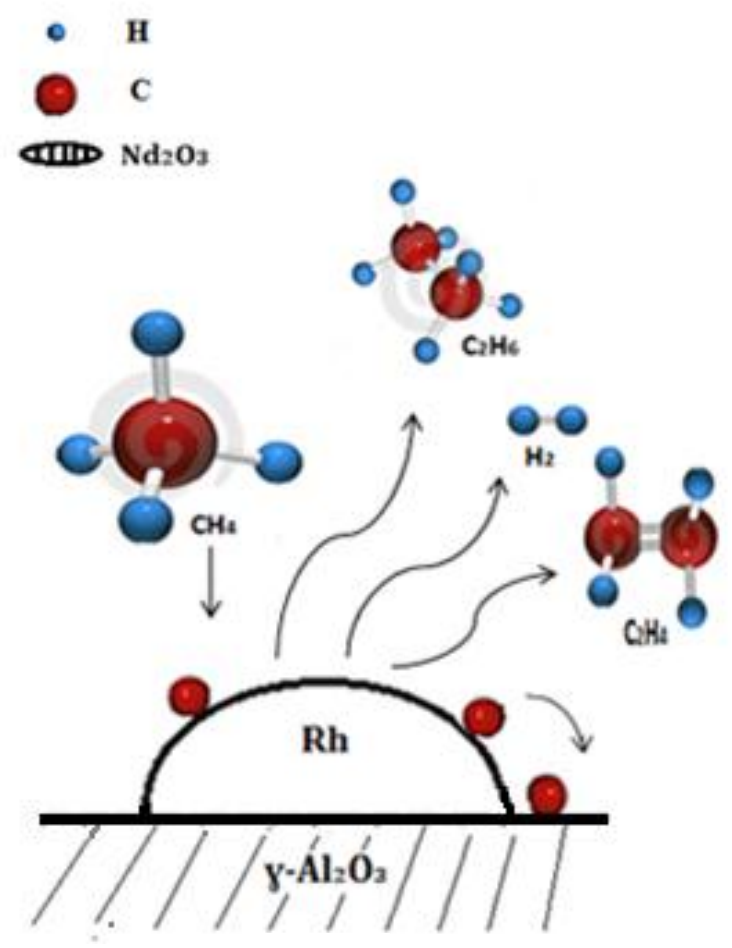

a)

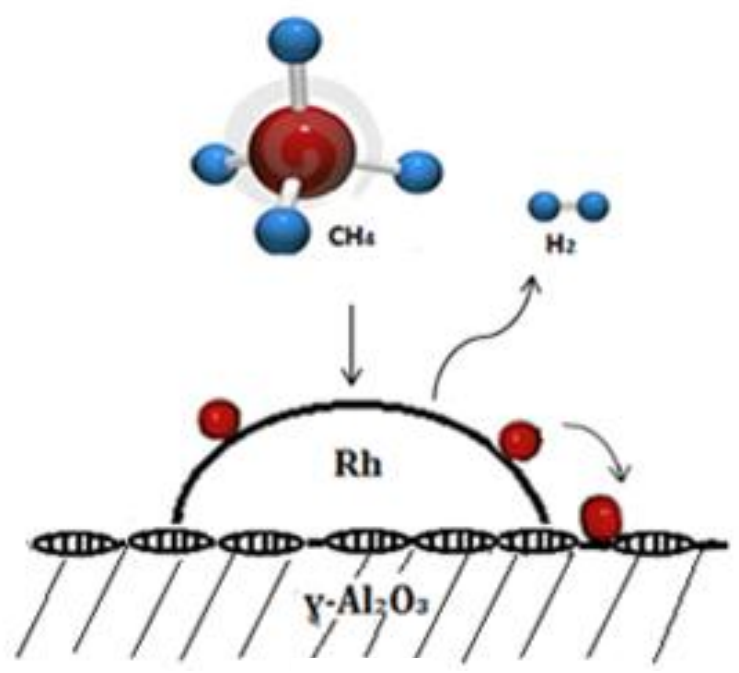

b)

Figura 15. Representación del comportamiento de la descomposición del metano en partículas metálicas Rh para: a) RhA y b) RhANd10.

Para determinar la estabilidad del catalizador RhANd10, la muestra, se mantuvo en un tiempo de reacción de $6 \mathrm{~h}$ a $700^{\circ} \mathrm{C}$, tal como se muestra en la Fig. 16, donde permaneció la selectividad. Además, con el aumento de la temperatura de reacción a $750{ }^{\circ} \mathrm{C}$, la selectividad hacia el hidrógeno permaneció inalterada al 100\%, Fig. 17. La producción de hidrógeno tiende a un rendimiento estable a medida que aumenta la temperatura. El hecho de que en el catalizador RhANd10 no disminuya la selectividad, incluso si el carbono se deposita sobre las partículas superficiales Rh, podría explicarse asumiendo que el carbono depositado puede estar participando en la reacción y que actúa como un sitio activo [79]. Se ha informado de que el $\mathrm{C}$ puede disolverse en $\mathrm{Rh}$ a temperaturas elevadas y que parte del $\mathrm{C}$ disuelto se acumula en la superficie sobre las partículas Rh [80]. Después de 600 minutos, el rendimiento de $\mathrm{H}_{2}$ mantiene un valor estable, lo que indica algún tipo de equilibrio en la 
superficie del catalizador entre la velocidad de depósito de carbono y la descomposición de metano [81].

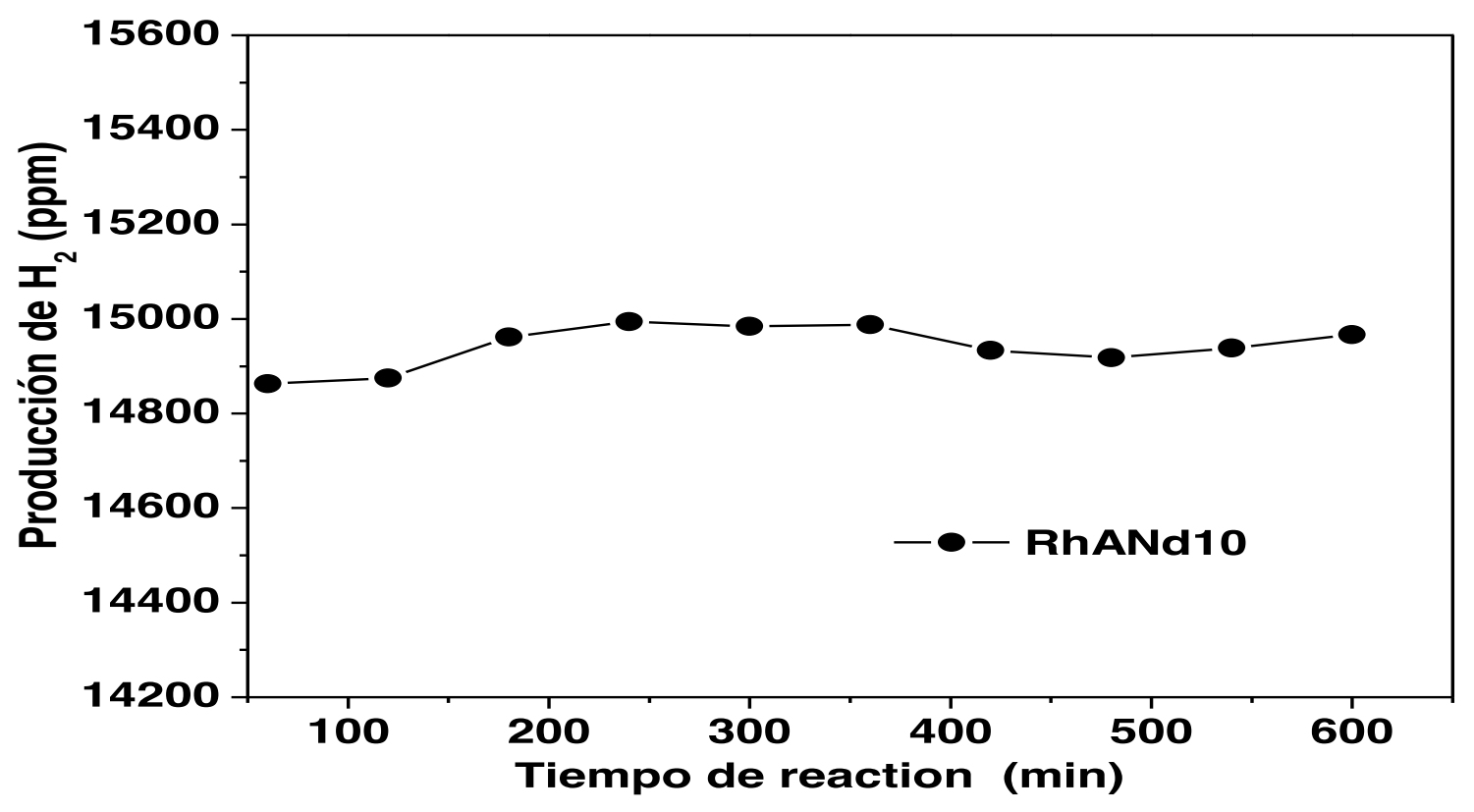

Figura 16. Estabilidad del catalizador RhANd10 durante 600 min.

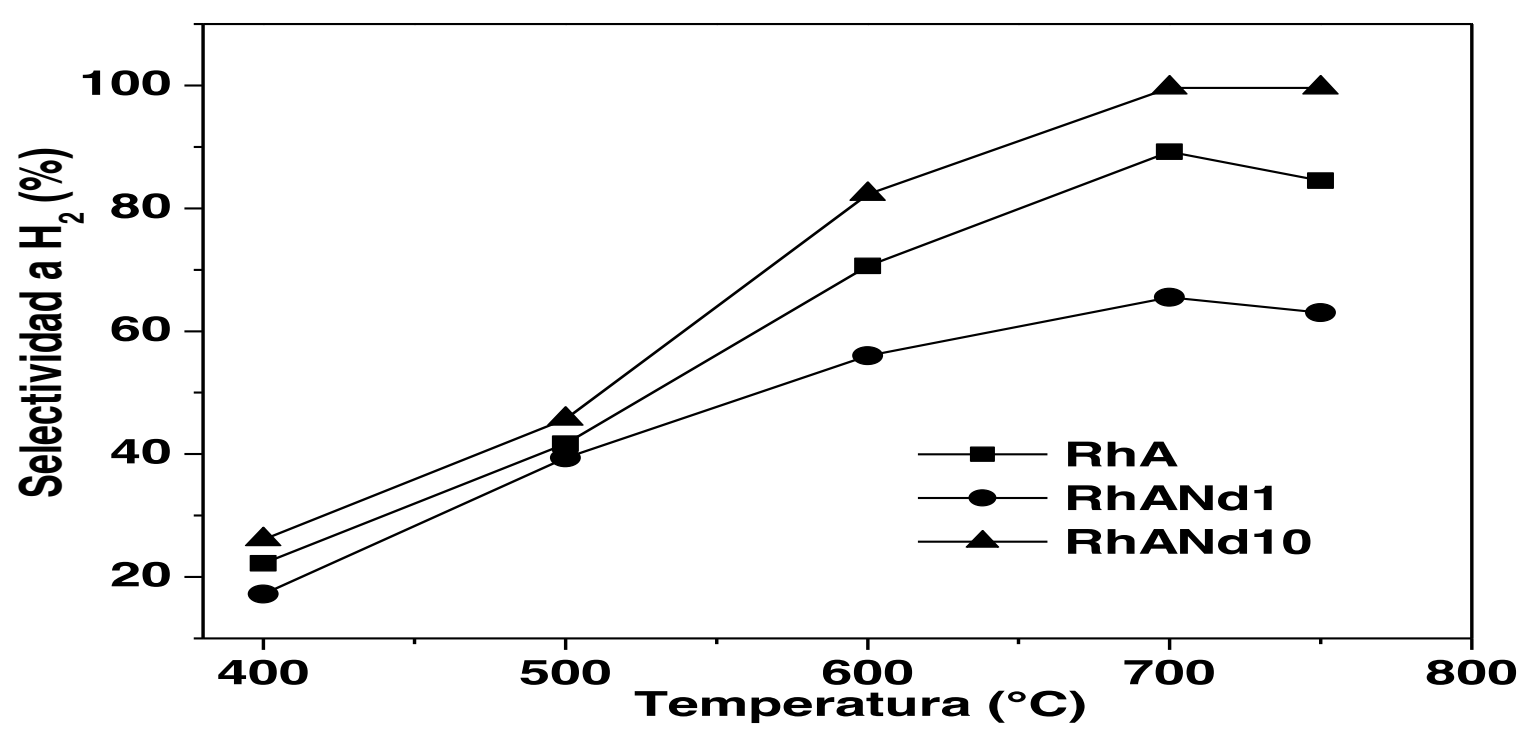

Figura 17. Selectividad a la producción de hidrógeno en función de la temperatura para la descomposición del metano sobre catalizadores de Rh soportados en alúmina-neodimio. 
En la Tabla 10 se presenta el tamaño promedio del cristalito de Rh para el catalizador RhANd10 fresco y usado mientras que la distribución del tamaño de cristalito de Rh se muestra en las Figuras 9 (fresco) y 18 (usado). El catalizador usado se obtuvo después de la reacción a las diferentes temperaturas: $400,500,600,700$ y $750{ }^{\circ} \mathrm{C}$. El catalizador fresco mostró un tamaño de partícula de 3,3 nm y el catalizador usado un tamaño de cristalito de 4,3 nm debido a la sinterización de las partículas de Rh. Sin embargo, la actividad no se vio afectada. Por el contrario, los catalizadores RhA y RhANd1 mostraron una ligera disminución en la selectividad cuando la temperatura aumentó a $750{ }^{\circ} \mathrm{C}$ (Fig. 17), se pudo formar una estructura de superficie diferente sobre las partículas de Rh con el sinterizado de las partículas y pudo ocurrir el depósito de especies de carbón deshidrogenados en los sitios activos, inhibiendo la deshidrogenación de $\mathrm{CH}_{4}$.

En el curso de la descomposición de metano sobre la superficie Rh se produce un depósito de los intermedios carbonosos. Se han detectado varios tipos de carbono formados en la superficie de los catalizadores de acuerdo con la temperatura de reacción: carbono carbídico, carbono amorfo, carbono grafítico [82]. El depósito de carbono sobre el rodio podría bloquear algunos sitios activos y desactivar el catalizador y luego modificar la selectividad. 
Tabla 10. Tamaño de cristalito de Rh para el catalizador de RhANd10, fresco y usado, en la descomposición del metano y el \% de carbón detectado por EDS

\begin{tabular}{lccc}
\hline Catalizador & ${ }^{1} \mathrm{~d}(\mathrm{~nm})$ & ${ }^{2} \mathrm{~d}_{1}(\mathrm{~nm})$ & $\begin{array}{c}\text { 3Carbón } \\
\text { amorfo }\end{array}$ \\
& Fresco & Usado & (\% peso) \\
\hline RhANd10 & $3.3 \pm 0.7$ & $4.3 \pm 1.2$ & $18.61 \pm 0.83$ \\
\hline
\end{tabular}

${ }^{1} \mathrm{~d}=$ Tamaño promedio del cristalito por MET

${ }^{2} \mathrm{~d}_{1}=$ Tamaño promedio del cristalito por MET para el catalizador después de reacción a diferentes temperaturas $\left(400-700^{\circ} \mathrm{C}\right)$.

${ }^{3}$ Carbón amorfo $=\%$ en peso de $\mathrm{C}$ depositado sobre la superficie del catalizador después de reacción, determinado por MET- EDERX, (SEM-EDS por sus siglas en inglés) .

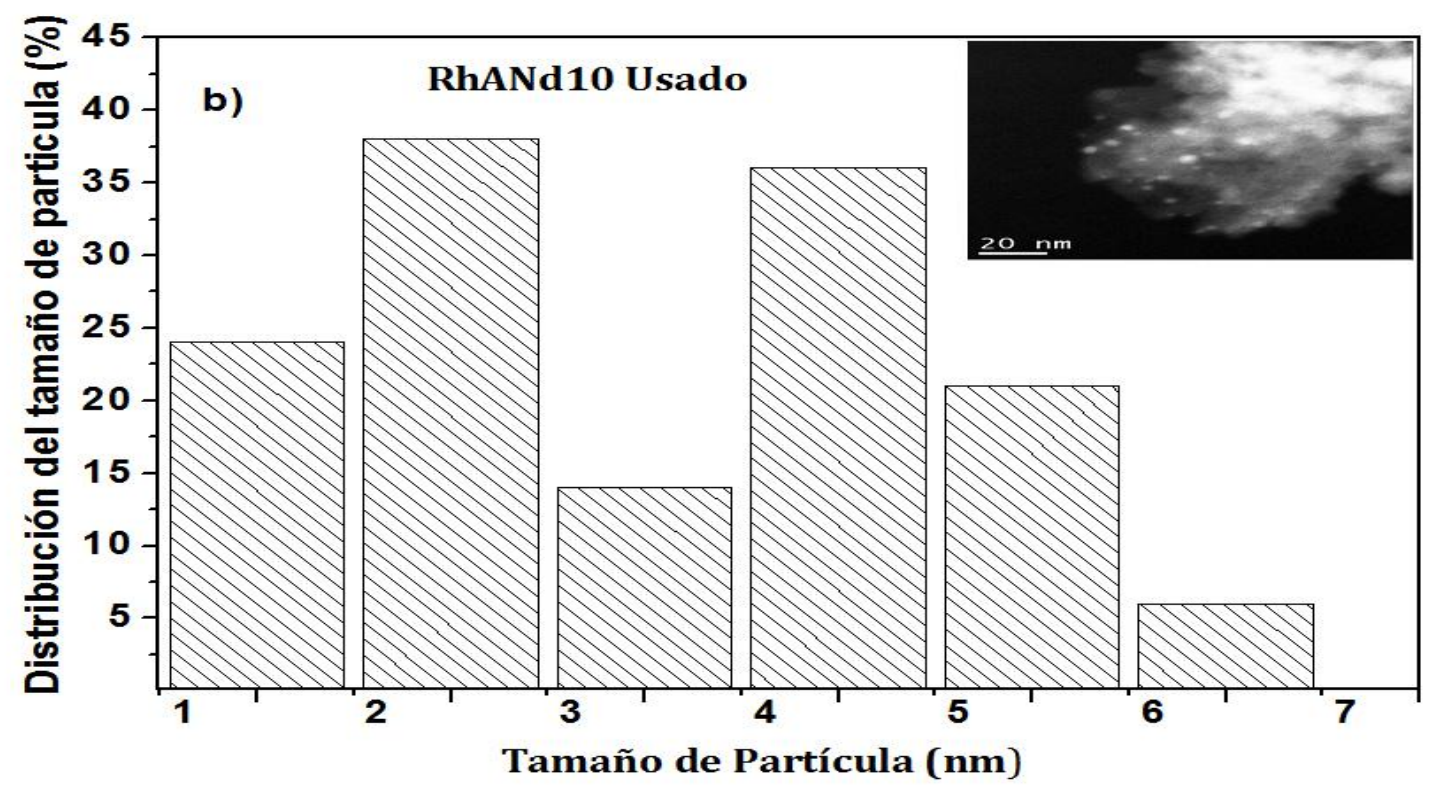

Figura 18. Histograma del catalizador RhANd10 después de reacción. 
El carbono depositado en los catalizadores usados RhA, RhANd1 y RhANd10 se estudió por difracción de rayos X. Los patrones de difracción para todos los catalizadores usados se muestran en la Fig. 19. Se observó un espectro de difracción similar para los catalizadores RhA-fresco y RhA-usado después de reacción respecto a la posición de los picos principales característicos de la $\gamma$-alúmina $\left(2 \theta=67,45,9\right.$ y $\left.37,6^{\circ}\right)$, pero mostrando menos intensidad en la muestra utilizada, lo que indica una pérdida de cristalinidad de la alúmina. Los picos en la región $2 \theta<40^{\circ}$ muestran una señal amplia causada por la presencia de carbono sobre el catalizador. También se percibe un pico, en el catalizador RhA-usado a $2 \theta=40.069^{\circ}$ que corresponde al Rh (111), la detección de este pico se debe a la sinterización del metal Rh después de la reacción, ya que no era detectado en el catalizador fresco.

Se ha observado un patrón de difracción similar para los dos catalizadores usados que contienen Nd, RhANd1 y RhANd10 (Figura 19). Se observa claramente sólo un pico típico de la $\gamma-\mathrm{Al}_{2} \mathrm{O}_{3}$, colocado a $2 \theta=67^{\circ}$, cuya intensidad es menor debido a la pérdida de cristalinidad de ambas muestras. El patrón de difracción muestra dos picos anchos y superiores causados por la presencia del carbono formado y depositado sobre el catalizador, que se caracterizó como carbono amorfo. Las imágenes muy similares mostradas por los dos catalizadores de $\mathrm{Rh}$ promovidos por neodimio indican que la presencia de neodimio podría ser el responsable de este comportamiento actuando como una trampa del carbono. 


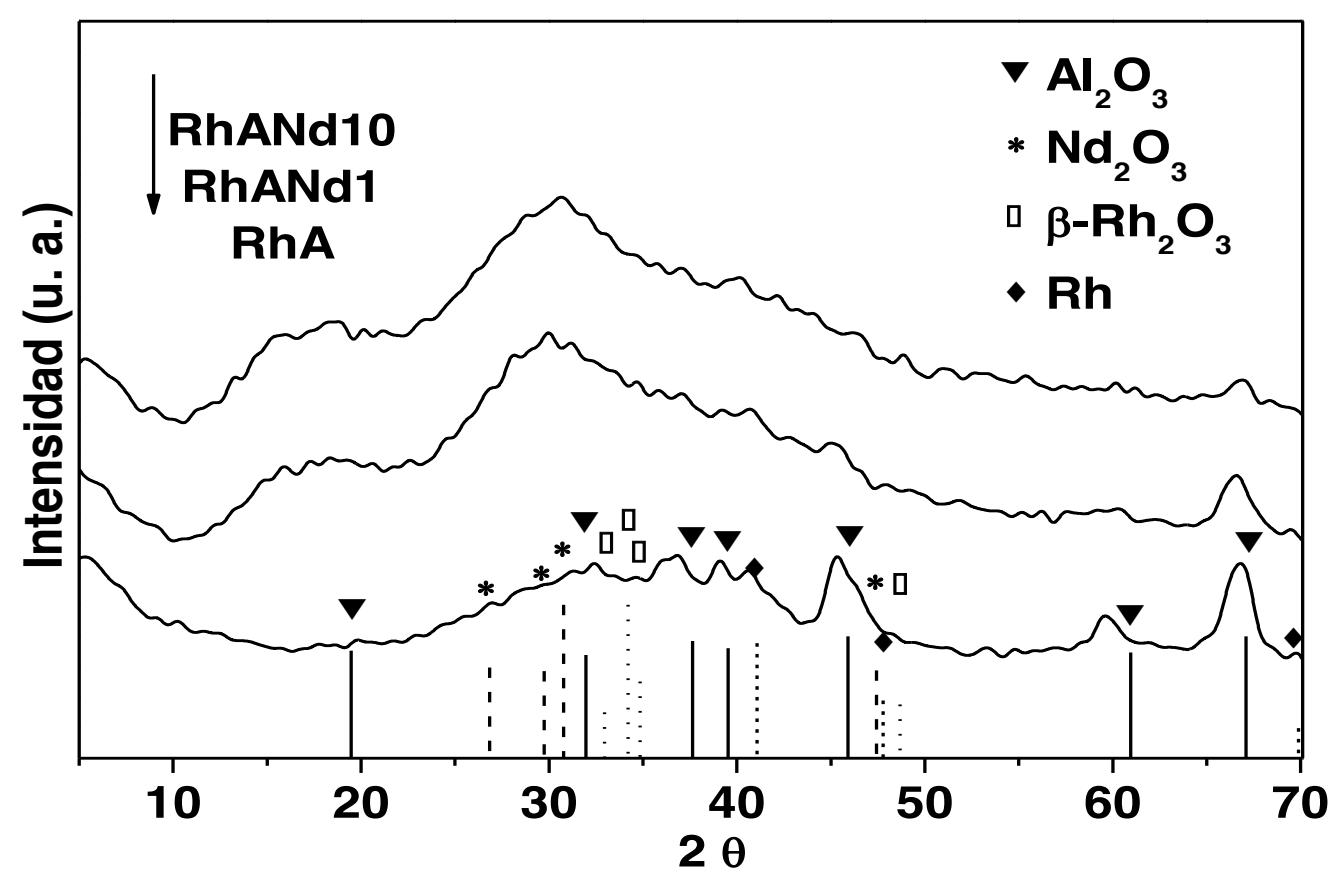

Figura 19. Patrones de difracción de rayos X para todos los catalizadores de Rh usados.

En la Fig. 20 se muestra el análisis MEB-EDERX (SEM-EDS por sus siglas en inglés) del catalizador RhANd10-usado para el mapeo y la exploración de la composición. Los mapas de rayos $\mathrm{X}$ describen los elementos presentes en la muestra como $\mathrm{Al}, \mathrm{O}, \mathrm{Nd}, \mathrm{Rh}$ y $\mathrm{C}$. que corresponden a $\mathrm{Al}_{2} \mathrm{O}_{3}, \mathrm{Nd}_{2} \mathrm{O}_{3}$, $\mathrm{Rh}$ y C., muestra el \% en peso de cada elemento presente en la muestra del catalizador. Como puede observarse en la cartografía de cada elemento, los perfiles de $\mathrm{Al}, \mathrm{O}$ y $\mathrm{C}$ presentan un perfil muy similar indicando que el carbono presente en el catalizador se coloca principalmente sobre la superficie del soporte de alúmina. En la tabla se indica la cantidad de carbono sobre el catalizador determinada por MEB-EDERX para el catalizador RhANd10-usado que es aproximadamente $18,6 \%$ en peso. 


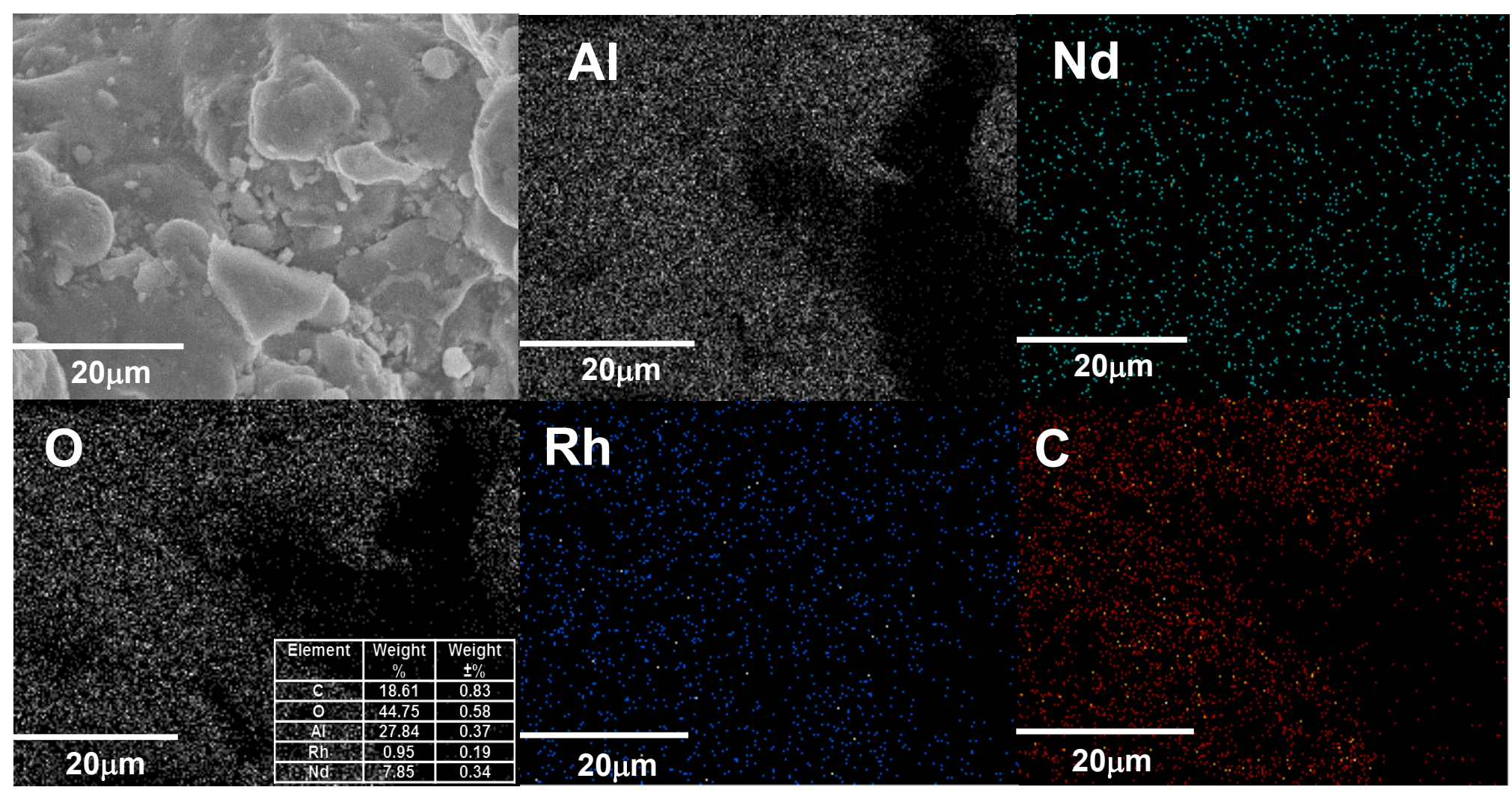

Figura 20. Análisis de mapeo de puntos MEB-EDERX (SEM_EDS) para el catalizador RhANd10-usado.

El estudio de METAR (HRTEM por sus siglas en inglés) se realizó con el objetivo de identificar las fases en los catalizadores y analizar el tipo de carbono formado en la superficie de la muestra seleccionada de RhANd10-usado, durante la reacción. La figura 21 muestra una imagen de alta resolución de una región de la muestra RhANd10 usada con sus respectivas transformadas de Fourier (TF) de las zonas analizadas a), b), c) y d). La asignación de las distancias interplanares fue realizada con las respectivas tarjetas de difracción (JCPDS) para cada una de las fases encontradas. Las distancias interplanares con 1.337, 1.398 y $1.977 \AA$ A corresponden a la $\gamma$-alúmina y la de $2.225 \AA$ al plano $\mathrm{Nd}_{2} \mathrm{O}_{3}(0,1,2)$. Las distancias interplanares $2.673,2.299,1.309,3.671$ y $1.835 \AA ̊$ corresponden al $\beta-\mathrm{Rh}_{2} \mathrm{O}_{3} \mathrm{y}$ la de $2.196 \AA$ Å correspondiente a los planos $(1,1,1)$ del Rh metálico, se detectó el mismo tipo de plano para Rh en la muestra usada de RhANd10 por DRX. Finalmente, las distancias interplanares de $2.547,1.86,2.052$ y $2.128 \AA ̊ ̊$ corresponden al carbono amorfo. 


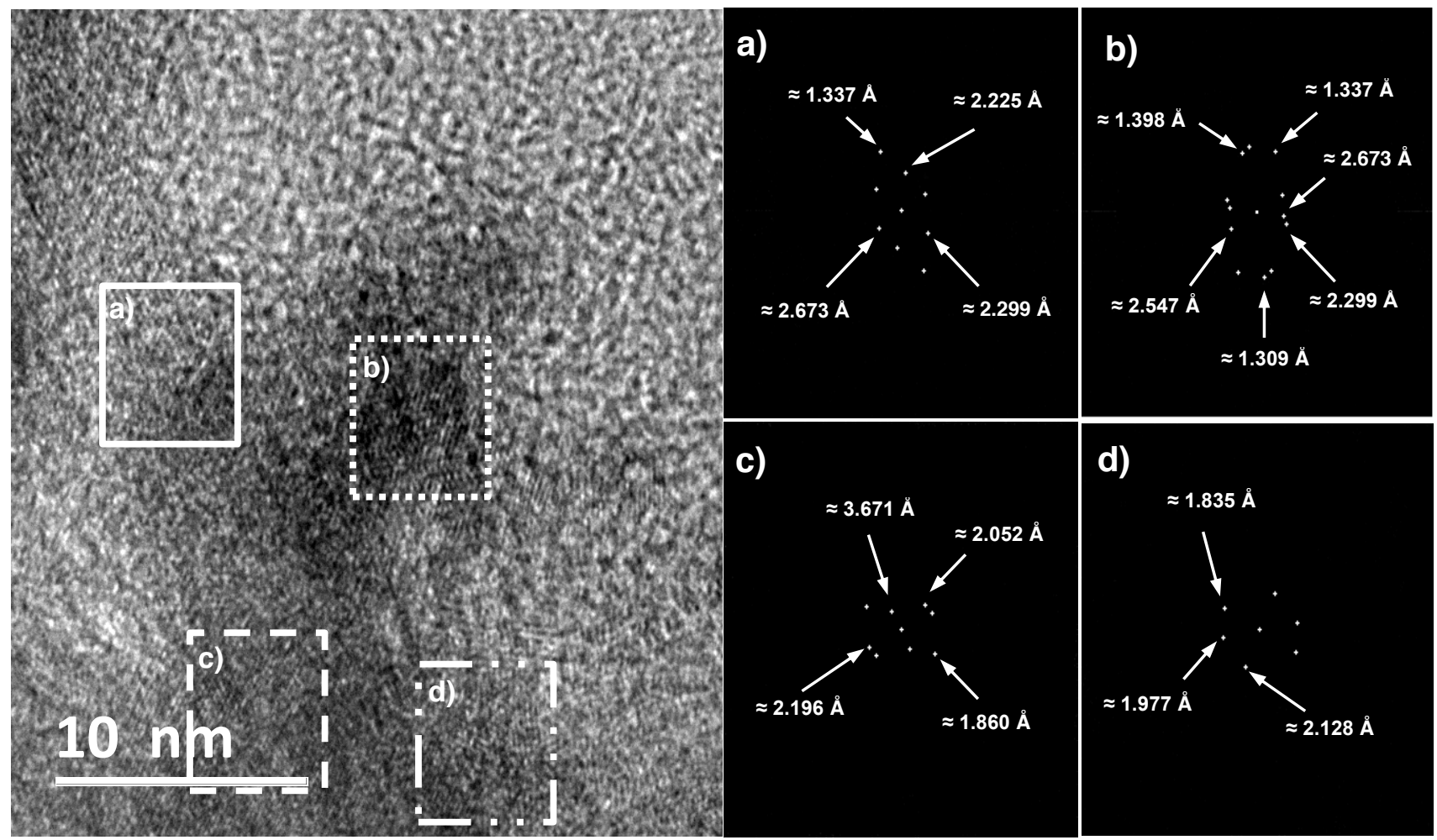

Figura 21. Imágenes METAR del catalizador RhANd10 después de reacción, a), b), c) y d) corresponden a TF de las áreas escaneadas.

Como se observó por las caracterizaciones DRX, METAR y MEB-EDEREX todo el carbono producido alrededor de $700{ }^{\circ} \mathrm{C}$ es carbono amorfo. De acuerdo con los resultados de mapeo MEB-EDERX y DRX se puede suponer que el carbono se deposita en el soporte en gran proporción. La DRX presenta una alta modificación del patrón de difracción en los catalizadores usados de Rh que contienen Nd y en la cartografía MEB se observa que el carbono sigue los mismos perfiles que la alúmina y el oxígeno, sobre el mismo catalizador RhANd10 usado, con el depósito de carbono después reacción. Estos resultados son más notables en los catalizadores que contienen neodimio en una proporción adecuada que favorece una alta selectividad a la producción de hidrógeno, estabilizan también la producción de hidrógeno a alta temperatura e impiden la desactivación a pesar de la presencia de carbono formado durante la reacción. El óxido de neodimio depositado sobre el soporte de alúmina-Nd en los catalizadores Rh podría actuar como una trampa para el carbono. 
Con el fin de obtener más información sobre la formación de coque en los catalizadores, las muestras usadas de los diferentes catalizadores ensayados se sometieron a oxidación programada por temperatura (TPO, por sus siglas en inglés). La figura 22 muestra los resultados de los experimentos. Se pueden observar tres picos principales, el primero a menos de $200{ }^{\circ} \mathrm{C}$, el segundo alrededor de los $500^{\circ} \mathrm{C}$ y el último a temperaturas mayores de $800{ }^{\circ} \mathrm{C}$.

Dichos picos podrían atribuirse a la formación de especies de carbono poliméricas que podrían resultar de la adsorción de metano en los soportes y la posterior evolución de los carburos superficiales $(\mathrm{C} \alpha)$ a especies de carbono de superficie menos reactivas durante el tiempo de reacción en flujo, de acuerdo con las observaciones realizadas por Verykios [37]. Los diferentes picos corresponderían así a especies de carbono polimérico superficial con diferente grado de hidrogenación, siendo de naturaleza más grafítica con temperaturas crecientes en la OTP.

La temperatura para el desprendimiento de $\mathrm{CO}_{2}$ sobre el catalizador $\mathrm{RhANd} 10$ es mucho menor que la de los catalizadores RhANd1 y RhA. Esto sugiere que las especies de carbono depositadas sobre el catalizador RhANd10 son más activas que las de los catalizadores RhANd1 y RhA.

La cantidad total de $\mathrm{CO}_{2}$ se usó para calcular la cantidad relativa de coque depositado sobre los catalizadores después de la reacción (Tabla 11). 


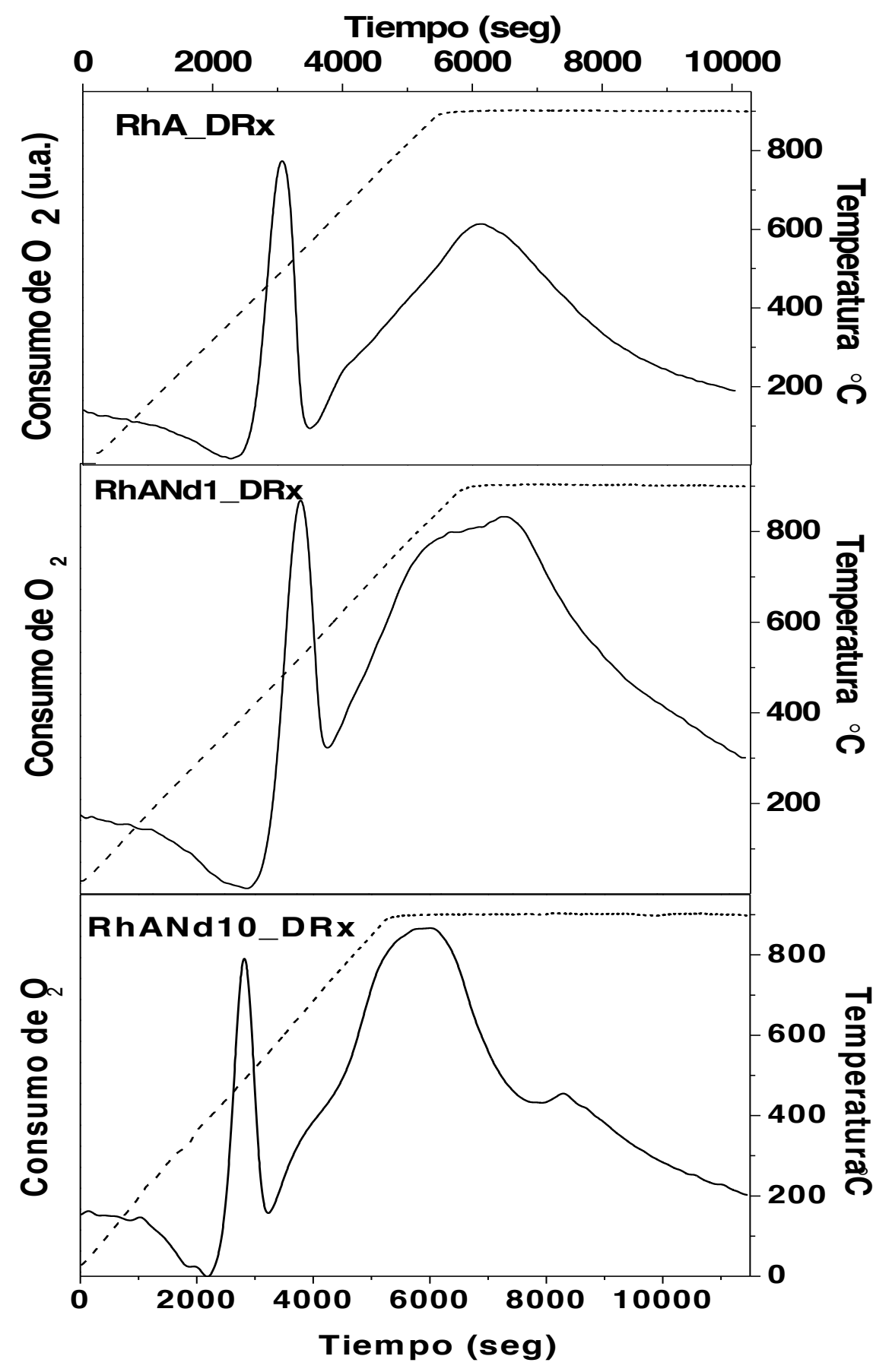

Figura 22. Perfiles de OTP de los catalizadores RhA, RhANd1 y RhANd10 después de reacción. 
Tabla 11. Cantidad total de carbón en los catalizadores RhA, RhANd1 y RhANd10 después de reacción.

\begin{tabular}{cc}
\hline Catalizador & $\begin{array}{c}\text { Carbono } \\
\text { (masacarbono/masa }\end{array}$ cat, \%) \\
\hline RhA & 8.75 \\
RhANd1 & 9.99 \\
RhANd10 & 10.92 \\
\hline
\end{tabular}

\section{Cinética de la reacción, pseudo-orden de reacción y energías activación}

También se llevó a cabo un estudio cinético de la reacción de descomposición del metano en el intervalo de temperatura de $400-750^{\circ} \mathrm{C}$ a presión atmosférica. Se utilizó un reactor de cuarzo de lecho fijo para investigar la cinética y evaluar los parámetros del modelo. La velocidad de descomposición del metano dependió fuertemente de la temperatura, el flujo de metano y la masa del catalizador.

$\mathrm{Al}$ aumentar el caudal en el lecho fijo, la eficiencia de contacto entre el metano y las partículas de catalizador disminuyó, y por lo tanto la conversión de metano disminuyó.

Asumiendo un flujo tapón para la fase gaseosa que fluye a través del lecho del catalizador, la integración de la ecuación diferencial del balance de masa conducida sobre el catalizador produjo la siguiente ecuación:

$$
\begin{aligned}
& \frac{W_{c a t}}{F_{C H 40}}=\int_{0}^{X_{C H 4}} \frac{d x_{C H 4}}{r_{C H 4}} \ldots \text { (7) } \\
& \text { Substituyendo } r_{C H 4}=K_{n} * C_{C H 4}^{n} \text { y } F_{C H 40}=v_{0} * C_{C H 40} \\
& \frac{W_{c a t}}{v_{0} * C_{C H 40}}=\int_{0}^{X_{C H 4}} \frac{d X_{C H 4}}{K_{n} * C_{C H 4}^{n}} \ldots \text { (8) }
\end{aligned}
$$


Y para la reacción de expansión en fase gaseosa, la relación entre $C_{C H 4}$ y la concentración inicial de metano $C_{C H 40}$ se define como:

$C_{C H 4}=C_{C H 40} \frac{1-X_{C H 4}}{1+\varepsilon X_{C H 4}}$

El resultado de la ecuación es como sigue:

$\frac{W_{c a t}}{v_{0}}=\frac{C_{C H 4}^{1-n}}{K_{n}} \int_{0}^{X_{C H 4}}\left\{\frac{\left[1+X_{C H 4}\right]}{\left[1-X_{C H 4}\right]}\right\}^{n} d X_{C H 4}$

donde $v_{0}$ es el flujo de metano en $\mathrm{L} / \mathrm{min}$, n es el orden de la reacción de la descomposición del metano y $\mathrm{K}_{\mathrm{n}}$ es la constante cinética $\left(\mathrm{L}\left(\mathrm{g}_{\mathrm{cat}} \mathrm{min}^{-1}\left(\mathrm{~mol} \mathrm{~L}^{-1}\right)^{1-\mathrm{n}}\right.\right.$ y $\varepsilon$ es el factor de expansión igual a 1 de acuerdo a la ecuación (6).

La ecuación (10) fue usada para determinar el pseudo orden de reacción n y la constante cinética kn graficando (Wcat/vo) contra el valor de la integral mostrada en el lado derecho de la ecuación (10), esto se llevó a cabo con los datos experimentales presentados en la Tabla 12 para experimentos con variación de la masa del catalizador (fig. 23 a-c) y para experimentos con variación en el flujo de alimentación de metano (fig. 23 d-f). Para ello se intentaron varios valores de $n(n=0,0,5,1,1,5$ y 2$)$ y se obtuvieron los mejores ajustes con $n=1.5$ (coeficiente de correlación entre $0,99>0,91$ ) para experimentos con variación de masa de catalizador y (coeficiente de correlación $>0,99$ y > 0,98) para experimentos con variación en el flujo de alimentación de metano. El valor de $\mathrm{k}$ se calculó a partir de la pendiente 64 - 95 (L/ gcat min) (tabla 13). 
Table 12. Datos experimentales usados para determinar el pseudo-orden de reacción.

\begin{tabular}{ccccc}
\hline & $\begin{array}{c}\text { Experimentos con variación de la } \\
\text { masa del catalizador }\end{array}$ & $\begin{array}{c}\text { Experimentos con variación en } \\
\text { el flujo de alimentación de } \\
\text { metano }\end{array}$ \\
\hline $\begin{array}{c}\text { Temperatura } \\
\left({ }^{\circ} \mathrm{C}\right)\end{array}$ & $\begin{array}{c}\text { Masa del } \\
\text { Catalizador } \\
(\mathrm{mg})\end{array}$ & $\begin{array}{c}\text { Flujo de } \\
\text { alimentación de } \\
\text { metano } \\
(\mathrm{mL} / \mathrm{min})\end{array}$ & $\begin{array}{c}\text { Masa del } \\
\text { Catalizador } \\
(\mathrm{mg})\end{array}$ & $\begin{array}{c}\text { Flujo de } \\
\text { alimentación } \\
\text { de metano } \\
(\mathrm{mL} / \mathrm{min})\end{array}$ \\
\hline 700 & 25 & 2 & 50 & 2 \\
700 & 50 & 2 & 50 & 4 \\
700 & 75 & 2 & 50 & 6 \\
700 & 100 & 2 & 50 & 8 \\
\hline
\end{tabular}

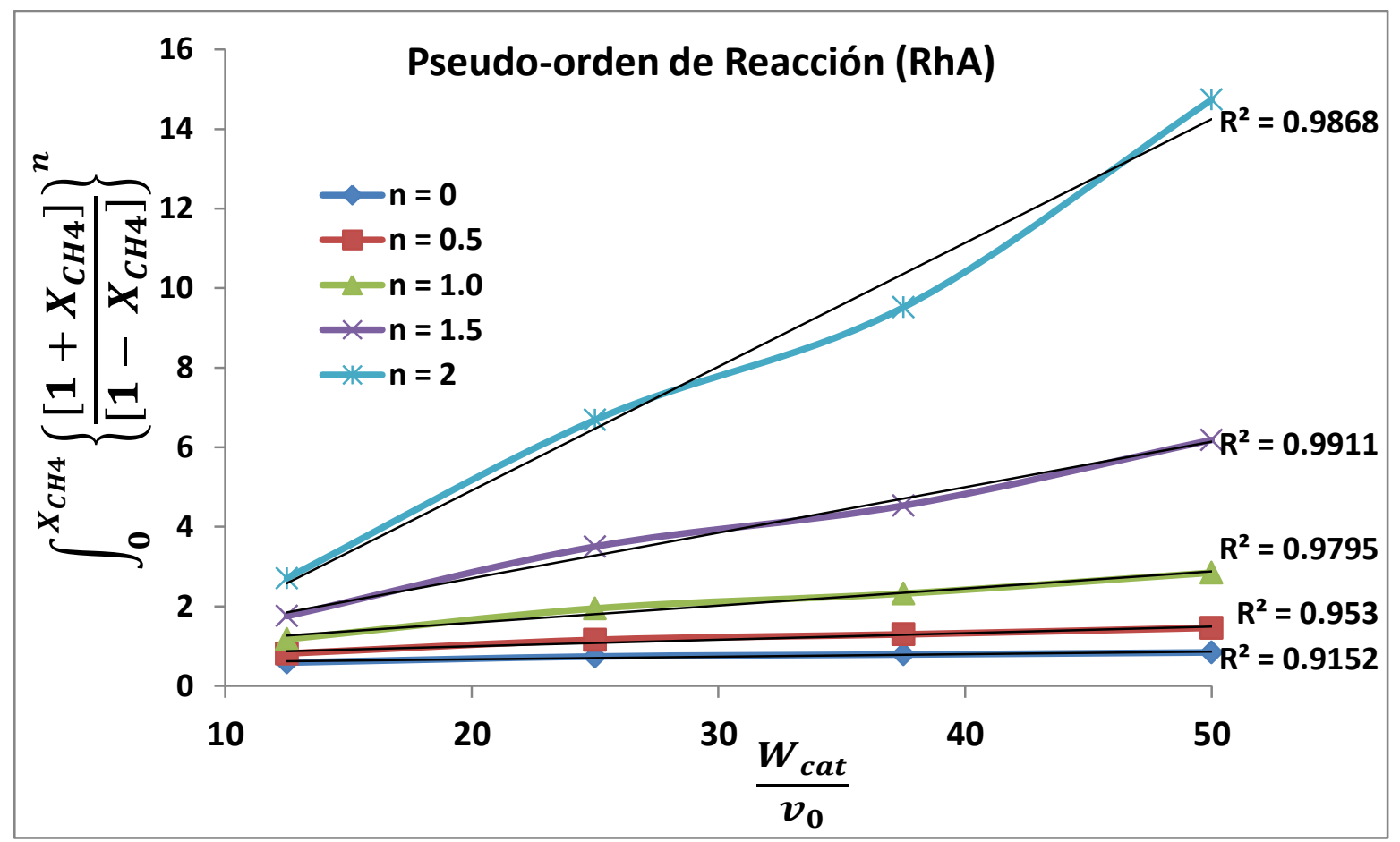

Figuras 23a. Pseudo orden de reacción a T y vo constantes y masa del catalizador variable para RhA. 


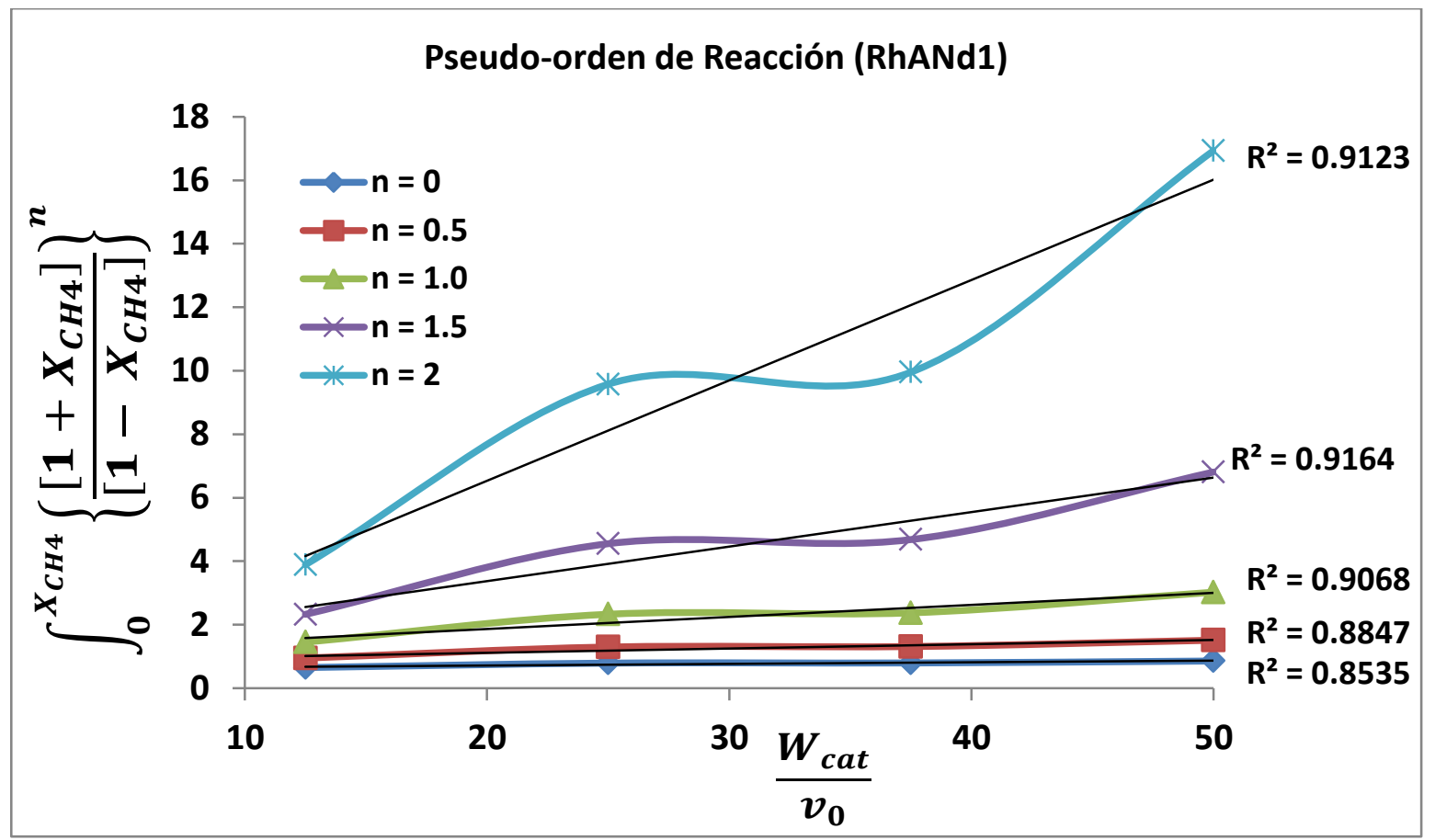

Figuras 23 b. Pseudo orden de reacción a T y vo constantes y masa del catalizador variable para RhANd1.

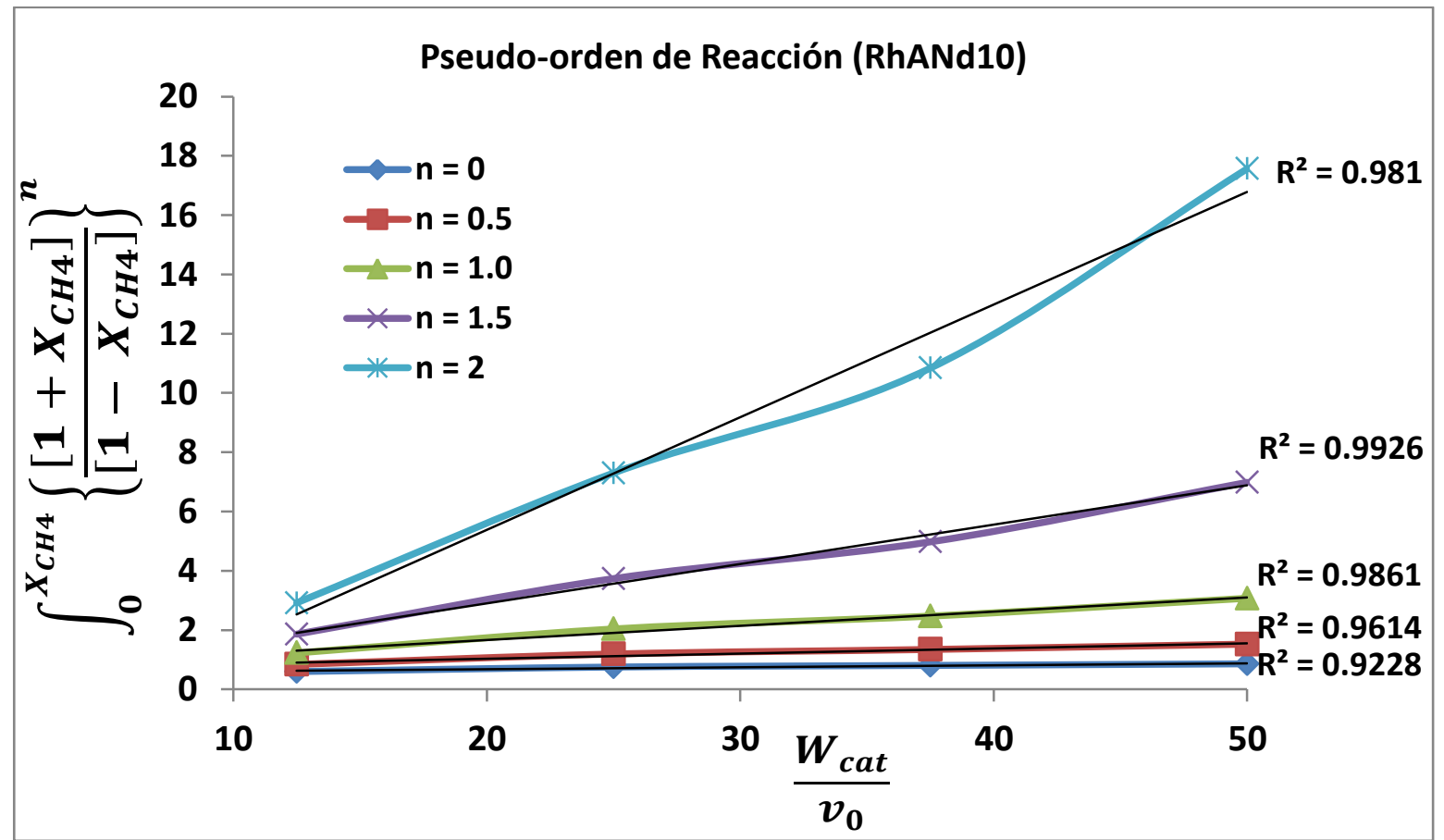

Figuras 23c. Pseudo orden de reacción a T y uo constantes y masa del catalizador variable para RhANd10. 


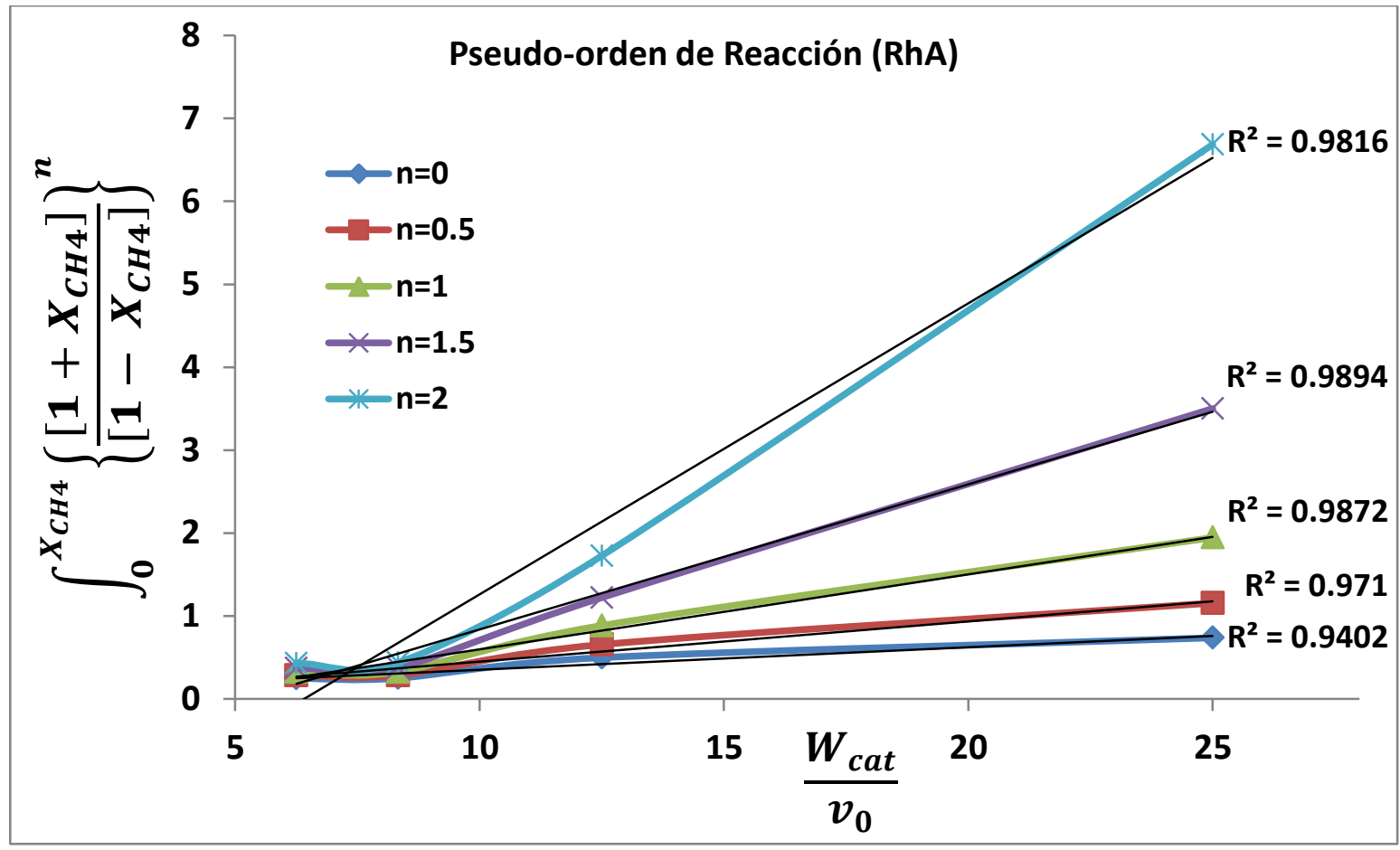

Figuras 23d. Pseudo orden de reacción a T y masa del catalizador constantes y vo variable para RhA.

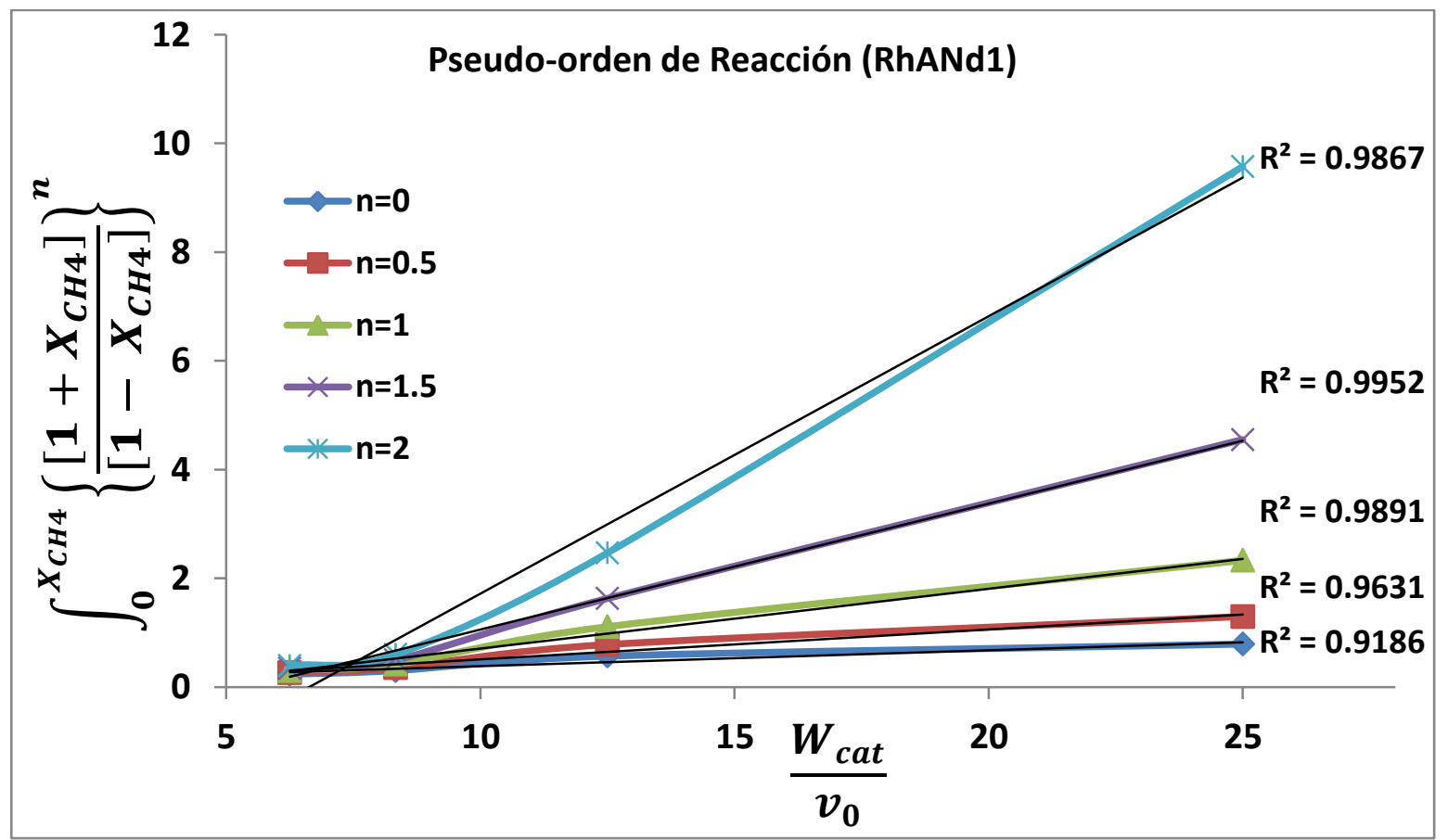

Figuras 23e. Pseudo orden de reacción a T y masa del catalizador constantes y vo variable para RhANd1. 


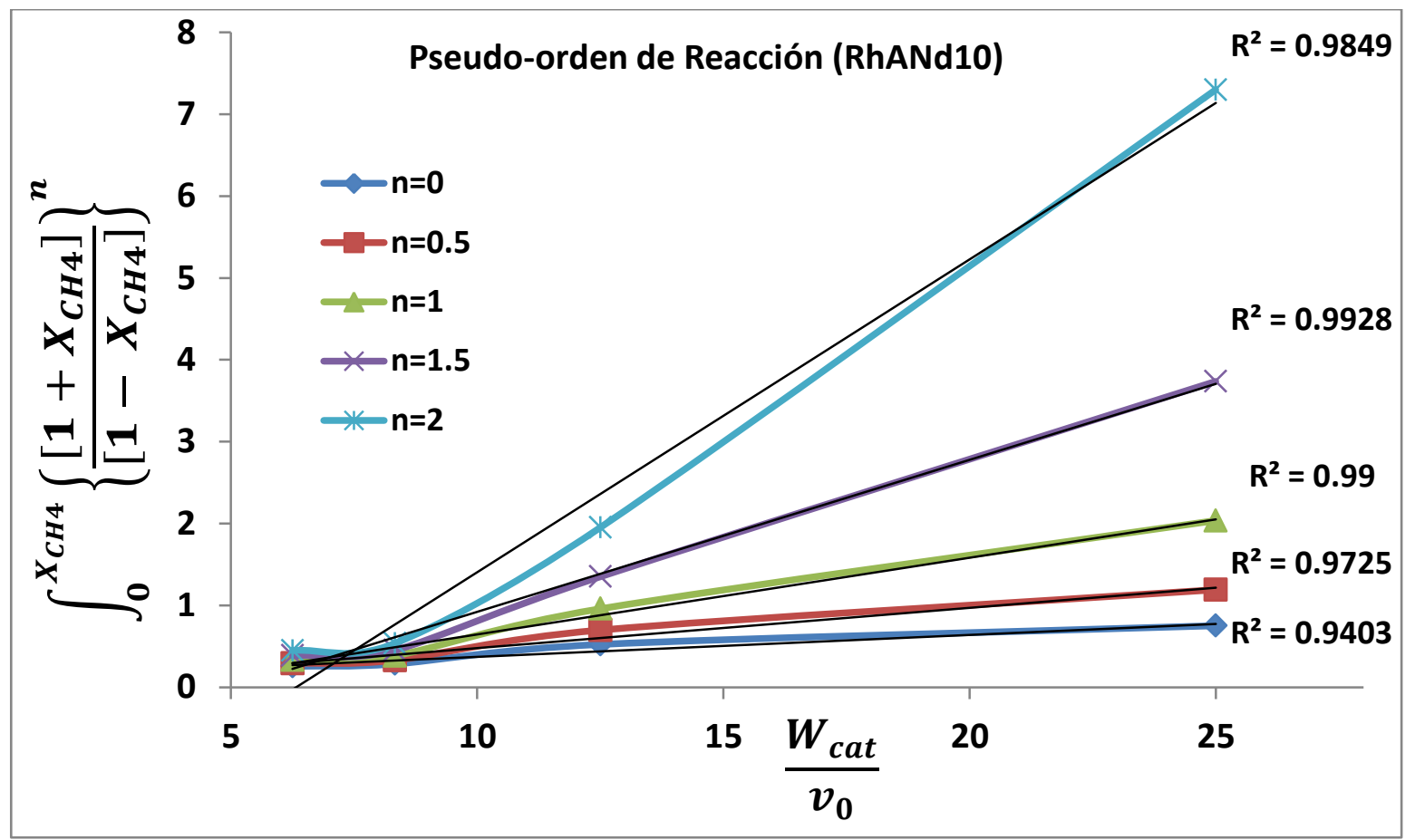

Figuras 23f. Pseudo orden de reacción a T y masa del catalizador constantes y vo variable para RhANd10.

Con el fin de encontrar k a temperaturas de 400, 500, 600, 700 y $750{ }^{\circ} \mathrm{C}$, se encontró el valor de la integral de la ecuación (10) según los datos de cada experimento y luego se calculó el valor de $\mathrm{k}$.

La energía de activación fue calculada usando un gráfico de Arrhenius de ln k contra 1/T y la pendiente de el gráfico lineal es (-Ea/R) (fig. 24). La energía de activación, el valor del factor preexponencial y la ecuación de Arrhenius aparecen en la tabla (13): 


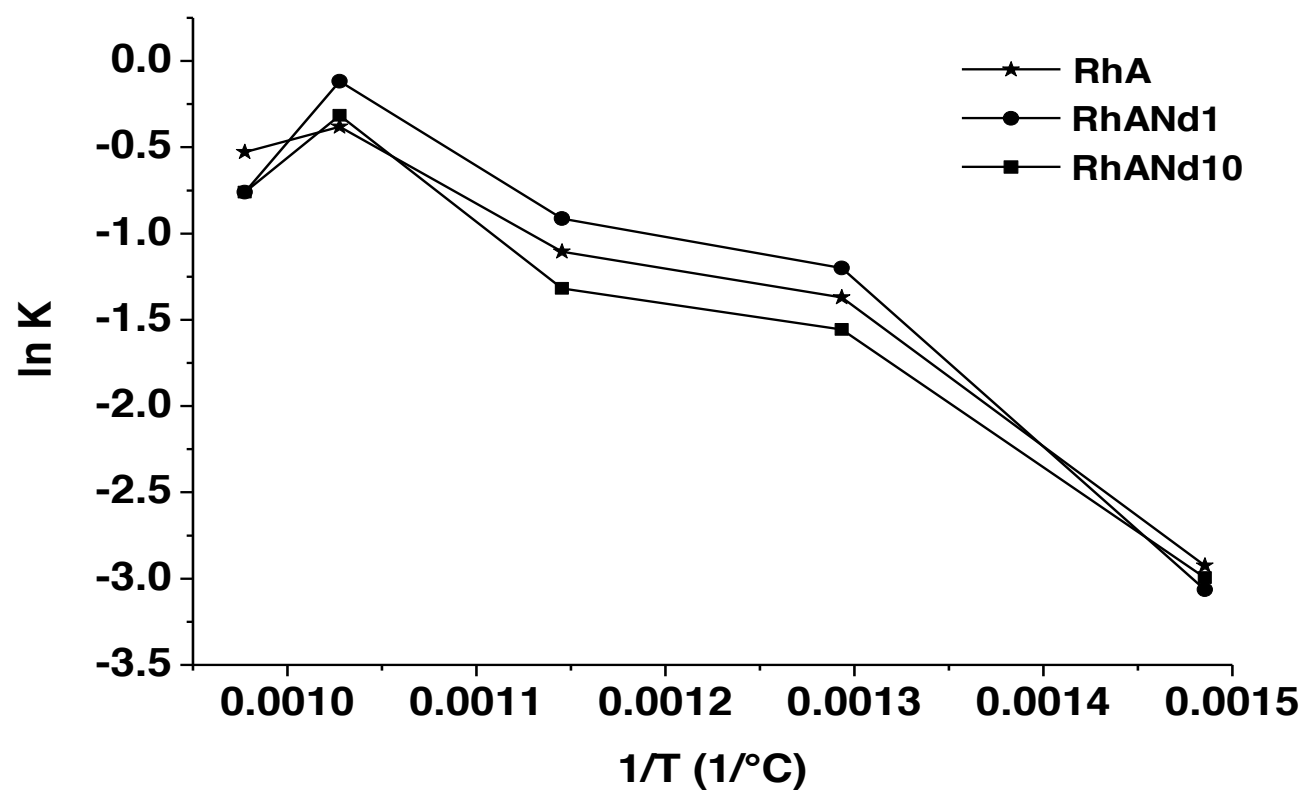

Figura 24. Gráfico de Arrhenius ln k vs. (1/T).

Tabla 13. Energía de activación, Valor del factor preexponencial y Ecuación de Arrhenius

\begin{tabular}{cccc}
\hline Catalizador & $\begin{array}{c}\text { Energía de } \\
\text { activación } \\
\text { KJ/mol }\end{array}$ & $\begin{array}{c}\text { Valor del factor } \\
\text { preexponencial (L/gcat } \\
\text { min) }\end{array}$ & Ecuación de Arrhenius \\
\hline RhA & 39.2 & 76.142 & $\mathrm{k}=76.14199863 \mathrm{e}^{\left(\frac{-4717.7}{\mathrm{~T}}\right)}$ \\
RhANd1 & 40.38 & 94.66 & $\mathrm{k}=94.6608 \mathrm{e}^{\left(\frac{-4858.9}{\mathrm{~T}}\right)}$ \\
RhANd10 & 38.9 & 64.16 & $\mathrm{k}=64.161285 \mathrm{e}^{\left(\frac{-4680.4}{\mathrm{~T}}\right)}$ \\
\hline
\end{tabular}




\section{A P Í T U L O 4}

\section{CATALIZADORES DE PLATINO RESULTADOS Y DISCUSIÓN}


Los diagramas de DRX de los catalizadores de Pt después de la reducción a $500{ }^{\circ} \mathrm{C}$ durante $5 \mathrm{~h}$, se muestran en la Fig. 25. Los difractogramas muestran los picos característicos de la fase $\gamma$-alúmina (JCPDS PDF 056-0457 Calidad: Rietveld). Las líneas asociadas con óxido de $\mathrm{Pt}$ no se observaron en estas muestras, $\mathrm{PtO}_{2}$ (JCPDS 84-1439), ninguna señal correspondiente a los cristales de Pt fueron detectados en ninguno de los catalizadores estudiados (JCPDS 04-0802), lo que indica que las partículas de metal eran pequeñas y probablemente debido a la baja concentración, que no pudo ser detectada por el equipo.

No se detectaron picos para $\mathrm{Nd}_{2} \mathrm{O}_{3}$ ( 1 y $10 \%$ en peso), la tarjeta que se consultó para los catalizadores con los diferentes contenidos fue (JCPDS PDF 01-079-9858 Calidad: Start (*)). El patrón de difracción del catalizador PtANd1 no muestra diferencia notable con respecto al difractograma para el catalizador PtA. Sin embargo, en el catalizador PtANd10 se produce una modificación del patrón de difracción, se observa una menor intensidad de los picos de alúmina, lo que indica una baja cristalinidad del sólido (Tabla 14). La presencia de neodimio al $10 \%$ en peso inhibe el crecimiento de los cristales de la alúmina [83]. En la Fig. 25 se traza un recuadro donde se observan los picos de la alúmina que tienen máximos en torno a $67^{\circ}$ en $2 \theta$. El aumento en el ancho se relaciona con la reducción del tamaño del cristalito a medida que aumenta la concentración de $\mathrm{Nd}_{2} \mathrm{O}_{3}$.

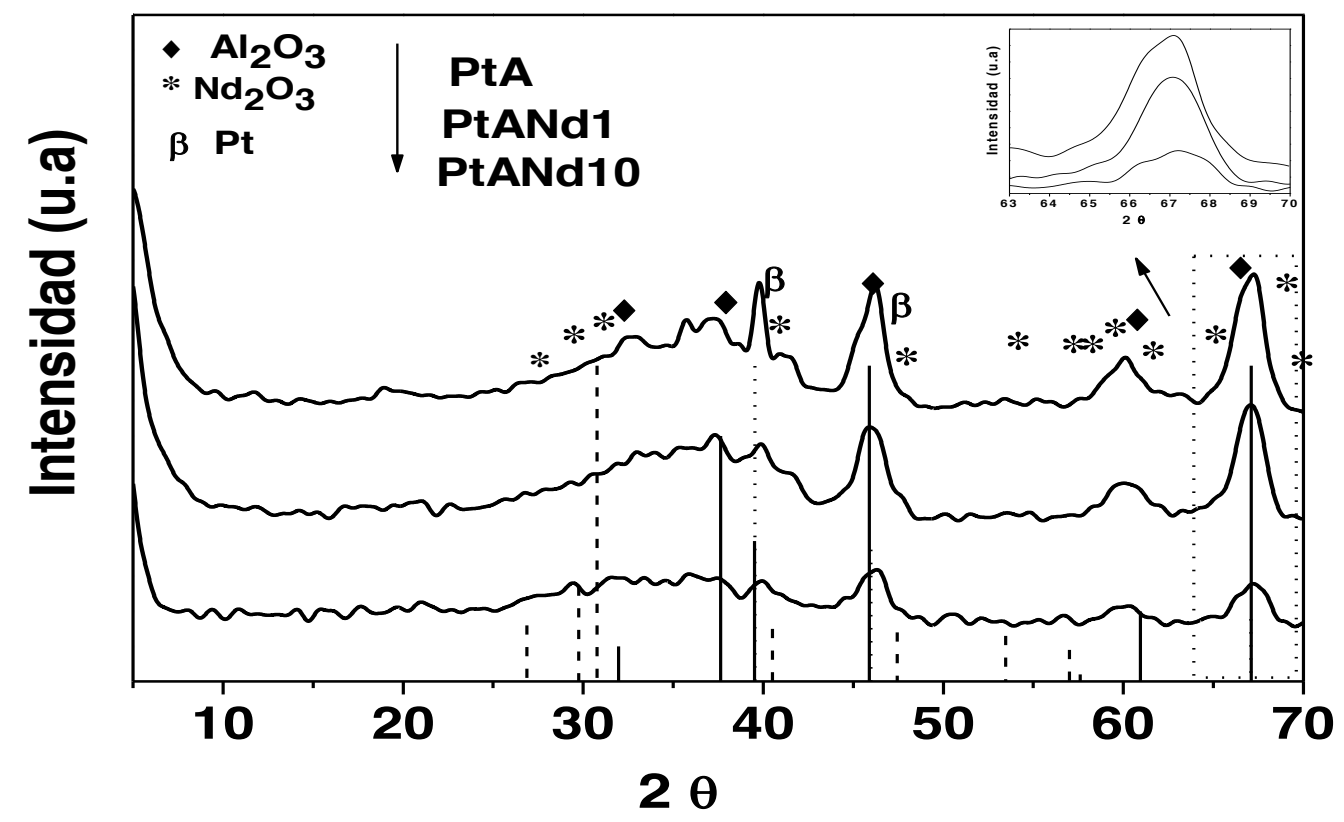

Figura 25. Patrones de difracción de rayos X para todos los catalizadores de Pt. 
Tabla 14. Tamaño de Cristalito de $\mathrm{\gamma}-\mathrm{Al}_{2} \mathrm{O}_{3}$ en los catalizadores de platino.

\begin{tabular}{c|c|c}
\hline Catalizadores & FWHM $2 \theta=67^{\circ}$ & Tamaño de Cristalito $(\AA)$ de $\gamma-\mathrm{Al}_{2} \mathrm{O}_{3}$ \\
\hline PtA & 2.15 & 97.5 \\
PtANd1 & 2.2 & 95 \\
PtANd10 & 2.4 & 86 \\
\hline
\end{tabular}

Las superficies especificas BET de los catalizadores frescos se indican en la Tabla 15. Las áreas superficiales fueron similares para todos los catalizadores, PtA $250 \mathrm{~m}^{2} \mathrm{~g}^{-1}$, PtANd1 $253 \mathrm{~m}^{2} \mathrm{~g}^{-1}$ y PtANd10 $249 \mathrm{~m}^{2} \mathrm{~g}^{-1}$ que son ligeramente menores respecto a la observada al área superficial del soporte de alúmina (A) que fue de $266 \mathrm{~m}^{2} \mathrm{~g}^{-1}$.

El volumen de poro y el diámetro de poro permanecieron constantes en el catalizador de PtA con respecto a la referencia $\gamma$-alúmina y disminuyeron con la cantidad creciente de $\mathrm{Nd}_{2} \mathrm{O}_{3}$ en el catalizador (figuras 26 y 27). Este comportamiento se debe al depósito de $\mathrm{Nd}_{2} \mathrm{O}_{3}$ en la boca de los poros de la alúmina, produciendo un poro pequeño aparente pero con la disminución esperada en el área superficial.

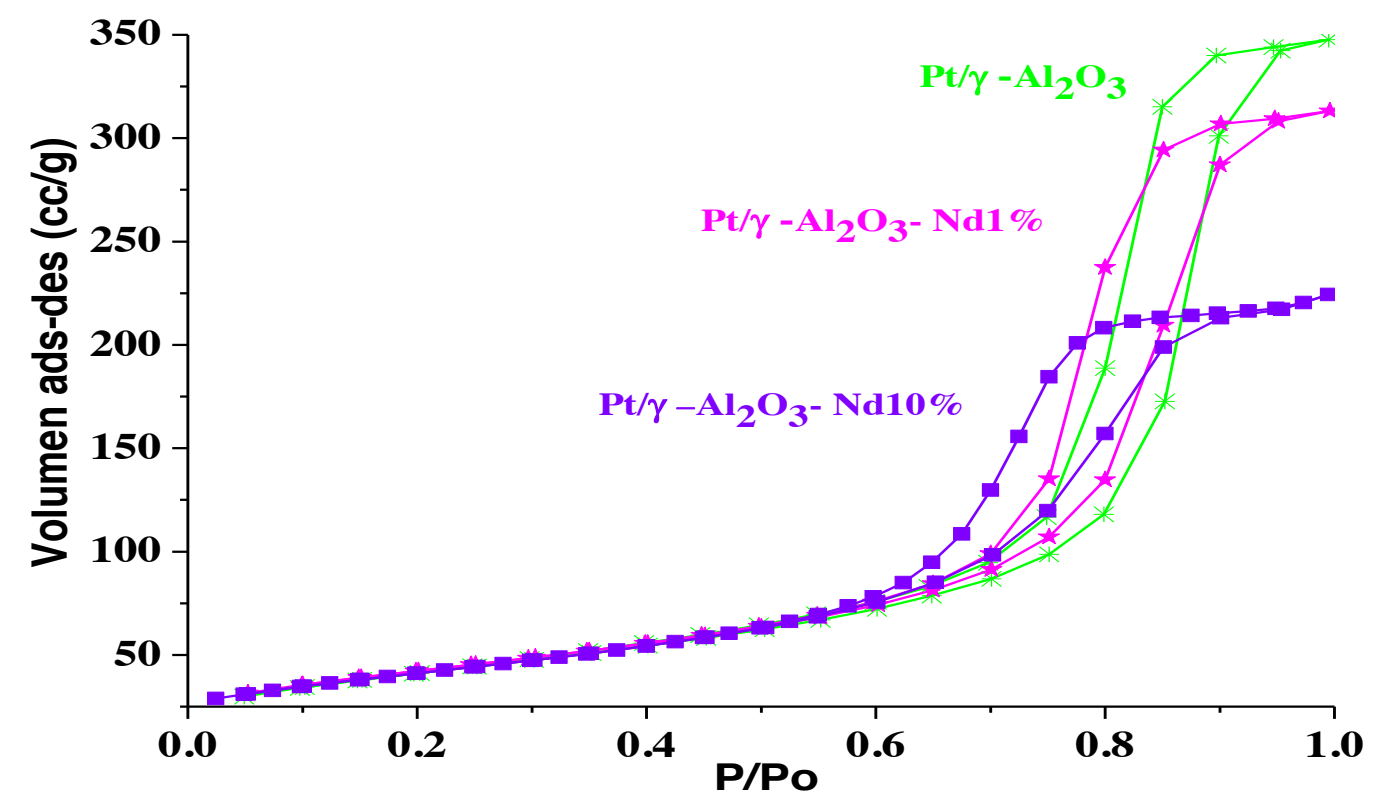

Figura. 26. Isotermas de adsorción-desorción de los catalizadores PtA y PtANdX 


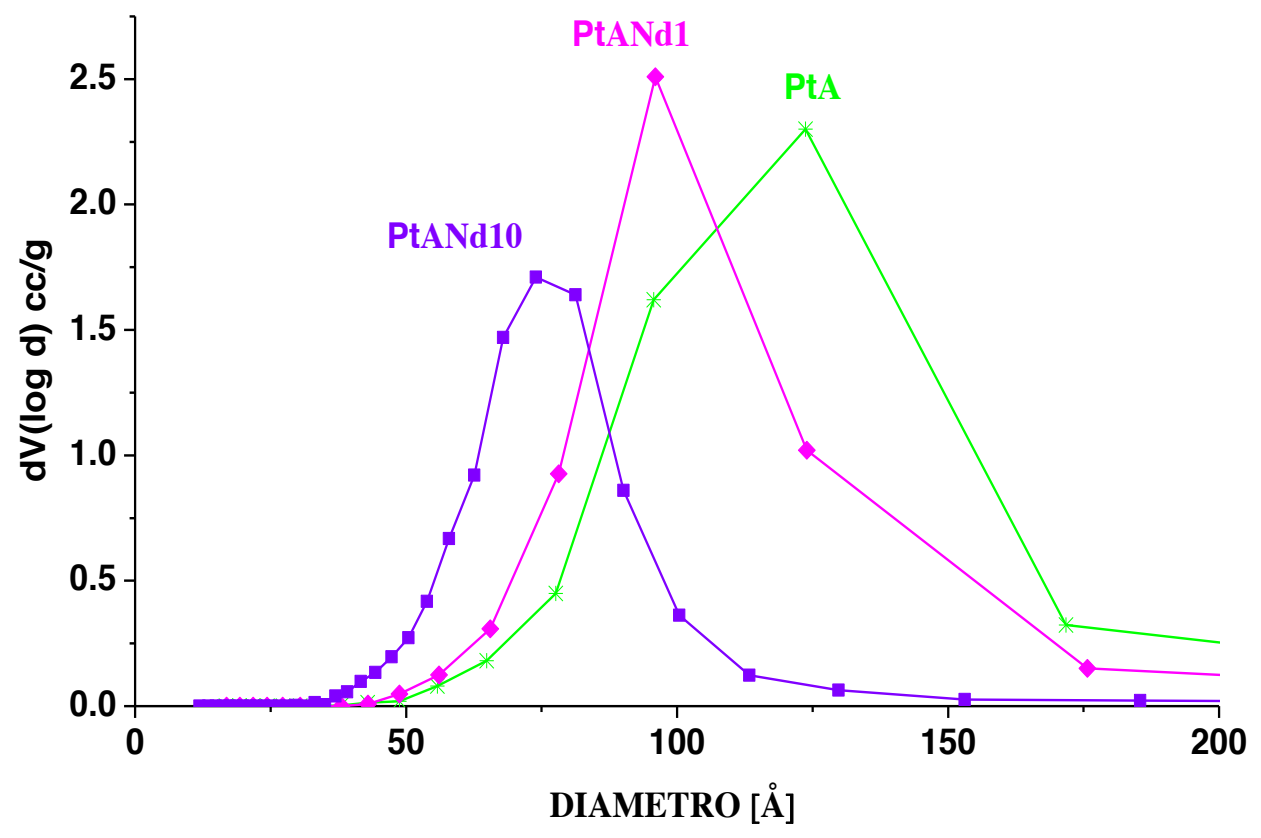

Figura. 27. Distribución del tamaño de poro de los catalizadores PtA y PtANdX

Tabla 15. Áreas BET, volumen y diámetro de poro de los catalizadores.

\begin{tabular}{cccc}
\hline Catalizador & $\begin{array}{c}\text { Áreas } \\
\text { BET m }^{2} / \mathrm{g}\end{array}$ & $\begin{array}{c}\text { Volumen de poro } \\
(\mathrm{cc} / \mathrm{g})\end{array}$ & $\begin{array}{c}\text { Diámetro de poro } \\
(\mathrm{nm})\end{array}$ \\
\hline PtA & 250 & 0.54 & 12.3 \\
PtANd1 & 253 & 0.48 & 9.6 \\
PtANd10 & 249 & 0.35 & 7.4 \\
\hline
\end{tabular}

El perfil RTP de los catalizadores PtA, PtANd1 y PtNd10 (figura 28) mostró al menos tres picos, el primero a 156,157 y $155^{\circ} \mathrm{C}$ respectivamente, correspondiente a la reducción de especies de $\mathrm{PtO}_{2}$, el segundo a 302, 300 y $268{ }^{\circ} \mathrm{C}$, surge de la reducción de las especies de $\mathrm{Pt}$ oxi-hidroxicloradas [84], y el tercero a 434,432 y $428^{\circ} \mathrm{C}$, que puede ser asignado a la fase PtOx en el bulk, y a partículas altamente dispersas con fuerte interacción con el soporte, como se informó anteriormente [85 - 86]. 
Esta observación puede explicarse por la interacción Pt-neodimio que conduce a una reducción más fácil. Además, la presencia de óxido de neodimio promueve reducciones de especies de Pt a temperaturas ligeramente inferiores mostrando una ligera modificación en la interacción entre óxidos de Pt con óxido de neodimio - alúmina debido a la interacción preferencial de Pt con neodimio en comparación con la de $\mathrm{\gamma}-\mathrm{Al}_{2} \mathrm{O}_{3}[87,88]$.

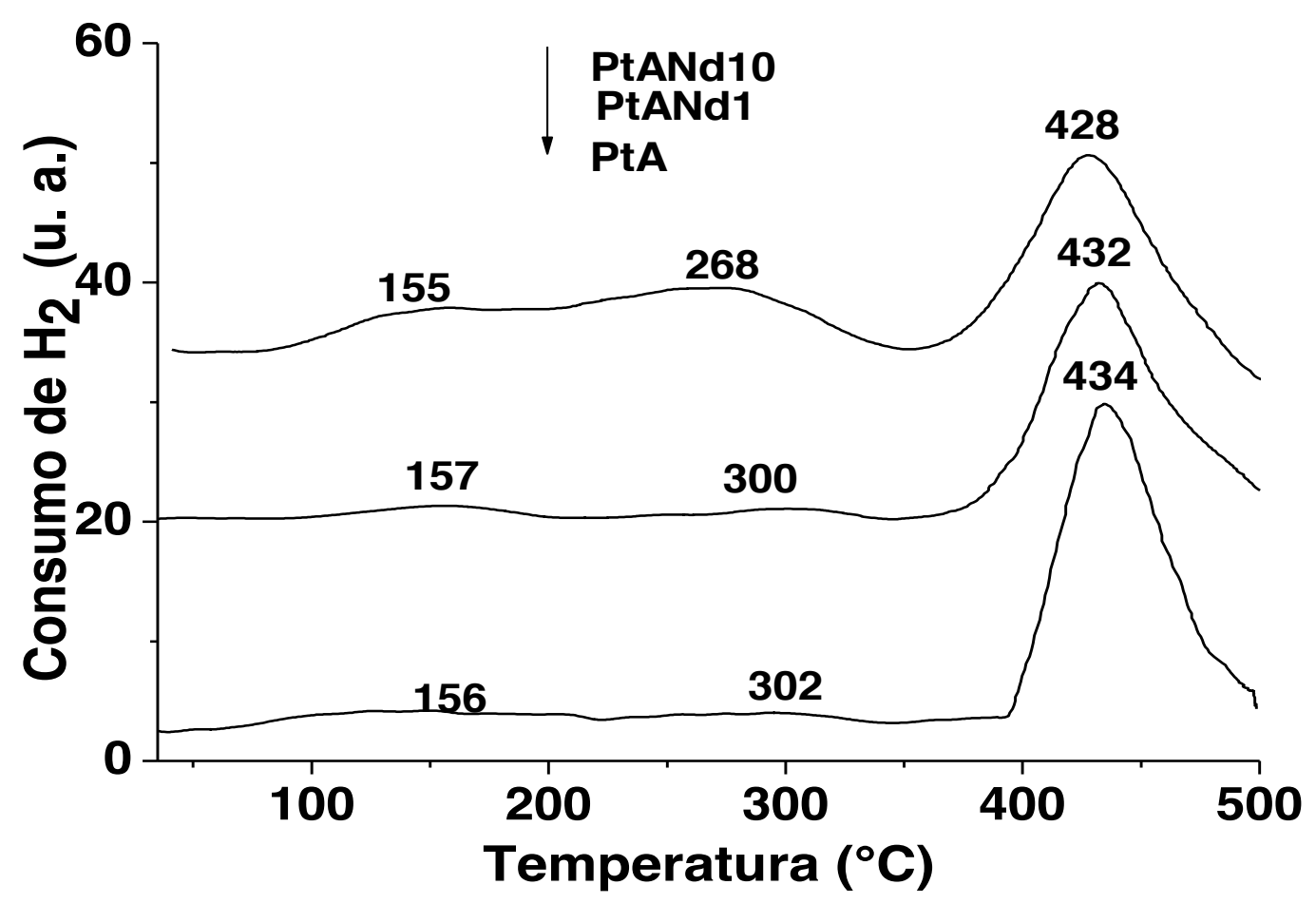

Figura 28. Perfiles RTP- $\mathrm{H}_{2}$ de los catalizadores PtA y PtANd1 y PtANd10 promovidos por neodimio.

La técnica EFRX (XPS, por sus siglas en inglés) se utilizó para determinar las energías de enlace (tabla 16) de las especies químicas de los elementos y las proporciones en la superficie de los catalizadores que se redujeron totalmente y después de la reacción (PtANd10_DRx). Para los catalizadores PtA, se ha descrito en la literatura [89-91] en la superposición de la línea $\mathrm{Al} 2 \mathrm{p}$ del soporte con las líneas más intensas de la fase activa del platino Pt 4f. Así que el estudio del platino en esta región es complicado para la asignación de las corrientes y las energías de unión. Por lo tanto, se elige otra línea de platino (4d) para 
el estudio (Figura 29) Esta línea de intensidad inferior ya no se traslapa con otra línea espectral de otro compuesto.

En la tabla (16) se reportan las energías de enlace de las muestras reducidas de los catalizadores de PtA y PtANdX. En la figura (29) se muestran los espectros de EFRX de la línea espectral Pt 4d $\mathrm{d}_{5 / 2}$ y los espectros EFRX correspondientes a la línea espectral de $\mathrm{Nd} 4 \mathrm{p}$. La deconvolución de los espectros de platino en componentes individuales presentan dos componentes en las muestras reducidas con energía de enlace, 314.15-314.50 eV para la especie $\mathrm{Pt}^{\circ}$ (ver Tabla 16). La primera energía de enlace esta correlacionada al platino totalmente reducido $\mathrm{Pt}^{0}$ como ya lo han reportado varios autores [92,93]. La siguiente energía de enlace 318.05-319.47 eV está correlacionada con la especie de $\mathrm{PtO}_{2}$ [92,94]. En la deconvolución de las especies de platino no se encuentra la especie de PtO con una energía de enlace de $315.3 \mathrm{eV}$. [95]. Una explicación para la especie de $\mathrm{PtO}_{2}$ la dan los autores [96] que al reducir el catalizador a $500{ }^{\circ} \mathrm{C}$, se observa que el platino mantiene un carácter $\delta^{+}$lo que indica que hay una fuerte interacción entre el metal y el soporte. Otros autores reportan [92] que la formación de esta especie está correlacionada con la descomposición incompleta de las especies $\left[\mathrm{Pt}^{\mathrm{IV}} \mathrm{O}_{\mathrm{x}} \mathrm{Cl}_{\mathrm{y}}\right]$ provenientes de la sal precursora $\mathrm{H}_{2} \mathrm{PtCl}_{6}$. 


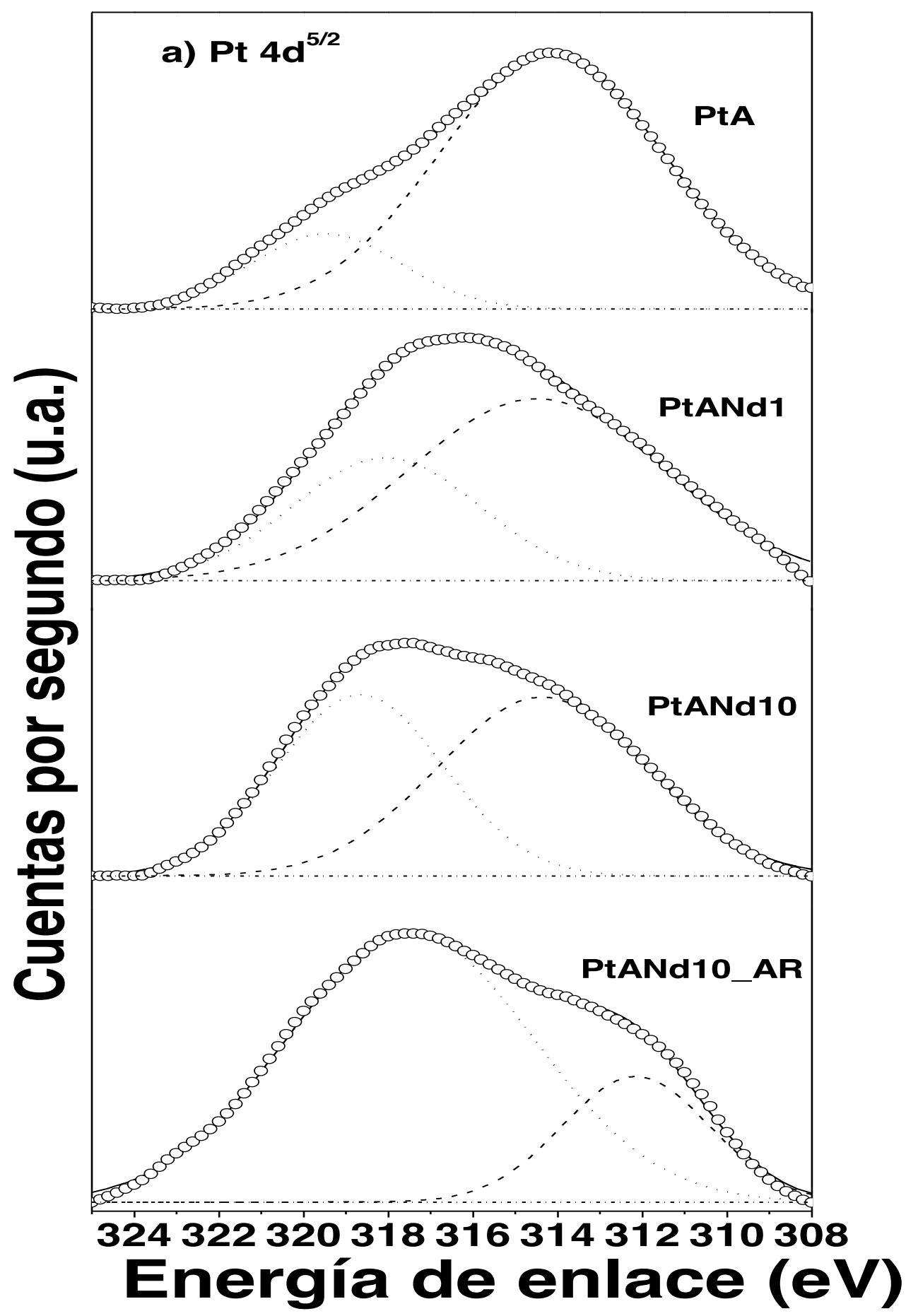




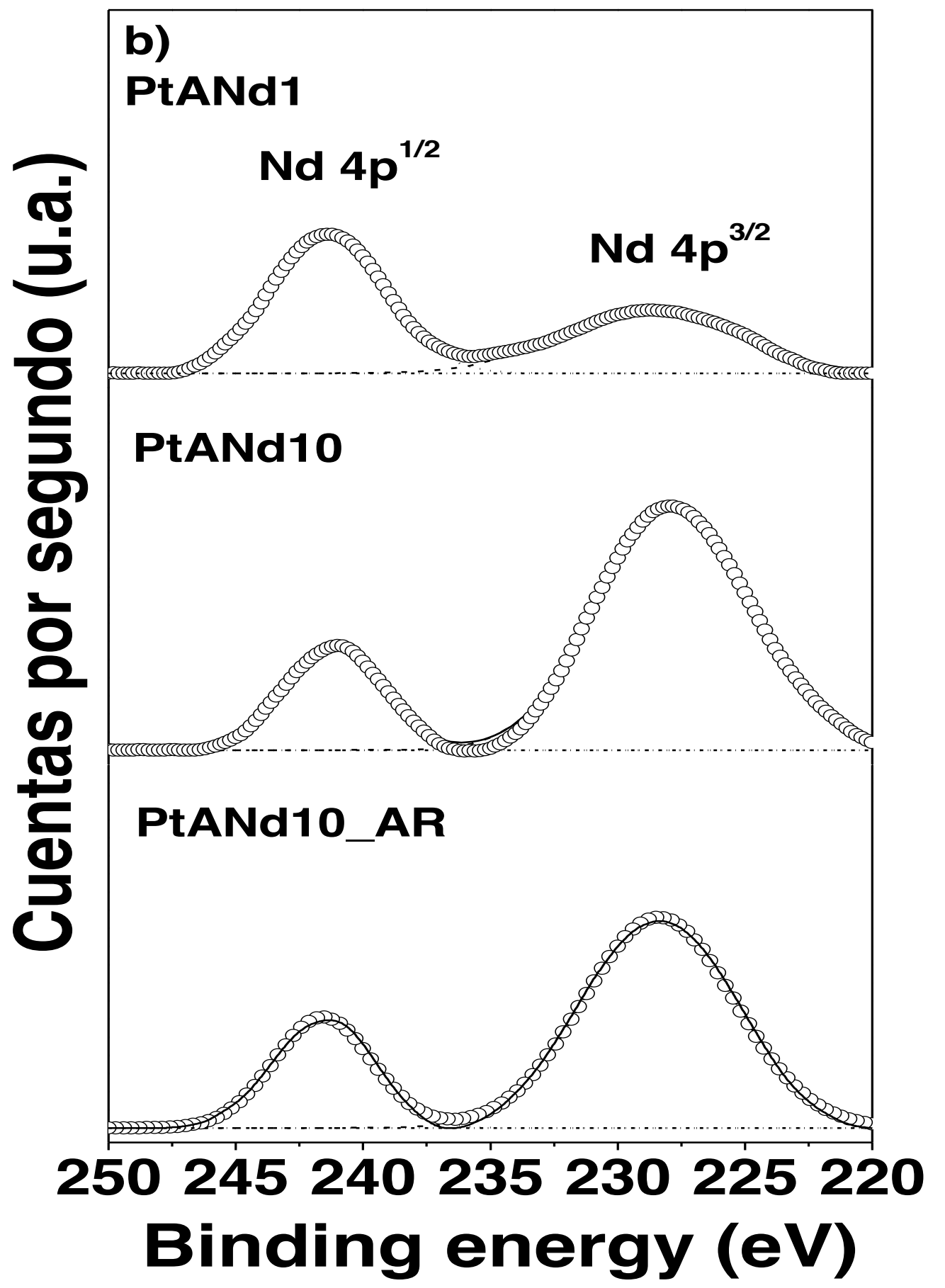

Figure 29. EFRX de Pt core levels $4 d_{5 / 2}$, (a) y $N d 4 p_{3 / 2}$ and $N d 4 p_{1 / 2}$ core levels (b), catalizadores de PtANdX. 
Tabla 16. Energías de unión (eV) de Pt4d $\mathrm{d}_{5 / 2}$, Nd $4 \mathrm{p}_{3 / 2}$ y Nd $4 \mathrm{p}_{1 / 2}$ en los catalizadores de PtA, PtANd1 y PtANd10.

\begin{tabular}{|c|c|c|c|c|}
\hline \multirow[t]{3}{*}{ Catalizador } & \multirow{3}{*}{$\mathrm{Pt} 4 d^{5 / 2}$} & \multirow{2}{*}{\multicolumn{2}{|c|}{$\mathrm{Nd}$}} & \multirow{3}{*}{ Al $2 p$} \\
\hline & & & & \\
\hline & & $\mathrm{Nd} 4 p^{3 / 2}$ & $\mathrm{Nd} 4 p^{1 / 2}$ & \\
\hline \multirow[t]{2}{*}{ PtA } & 314.15 (84) & - & - & 74.5 \\
\hline & 319.47 (16) & & & \\
\hline \multirow[t]{2}{*}{ PtANd1 } & $314.50(67)$ & $228.77(41)$ & 241.37 (59) & 74.5 \\
\hline & 318.05 (33) & & & \\
\hline \multirow[t]{2}{*}{ PtANd10 } & 314.36 (55) & $227.78(79)$ & $241.13(21)$ & 74.5 \\
\hline & $318.66(45)$ & & & \\
\hline \multirow[t]{2}{*}{ PtANd10a } & $312.16(22)$ & $228.38(75)$ & $241.57(25)$ & 74.5 \\
\hline & 317.48 (78) & & & \\
\hline
\end{tabular}

Los valores en paréntesis es la abundancia de las especies. (\%)

${ }^{a}$ Catalizador después de reacción a $400-750{ }^{\circ} \mathrm{C}$

Los histogramas de la distribución del tamaño de partícula determinada por MET (figura 30), para PtA, mostraron que el Pt estaba altamente disperso, con un diámetro de partícula del orden de 1,6 nm, la dispersión correspondiente a este valor fue del 71\%. Los catalizadores con neodimio ( 1 y $10 \%$ en peso) tuvieron una fracción importante de partículas con diámetro mayor que $2 \mathrm{~nm}$, con dispersiones de 54 y $48 \%$ respectivamente, se confirmaron los tamaños promedios de partículas de Pt medidos por IRTF-CO con los valores obtenidos por contraste Z (tabla 18). 

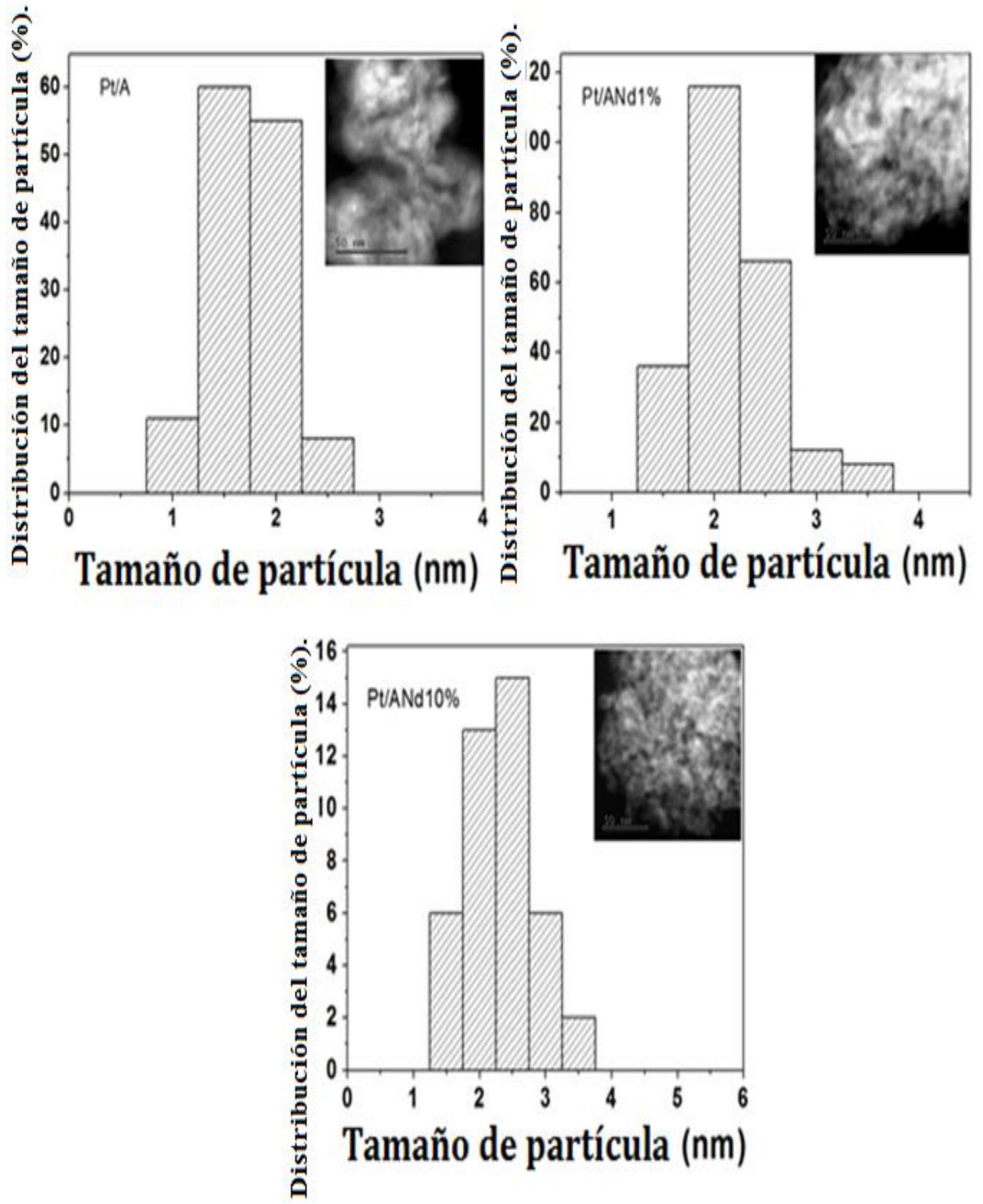

Figura 30. Imágenes MET e histogramas de distribución de tamaño de partículas metálicas para PtA y PtANd1 y PtANd10.

Se muestra la imagen METAR (HRTEM por sus siglas en inglés) del catalizador PtANd10, la cual fue examinada por varias zonas como se indica en la figura 31 con las casillas a), b), c) y d). Posteriormente estas zonas fueron trabajadas utilizando el TF-METAR (HRTEM-TF) 
para cada una de las áreas. En la parte derecha de la figura 31 se muestran las TF de las áreas examinadas que muestran varias distancias interplanares, las cuales fueron asignadas a diferentes fases cristalinas de la siguiente manera. La distancia 1,31 y 2,28 Å corresponde a los planos cristalográficos $(4,4,2)$ y $(2,2,2)$ pertenecientes a $\mathrm{\gamma}$-alúmina con el número de tarjeta JCPDS 00-056-0457 Calidad: Rietveld. La distancia 1,96 Å corresponde al plano $(2,0,0)$ de platino metálico con el número de tarjeta JCPDS 04-0802. Las distancias 1,06, $1,82,1,91$ y 2,22 Å corresponden a los planos $(2,1,3),(1,1,1),(1,1,0)$ y $(0,1,2)$ para el $\mathrm{Nd}_{2} \mathrm{O}_{3}$ JCPDS 01-079-9858 Calidad: Star $\left(^{*}\right)$. Finalmente se encontraron las distancias 1,30 y 1,34 $\AA$, que corresponden a los planos $(1,3,1)$ y $(3,0,1)$ de la fase cristalina de $\mathrm{PtO}_{2}$ con la tarjeta JCPDS número 84-1439.
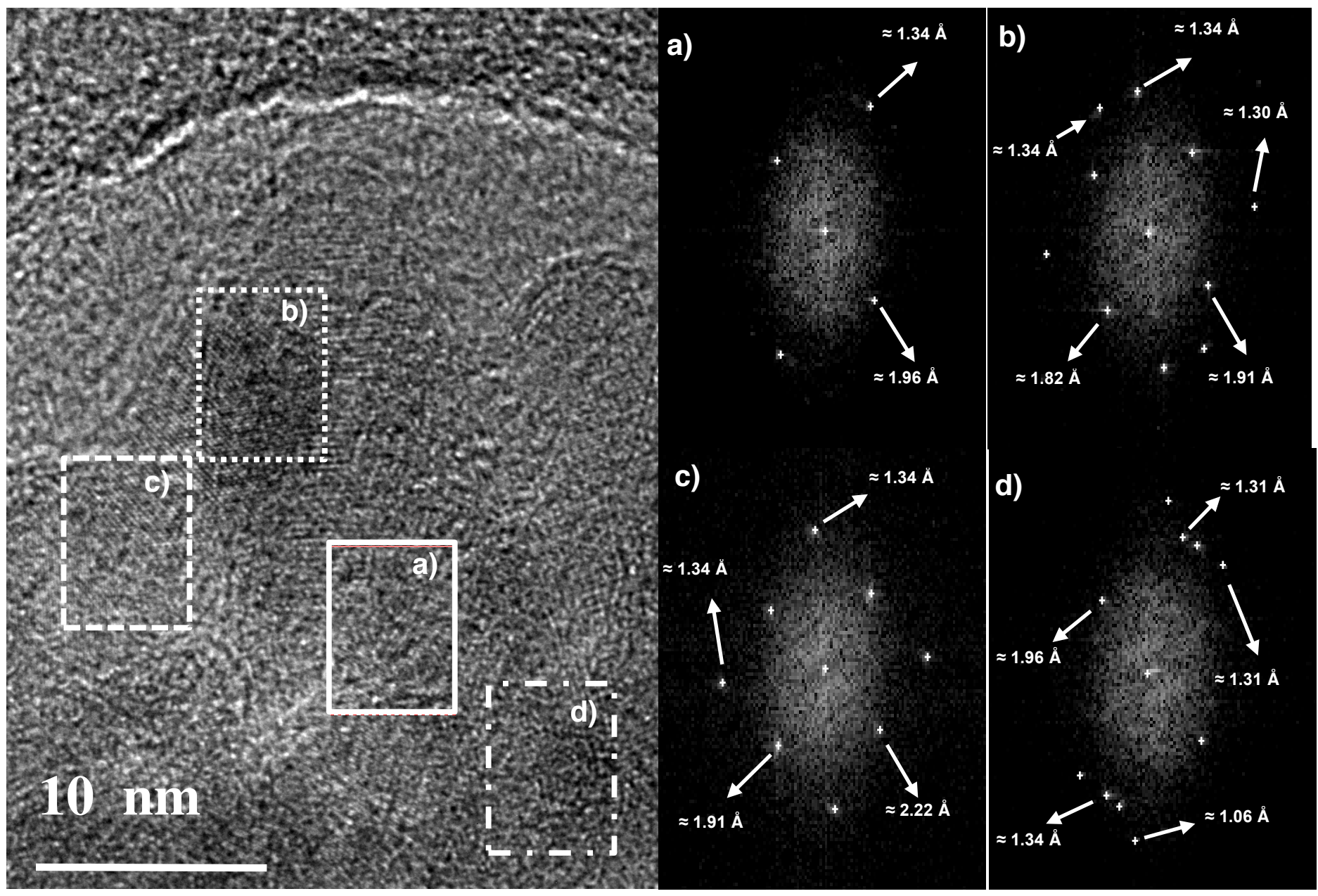

Figura 31. Imágenes HRTEM del catalizador PtANd10 con a), b), c) y d) correspondientes a FFT de las áreas escaneadas. 
En la MEB-EDERX (SEM-EDS, por sus siglas en inglés) del catalizador PtANd10, los recuadros corresponden a las zonas analizadas. En la parte derecha se observa el espectro 1 de PtANd10 (fig. 32) y la tabla insertada corresponde a la composición atómica de oxígeno, aluminio y neodimio de las zonas analizadas.

Figura 33. Imagen MEB-EDERX del catalizador PtANd10_DRx. Las casillas corresponden a las áreas. En la parte derecha se observa el espectro 2 de PtANd10 después de la reacción y en la tabla insertada corresponde a la composición atómica de oxígeno, aluminio, neodimio y carbón de las zonas analizadas.

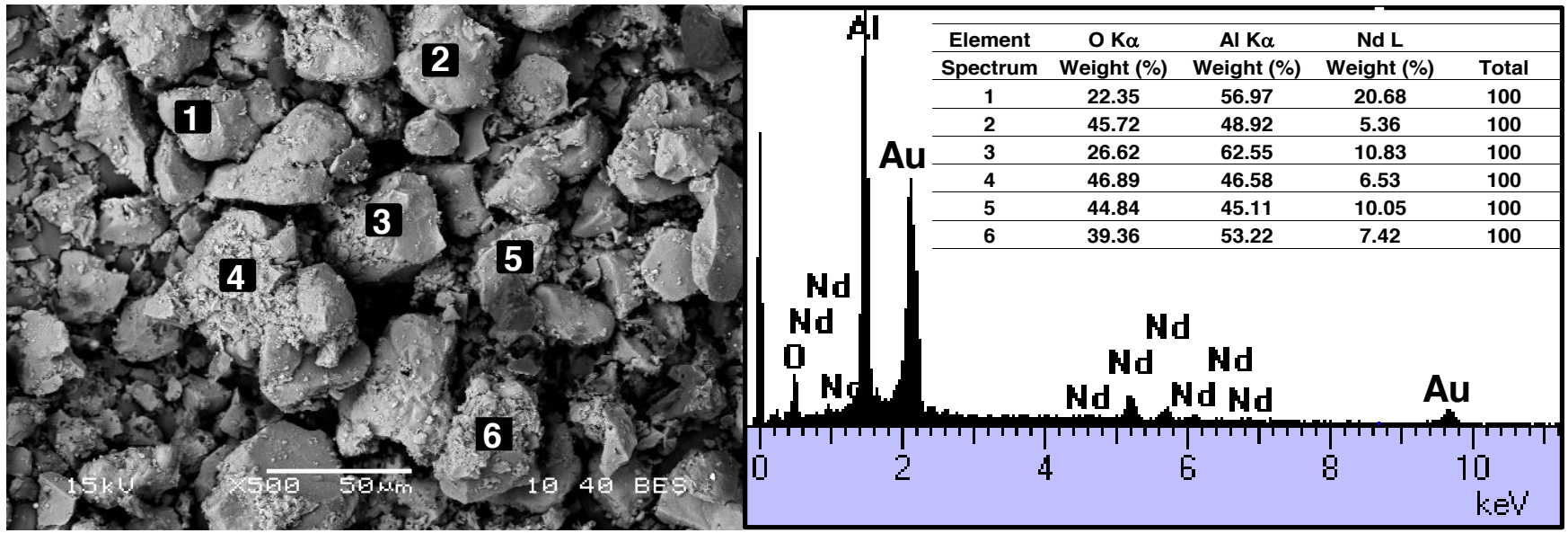

Figura 32. Análisis de mapeo de puntos MEB-EDERX para el catalizador PtANd10.

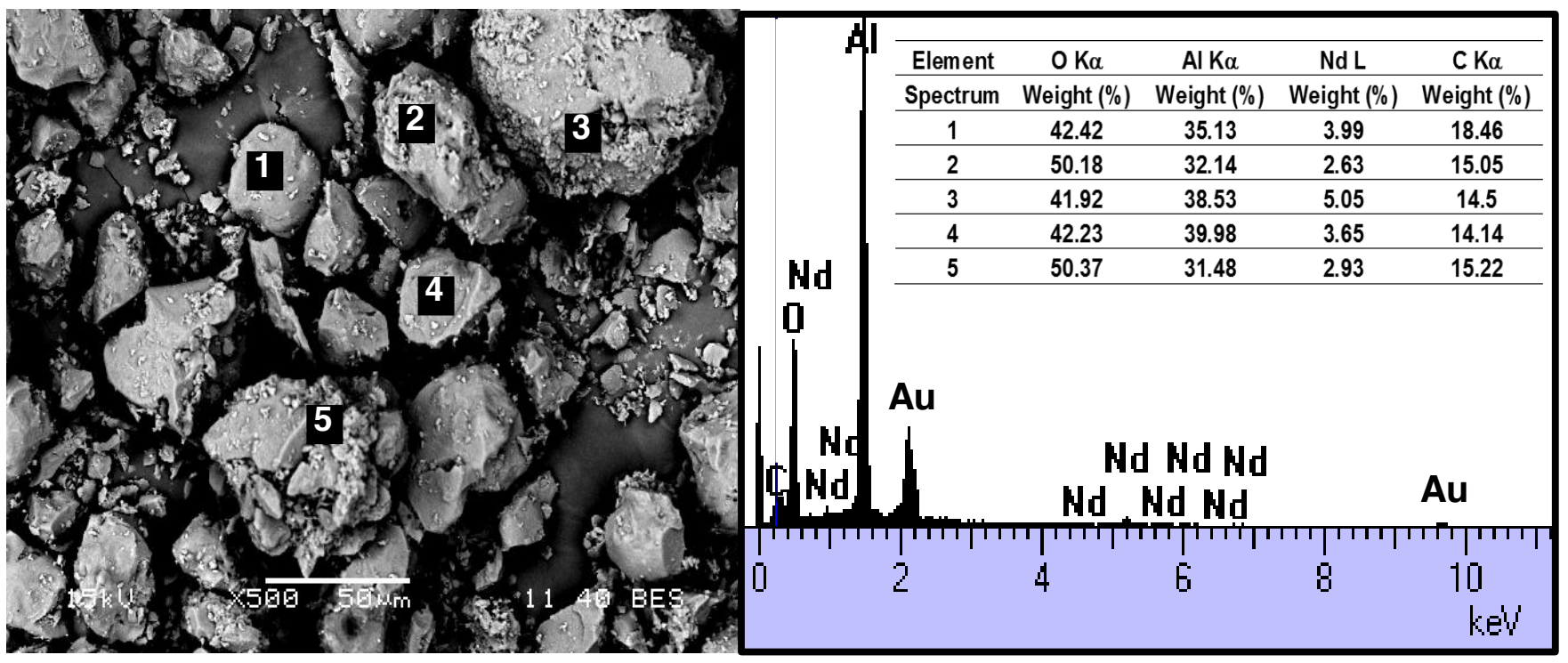

Figura 33. Análisis de mapeo de puntos MEBEDERX para el catalizador PtANd10_DRx. 
La adsorción de CO como una molécula sonda, es una técnica mediante la cual los catalizadores de Pt soportados en alúmina pueden caracterizarse por IRTF. En la Fig. 34 se muestran los espectros IRTF-CO deconvolucionados de los catalizadores de platino ( $1 \%$ en peso) soportados sobre $\gamma-\mathrm{Al}_{2} \mathrm{O}_{3}$ y $\gamma-\mathrm{Al}_{2} \mathrm{O}_{3}$ modificados con 1 y $10 \%$ en peso de neodimio. En los espectro de IRTF-CO de PtA, PtANd1 y PtANd10 se detectaron diferentes bandas entre 1930-1700 $\mathrm{cm}^{-1}$, esta región fue asignada al enlace múltiple de la molécula de CO con el platino [97], otros autores consideran que la banda débil en $1850 \mathrm{~cm}^{-1}$ corresponde al enlace puenteado $\mathrm{Pt}^{\circ}-\mathrm{CO}-\mathrm{Pt}^{\circ}$ [98] y la banda en $1784 \mathrm{~cm}^{-1}$ corresponde al $\mathrm{CO}$ adsorbido y está triplemente unido al Pt [99].

La región situada entre 2010-1990 $\mathrm{cm}^{-1}$ se correlaciona con las especies de CO unidas linealmente en el platino metálico en una esquina aislada (esquinas aisladas de $\mathrm{Pt}^{\circ}$-CO), la siguiente región en el rango de 2080-2040 $\mathrm{cm}^{-1}$ al enlace carbonilo lineal del CO con el platino metálico [100], otros autores lo correlacionan con la adsorción de CO lineal en una esquina de la partícula metálica de platino (esquinas $\mathrm{Pt}^{\circ}$-CO) en el rango de $2066-2041 \mathrm{~cm}^{-1}$ y la siguiente región localizada entre $2162-2158 \mathrm{~cm}^{-1}$ se correlaciona con la especie de platino oxidado $\left(\mathrm{Pt}^{2+}-\mathrm{CO}\right)$ que se produce a $2134 \mathrm{~cm}^{-1}$ [101].

La figura 34 muestra un ligero desplazamiento en las especies absorbidas de CO en el Pt metálico, que puede ser debido a la presencia de neodimio. 

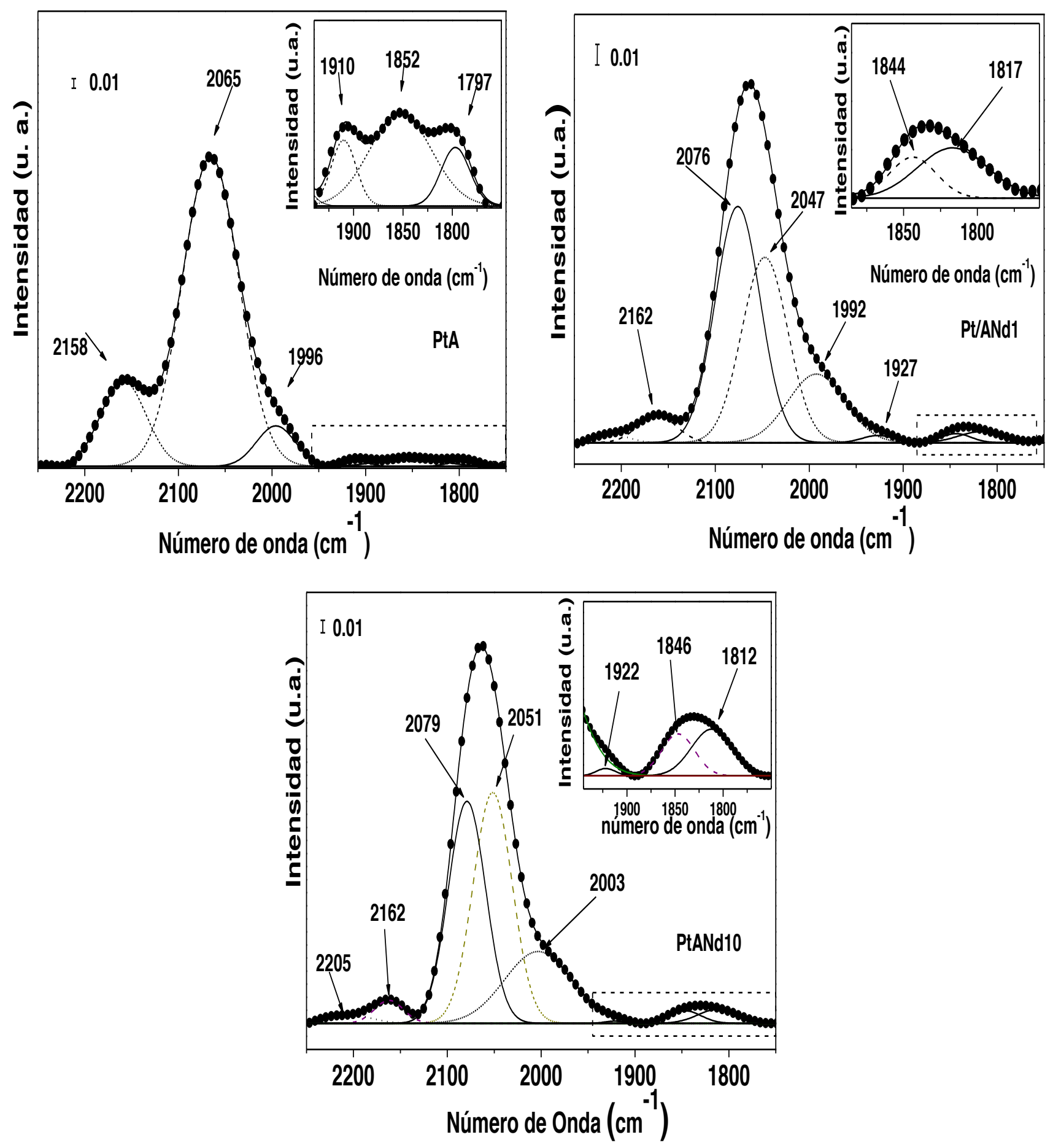

Figura 34. Deconvolución de los espectros infrarrojos de $\mathrm{CO}$ de catalizadores monometálicos de Pt soportados en $\gamma \mathrm{Al}_{2} \mathrm{O}_{3}$ y $\gamma-\mathrm{Al}_{2} \mathrm{O}_{3}$ modificado con neodimio 1 y $10 \%$ en peso, a) PtA, b) PtANd1 y c) PtANd10. 
Los resultados obtenidos por espectroscopia IRTF-adsorción de piridina, permitieron dilucidar la cantidad de sitios ácidos de Brönsted y sitios ácidos de Lewis presentes en las muestras. Se ha propuesto que la interacción metal-soporte se asocia con la acidez/alcalinidad del soporte [102,103]. Con el aumento de la alcalinidad del soporte, la transferencia de electrones entre los átomos de oxígeno del soporte y las partículas de metal cercanas puede aumentar la densidad electrónica en las partículas de metal.

La existencia de sitios ácidos de Lewis se mostró por los picos a 1448 y $1614 \mathrm{~cm}^{-1}$, mientras que no se observó ninguna banda de adsorción característica de los sitios ácidos de Brönsted a $1540 \mathrm{~cm}^{-1}$ (fig. 35). La acidez de los catalizadores de platino se muestra en la tabla 18, como se observó anteriormente en los soportes, la acidez disminuyó con el aumento de la cantidad de neodimio.

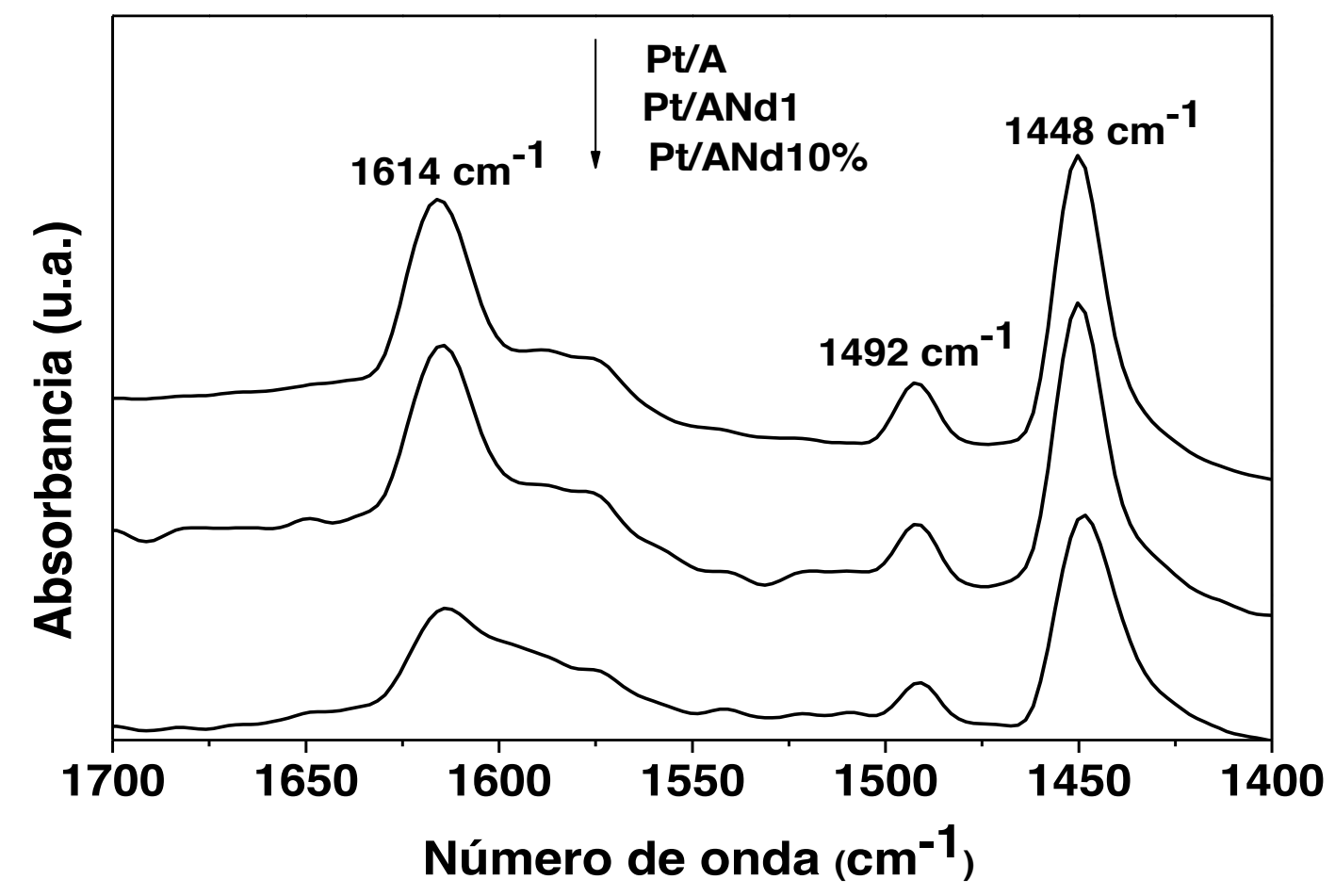

Figura 35. Espectros de IRTF de piridina adsorbida sobre catalizadores PtA, PtANd1 y PtANd10. 


\section{Actividad, Selectividad y carbono.}

La deshidrogenación del metano se llevó a cabo a temperaturas de 400, 500, 600, 700 y 750 ${ }^{\circ} \mathrm{C}$ con flujo de metano no diluido y una velocidad espacial de $6 \mathrm{~L} \mathrm{~h}^{-1} \mathrm{~g}^{-1}$. La figura 36 muestra los perfiles de conversión de metano en función de la temperatura. Se puede ver que la conversión de metano aumenta a medida que la temperatura aumenta de $400{ }^{\circ} \mathrm{C}$ a una conversión máxima a $750{ }^{\circ} \mathrm{C}$.

El catalizador de PtA presenta una conversión de $64 \%$ a $750{ }^{\circ} \mathrm{C}$ y actividad por sitio de 34,2 $\mathrm{h}^{-1}$ con el tamaño de cristalito de 1,6 nm, este catalizador muestra una producción de hidrógeno (flujo molar) de 0,19 mmoles de $\mathrm{H}_{2} / \mathrm{min}^{*} \mathrm{~g}_{\text {cat, }}$ mientras que el catalizador PtANd1 presenta un comportamiento similar al catalizador de PtA, con una conversión de 56,8\% a $750{ }^{\circ} \mathrm{C}$ y actividad por sitio de $33,6 \mathrm{~h}^{-1}$ con el tamaño de cristalito de 2,1 nm, este catalizador muestra el mayor flujo molar de 0,27 mmoles de $\mathrm{H}_{2} / \mathrm{min}^{*} \mathrm{~g}_{\text {cat, }}$ el catalizador PtANd10, presenta su mayor producción a $750{ }^{\circ} \mathrm{C}$, con una conversión de $80 \%$ de metano (tabla 17), un tamaño de cristalito de 2,4 nm, actividad por sitio de 38,6 h-1 y un flujo molar de 0,29 mmoles de $\mathrm{H}_{2} / \mathrm{min}^{*} \mathrm{~g}_{\text {cat }}$ (figura 37 ). Esto puede ocurrir tal vez porque las partículas de Pt más grandes podrían presentar sitios más activos para la reacción, donde el metano podría ser adsorbido mostrando mayor actividad. En los presentes catalizadores se podría considerar que PtANd1 y PtANd10 con mayor tamaño de cristalito tendrían sitios más accesibles.

Los estudios RTP- $\mathrm{H}_{2}$ y EFRX mostraron que existe una alta interacción entre Pt y el soporte de $\gamma-\mathrm{Al}_{2} \mathrm{O}_{3}-\mathrm{Nd}_{2} \mathrm{O}_{3}$ que depende de la cantidad de enriquecimiento superficial de neodimio en el catalizador. Una superficie de $\gamma-\mathrm{Al}_{2} \mathrm{O}_{3}$ rica en óxido de neodimio (10\% en peso) conduce a una fuerte interacción de superficie entre Pt-soporte $\mathrm{Nd}_{2} \mathrm{O}_{3}-\gamma \mathrm{Al}_{2} \mathrm{O}_{3}$ [105].

La presencia de pequeñas cantidades de $\mathrm{C}_{2} \mathrm{H}_{4}$ y $\mathrm{C}_{2} \mathrm{H}_{6}$ (menos del 1\%) en la salida de la corriente podría deberse a que el $\mathrm{CH}_{4}$ no se adsorbe disociativamente en las partículas superficiales de $\mathrm{Pt}$, produciendo sólo $\mathrm{H}_{2}$ y trazas de hidrocarburos. Se ha informado que la principal especie observada en la descomposición de $\mathrm{CH}_{4}$ es el hidrocarburo $\mathrm{C}_{2}$ y depende de la naturaleza del soporte [106]. 


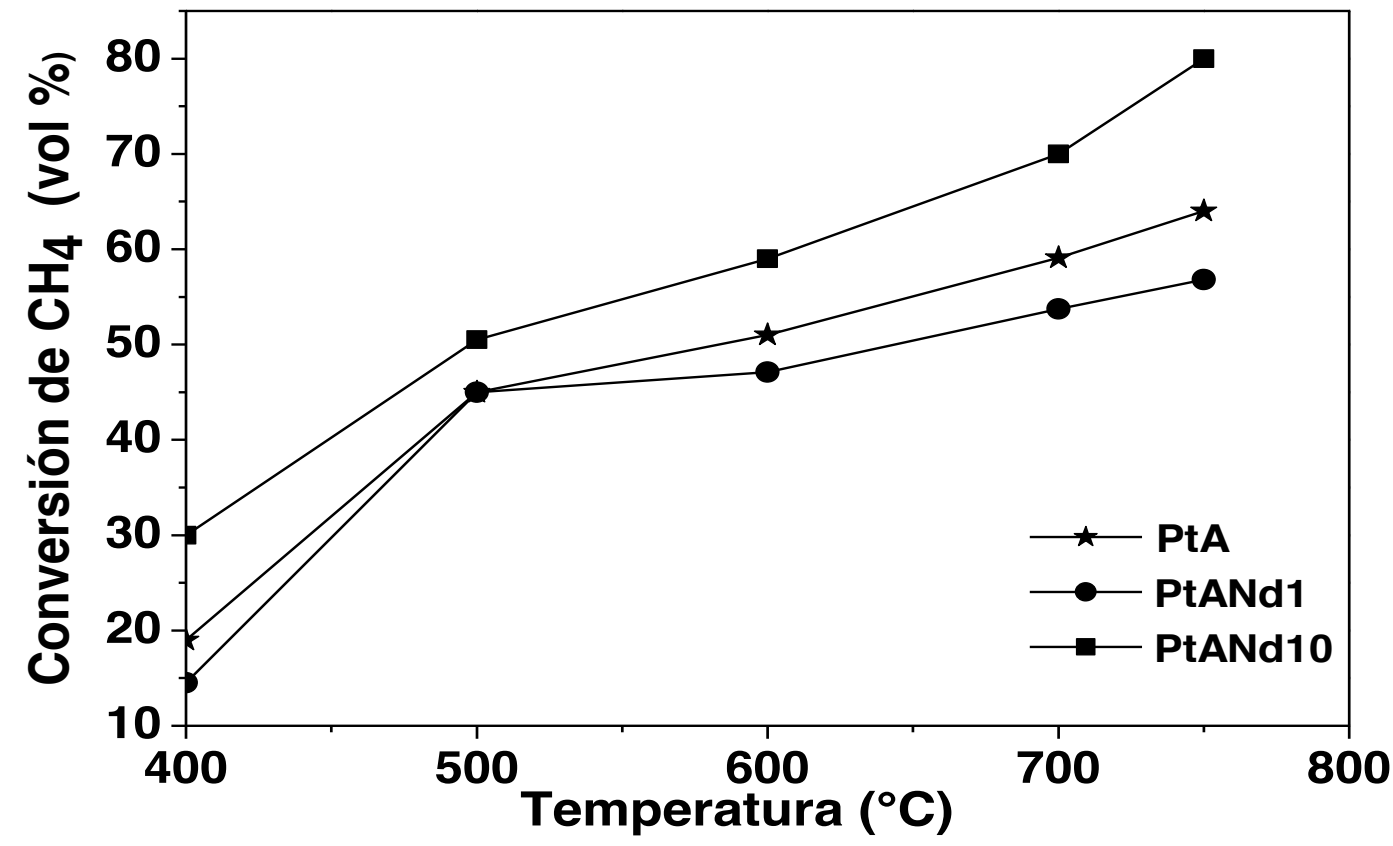

Figura 36. Perfiles de conversión de metano en función de la temperatura.

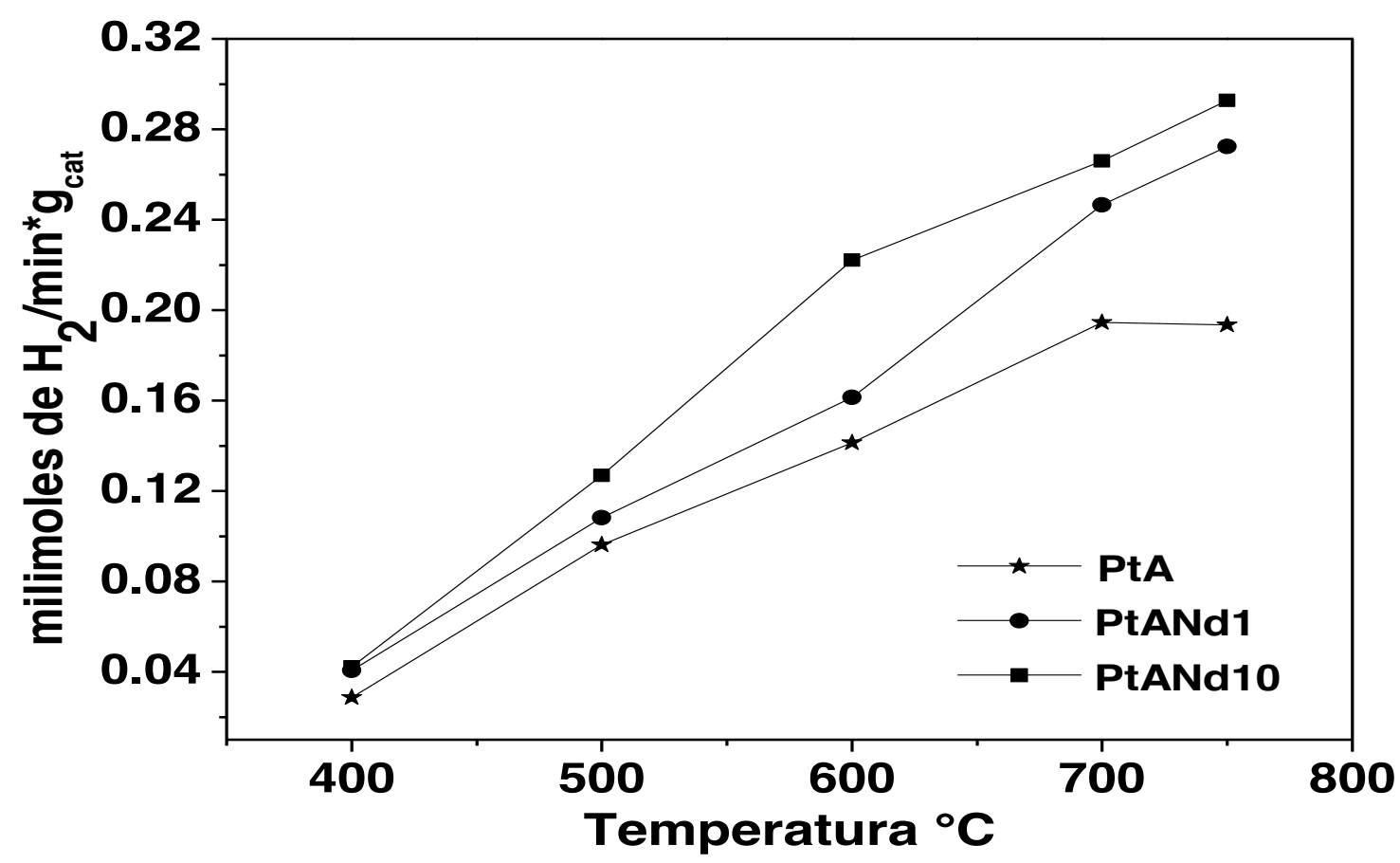

Figura 37. Producción de $\mathrm{H}_{2}$ (milimoles de $\mathrm{H}_{2} / \mathrm{min}^{*}$ gcat) en función de la temperatura. 
Tabla 17. Conversión, TOF, selectividad y rendimiento para la deshidrogenación del metano sobre los catalizadores de PtANd $X$ a $750^{\circ} \mathrm{C}$.

\begin{tabular}{|c|c|c|c|c|}
\hline Catalizador & $\begin{array}{c}\text { Conversión } \\
\text { (\%) }\end{array}$ & $\begin{array}{l}\text { TOF } \\
\left(h^{-1}\right)\end{array}$ & $\begin{array}{c}\text { Selectividad } \\
(\%) \\
\mathrm{H}_{2}\end{array}$ & $\begin{array}{c}\text { Rendimiento } \\
(\%)\end{array}$ \\
\hline PtA & 64 & 34.2 & 99.9 & 63.9 \\
\hline PtANd1 & 56.8 & 33.6 & 99.9 & 56.7 \\
\hline PtANd10 & 80 & 38.6 & 99.9 & 79.9 \\
\hline
\end{tabular}

Las concentraciones de Pt en los catalizadores se determinaron por absorción atómica y se indican en la Tabla 18. La concentración nominal de Pt fue 1,0\% en peso, las concentraciones reales son $0.51,0.60$ y $0.83 \%$ en peso.

Tabla 18. Características de los catalizadores de Pt.

\begin{tabular}{|c|c|c|c|c|c|c|c|}
\hline Catalizador & $\begin{array}{l}\text { Áreas } \\
\text { BET } \\
\left(\mathrm{m}^{2} / \mathrm{g}\right)\end{array}$ & $\begin{array}{c}\text { Acidez } \\
\text { ( } \mu \mathrm{mol} / \text { gcat })\end{array}$ & $\begin{array}{c}\mathrm{d}^{\mathrm{a}} \\
(\mathrm{nm})\end{array}$ & $\begin{array}{c}\mathrm{d}^{\mathrm{b}} \\
(\mathrm{nm})\end{array}$ & $\begin{array}{c}\mathrm{Pt}^{\mathrm{c}} \\
(\mathrm{wt} \%)\end{array}$ & $\begin{array}{l}\% \\
\mathrm{D}^{\mathrm{d}}\end{array}$ & $\begin{array}{c}\text { Producción } \\
\text { de } \mathrm{H}_{2} \text { a } \\
750^{\circ} \mathrm{C} \\
(\mathrm{ppm})\end{array}$ \\
\hline PtA & 147 & 258 & $1.6 \pm 0.32$ & 1.95 & 0.51 & 71 & 14,482 \\
\hline PtANd1 & 150 & 239 & $2.1 \pm 0.48$ & 2.55 & 0.60 & 54 & 20,393 \\
\hline PtANd10 & 146 & 213 & $2.4 \pm 0.57$ & 2.7 & 0.83 & 48 & 21,922 \\
\hline
\end{tabular}

a $\mathrm{d}=$ tamaño promedio de cristalito por MET

b $\mathrm{d}=$ tamaño promedio de la particular de platino medido por IRTF-CO

c Absorción Atómica

d Dispersión (\%) $=\left({ }^{\mathrm{a}} \mathrm{N}_{(\mathrm{S})} \mathrm{Pt} /{ }^{\mathrm{b}} \mathrm{N}_{(\mathrm{T})} \mathrm{Pt}\right) \times 100 .{ }^{a} \mathrm{~N}_{(\mathrm{S})} \mathrm{Pt}=$ úmero de átomos activos de Platino disponibles para la reacción. ${ }^{b} \mathrm{~N}_{(\mathrm{T})} \mathrm{Pt}=$ Número total de átomos de Platino Total en el catalizador. 
Los contenidos de carbono de los catalizadores de Pt después de reacción obtenidos por análisis de OTP se muestran en la Fig. 38, los catalizadores de metales nobles son más tolerantes a la coquización que los catalizadores convencionales de níquel. La mayor actividad junto con la mejor resistencia a la coquización extiende la vida útil del catalizador, haciendo posible el uso de metales nobles [107].

La Oxidación a Temperatura Programada se ha utilizado ampliamente para estudiar la formación de coque [108, 109]. La OTP permite la caracterización de depósitos de coque a través de la oxidación en la superficie del catalizador. La temperatura a la que se produce la oxidación está determinada por la ubicación y naturaleza química de la especie de coque. Dado que los metales catalizan la oxidación, la ubicación se representa por la distancia desde el metal activo. Además, las formas más grafíticas de coque se oxidan a altas temperaturas [110]. Se pueden clasificar entonces diferentes formas de coque con respecto a su naturaleza química y su localización sobre el catalizador.

Utilizamos el análisis OTP para investigar las diferencias en la reactividad del coque formado sobre catalizadores de metales nobles, el área bajo la curva al perfil de OTP (figura 38), representa la cantidad total de $\mathrm{CO}_{2}$ formada en el transcurso de un experimento. La cantidad total de $\mathrm{CO}_{2}$ se usó para calcular la cantidad relativa de coque depositado sobre los catalizadores después de la reacción (Tabla 19).

De este modo se obtiene información sobre la ubicación del coque y su naturaleza química. Las especies de coque difieren en su reactividad al oxígeno de acuerdo con su naturaleza aromática, polimérica o grafítica y su distancia desde el metal activo [109-111].

En los perfiles de OTP se observa un cambio a temperaturas de oxidación más bajas, a medida que se aumenta el contenido de neodimio.

En los perfiles de OTP para el coque formado en la reacción hasta $750^{\circ} \mathrm{C}$, la oxidación del coque comienza alrededor de $80^{\circ} \mathrm{C}$, se supone que el coque que se oxida a temperaturas $<$ $200{ }^{\circ} \mathrm{C}$ está situado sobre el metal activo ya que los metales catalizan la oxidación. Los picos máximos de $\mathrm{CO}_{2}$ situados entre $500-600{ }^{\circ} \mathrm{C}$ sugieren que el coque se localizaba en la interfase metálica o soporte-metal y que la naturaleza de las especies carbonosas eran uniformes, por lo tanto los depósitos son poliaromáticos y su composición depende mucho del reactivo, su formación implica transferencia de hidrógeno (catalizadores ácidos) y deshidrogenación; $\mathrm{Y}$ el coque que se oxida a altas temperaturas $\left(>700^{\circ} \mathrm{C}\right)$ se considera más 
grafítico y se localiza en el soporte más que en el metal activo [111,112]. La formación de coque fue mayor en el catalizador de PtA con 4,77\%, seguido por catalizador PtANd10 con un 3,51\%, y el catalizador con menos formación de coque fue el catalizador PtANd1 con 2,84\%, aunque la conversión de metano fue también más baja en el último catalizador.

Durante la oxidación a temperatura programada, se detectó $\mathrm{CO}_{2}$ y la temperatura para el desprendimiento de $\mathrm{CO}_{2}$ sobre el catalizador PtANd10 es mucho menor que la de los catalizadores PtANd1 y PtA. Esto sugiere que las especies de carbono depositadas sobre el catalizador PtANd10 son más activas que las de los catalizadores PtANd1 y PtA. 


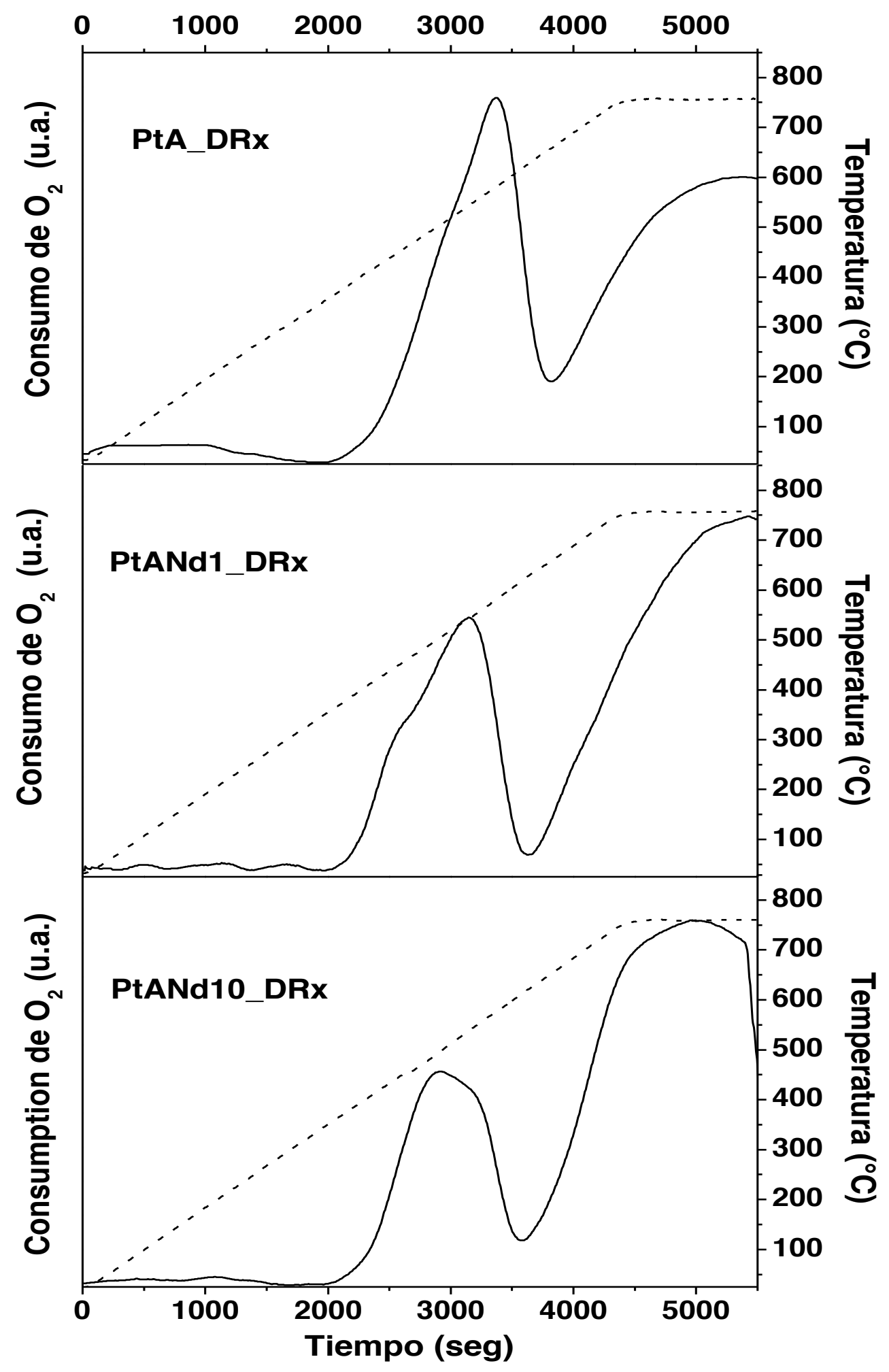

Figura 38. Perfiles de OTP de los catalizadores PtA, PtANd1 y PtANd10 después de reacción. 
Tabla 19. Cantidad total de carbón en los catalizadores PtA, PtANd1 y PtANd10 después de reacción.

\begin{tabular}{|c|c|}
\hline Catalizador & 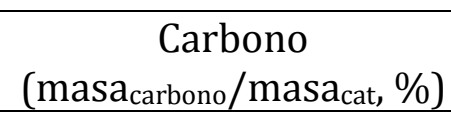 \\
\hline PtA & 4.77 \\
\hline PtANd1 & 2.84 \\
\hline PtANd10 & 3.51 \\
\hline
\end{tabular}

\section{Cinética de la reacción, pseudo-orden de reacción y energías activación}

También se llevó a cabo un estudio cinético de la reacción de descomposición del metano en el intervalo de temperatura de $400-750^{\circ} \mathrm{C}$ a presión atmosférica. Se utilizó un reactor de cuarzo de lecho fijo para investigar la cinética y evaluar los parámetros del modelo. La velocidad de descomposición del metano depende fuertemente de la temperatura, el flujo de metano y la masa del catalizador.

Al aumentar el caudal en el lecho fijo, la eficiencia de contacto entre el metano y las partículas de catalizador disminuyó, y por lo tanto la conversión de metano disminuyó $[113,114]$.

La velocidad de descomposición del metano aumentó con el aumento de la temperatura (figura 39). La velocidad de reacción en los catalizadores PtA y PtANd1 se igualó a $500{ }^{\circ} \mathrm{C}$ y se mantuvo similar en las otras temperaturas, la velocidad de reacción en el catalizador PtANd10 siempre fue mayor.

La velocidad de descomposición del metano fue calculada usando la siguiente ecuación:

$R_{C H 4}=F_{C H 40} * \frac{X_{C H 4}}{W_{c a t}} \quad \ldots(11)$

Dónde:

$\mathrm{R}_{\mathrm{CH} 4}$ la velocidad de descomposición del metano en (mol/gcat*s), $\mathrm{F}_{\mathrm{CH} 4 \mathrm{o}}$ es el caudal molar de Metano en mol/s, $\mathrm{X}_{\mathrm{CH} 4}$, la fracción de metano convertido y Wcat el peso del catalizador (g). 


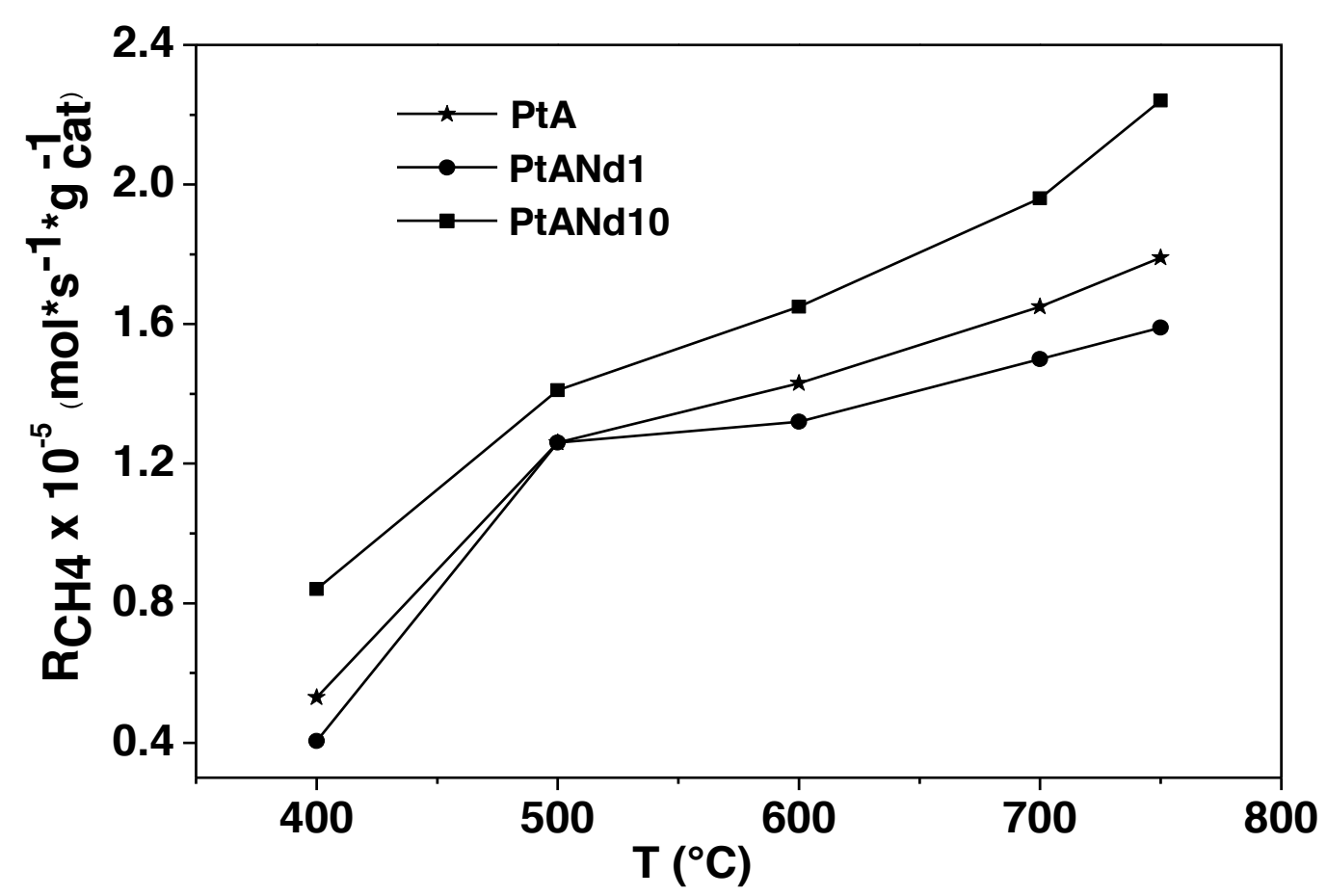

Figura 39. Velocidad de descomposición del metano contra la temperatura.

Asumiendo un flujo tapón para la fase gaseosa que fluye a través del lecho del catalizador, la integración de la ecuación diferencial del balance de masa conducida sobre el catalizador produjo la siguiente ecuación:

$\frac{W_{\text {cat }}}{F_{C H 40}}=\int_{0}^{X_{C H 4}} \frac{d x_{C H 4}}{r_{C H 4}}$

Substituyendo $r_{C H 4}=K_{n} * C_{C H 4}^{n}$ y $F_{C H 40}=v_{0} * C_{C H 40}$

$\frac{W_{c a t}}{v_{0} * C_{C H 40}}=\int_{0}^{X_{C H 4}} \frac{d X_{C H 4}}{K_{n} * C_{C H 4}^{n}}$

Y para la reacción de expansión en fase gaseosa, la relación entre $C_{C H 4}$ y la concentración inicial de metano $C_{C H 40}$ se define como: 
$C_{C H 4}=C_{C H 40} \frac{1-X_{C H 4}}{1+\varepsilon X_{C H 4}}$

El resultado de la ecuación es como sigue:

$\frac{W_{c a t}}{v_{0}}=\frac{C_{C H 40}^{1-n}}{K_{n}} \int_{0}^{X_{C H 4}}\left\{\frac{\left[1+X_{C H 4}\right]}{\left[1-X_{C H 4}\right]}\right\}^{n} d X_{C H 4}$

donde $v_{0}$ es el flujo de metano en $\mathrm{L} / \mathrm{min}$, $\mathrm{n}$ es el orden de la reacción de la descomposición del metano y $\mathrm{K}_{\mathrm{n}}$ es la constante cinética $\left(\mathrm{L}\left(\mathrm{g}_{\mathrm{cat}} \mathrm{min}^{-1}\left(\mathrm{~mol} \mathrm{~L}^{-1}\right)^{1-\mathrm{n}}\right.\right.$ y $\varepsilon$ es el factor de expansión igual a 1 de acuerdo a la ecuación (6).

La ecuación (10) fue usada para determinar el pseudo orden de reacción n y la constante cinética kn graficando (Wcat/vo) contra el valor de la integral mostrada en el lado derecho de la ecuación (10), esto se llevó a cabo con los datos experimentales presentados en la Tabla 20 para experimentos con variación de la masa del catalizador (fig. 40 a-c) y para experimentos con variación en el flujo de alimentación de metano (fig. 40 d-f). Para ello se intentaron varios valores de $\mathrm{n}(\mathrm{n}=0,0,5,1,1,5$ y 2 ) y se obtuvieron los mejores ajustes con $\mathrm{n}=1$ (coeficiente de correlación $0,99>0,97$ ) para experimentos con variación de masa de catalizador y (coeficiente de correlación $0,99>0,98$ ) para experimentos con variación en el flujo de alimentación de metano. El valor de k se calculó a partir de la pendiente 4.1 - 4.75 (L/gcat min).

Tabla 20. Datos experimentales usados para determinar el pseudo-orden de reacción.

\begin{tabular}{ccccc}
\hline & $\begin{array}{c}\text { Experimentos con variación de la } \\
\text { masa del catalizador }\end{array}$ & $\begin{array}{c}\text { Experimentos con variación en } \\
\text { el flujo de alimentación de } \\
\text { metano }\end{array}$ \\
\hline $\begin{array}{c}\text { Temperatura } \\
\left({ }^{\circ} \mathrm{C}\right)\end{array}$ & $\begin{array}{c}\text { Masa del } \\
\text { Catalizador } \\
(\mathrm{mg})\end{array}$ & $\begin{array}{c}\text { Flujo de } \\
\text { alimentación de } \\
\text { metano } \\
(\mathrm{mL} / \mathrm{min})\end{array}$ & $\begin{array}{c}\text { Masa del } \\
\text { Catalizador } \\
(\mathrm{mg})\end{array}$ & $\begin{array}{c}\text { Flujo de } \\
\text { alimentación } \\
\text { de metano } \\
(\mathrm{mL} / \mathrm{min})\end{array}$ \\
\hline 700 & 25 & 2 & 50 & 2 \\
700 & 50 & 2 & 50 & 4 \\
700 & 75 & 2 & 50 & 6 \\
\hline 700 & 100 & 2 & 50 & 8 \\
\hline
\end{tabular}




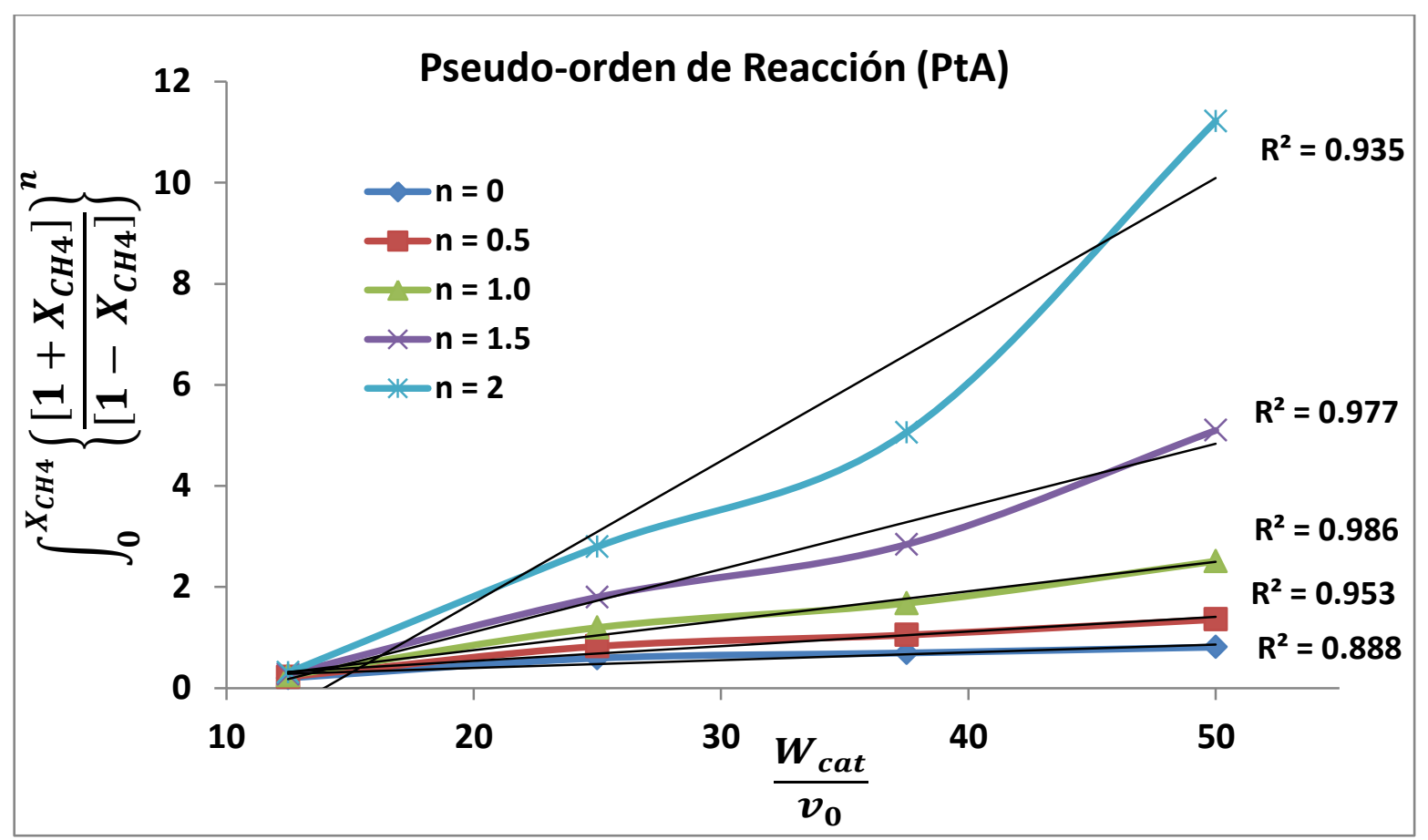

Figuras 40a. Pseudo orden de reacción a T y vo constantes y masa del catalizador variable para PtA.

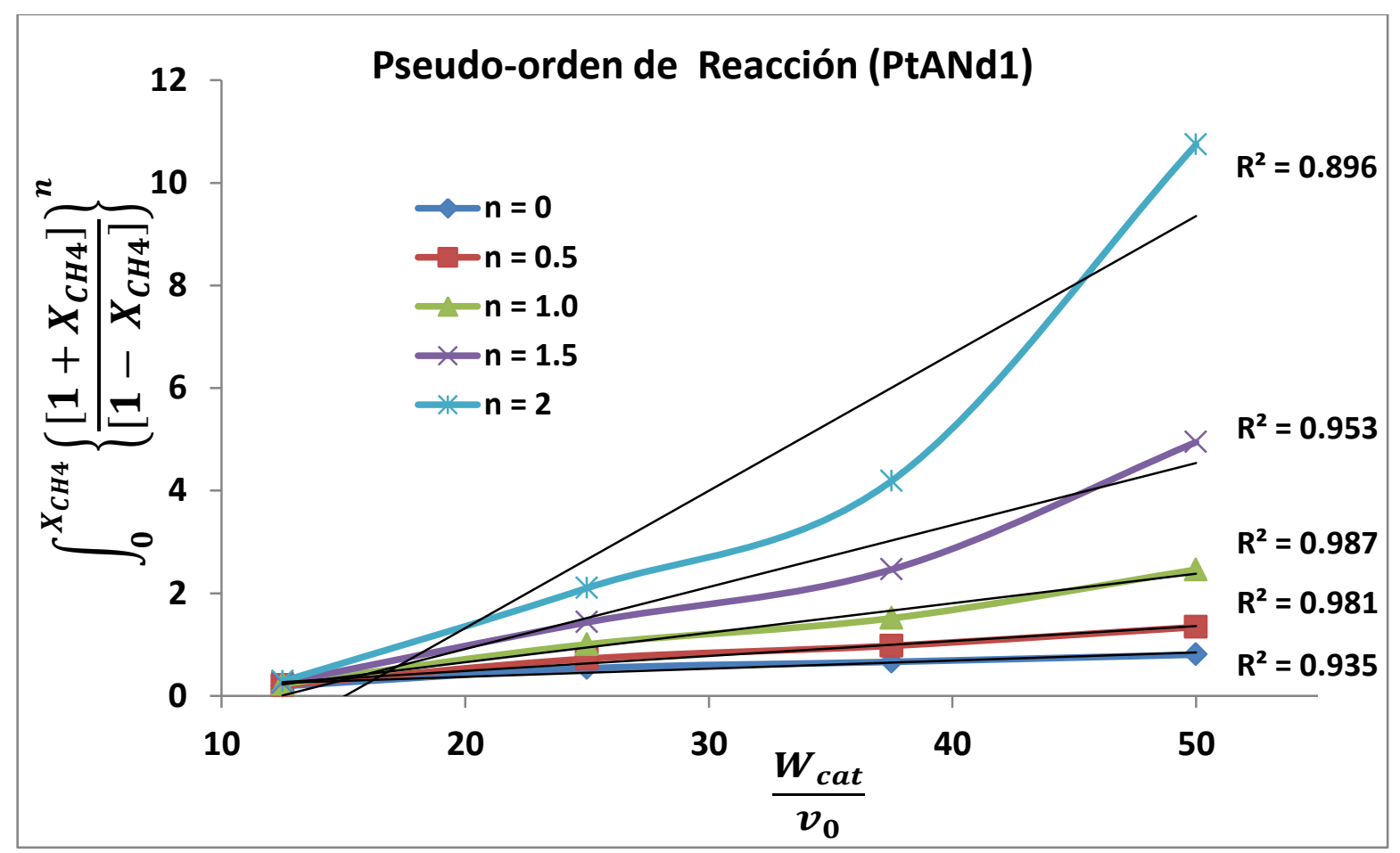

Figuras 40b. Pseudo orden de reacción a T y vo constantes y masa del catalizador variable para PtANd1. 


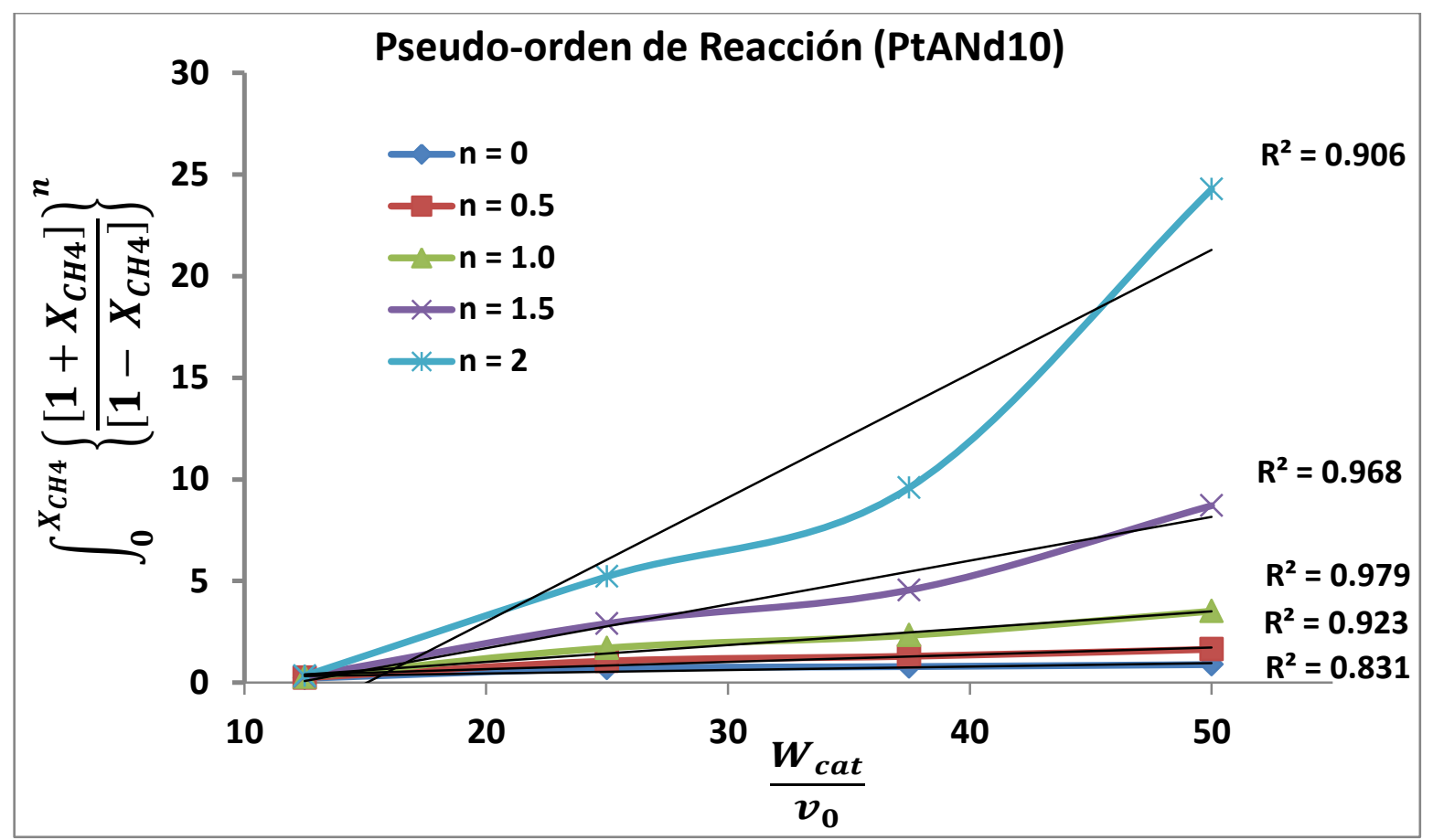

Figuras 40c. Pseudo orden de reacción a T y vo constantes y masa del catalizador variable para PtANd10.

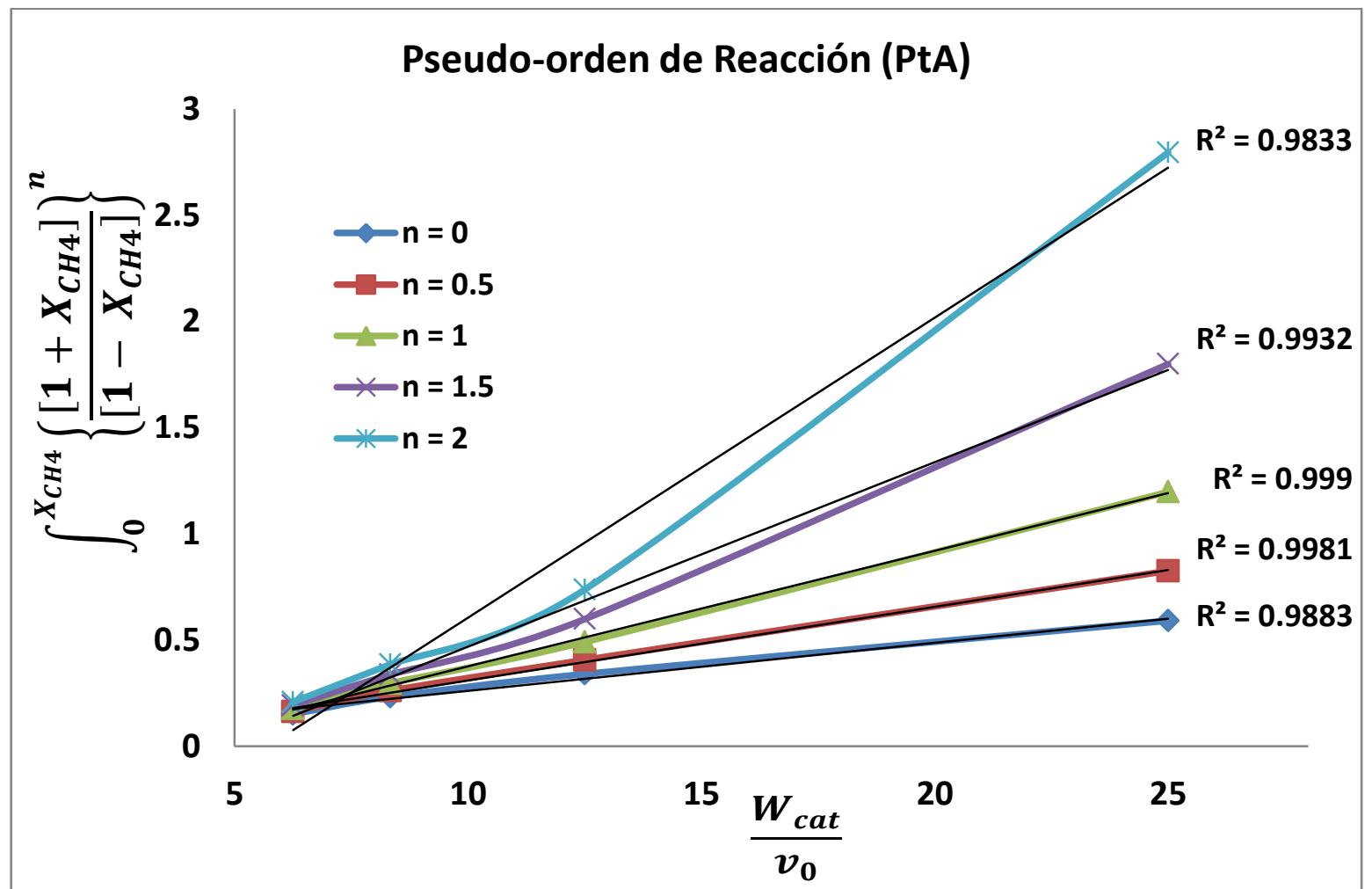

Figuras 40 d. Pseudo orden de reacción a T y masa del catalizador constantes y vo variable para PtA. 


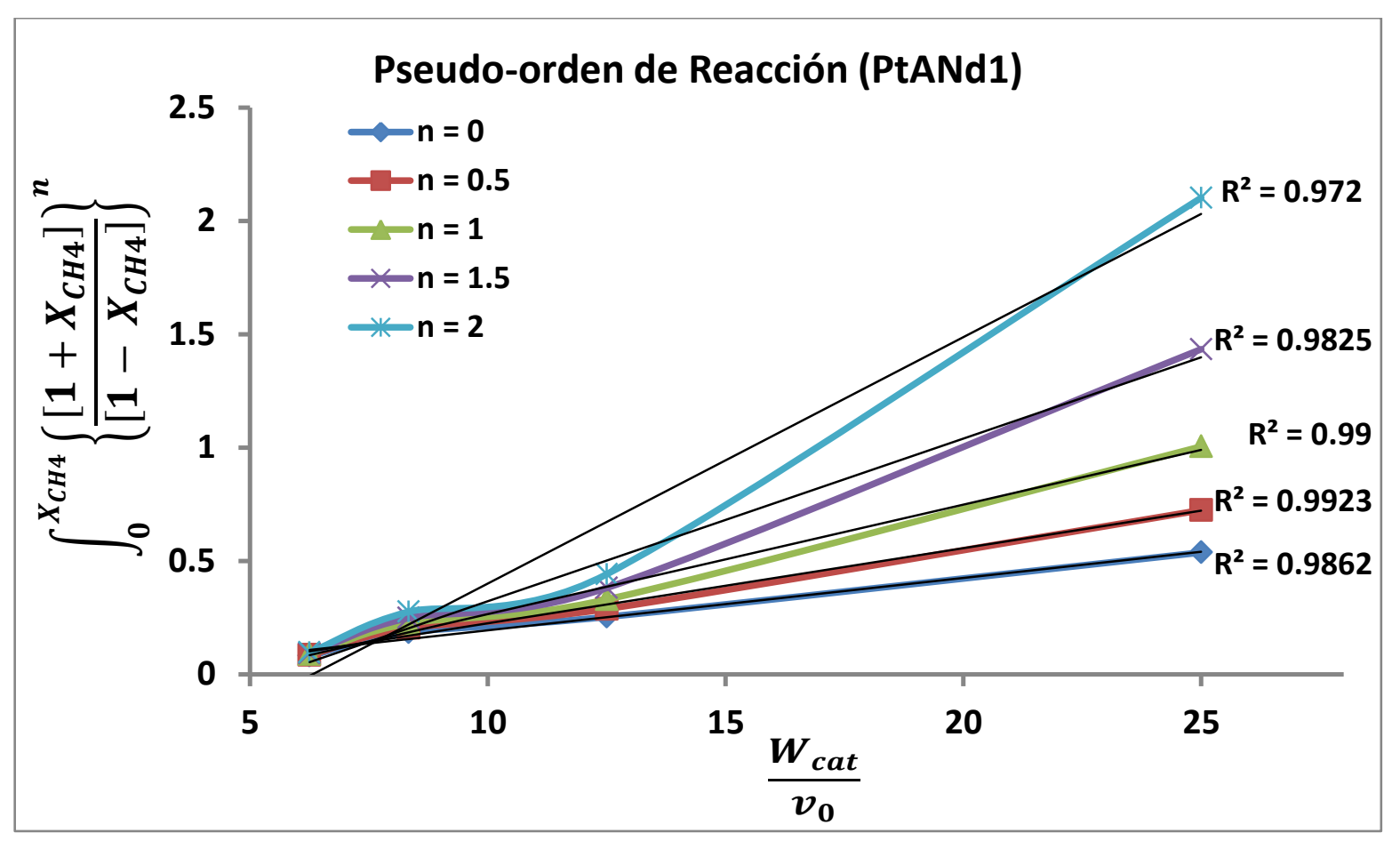

Figuras 40e. Pseudo orden de reacción a T y masa del catalizador constantes y vo variable para PtANd1.

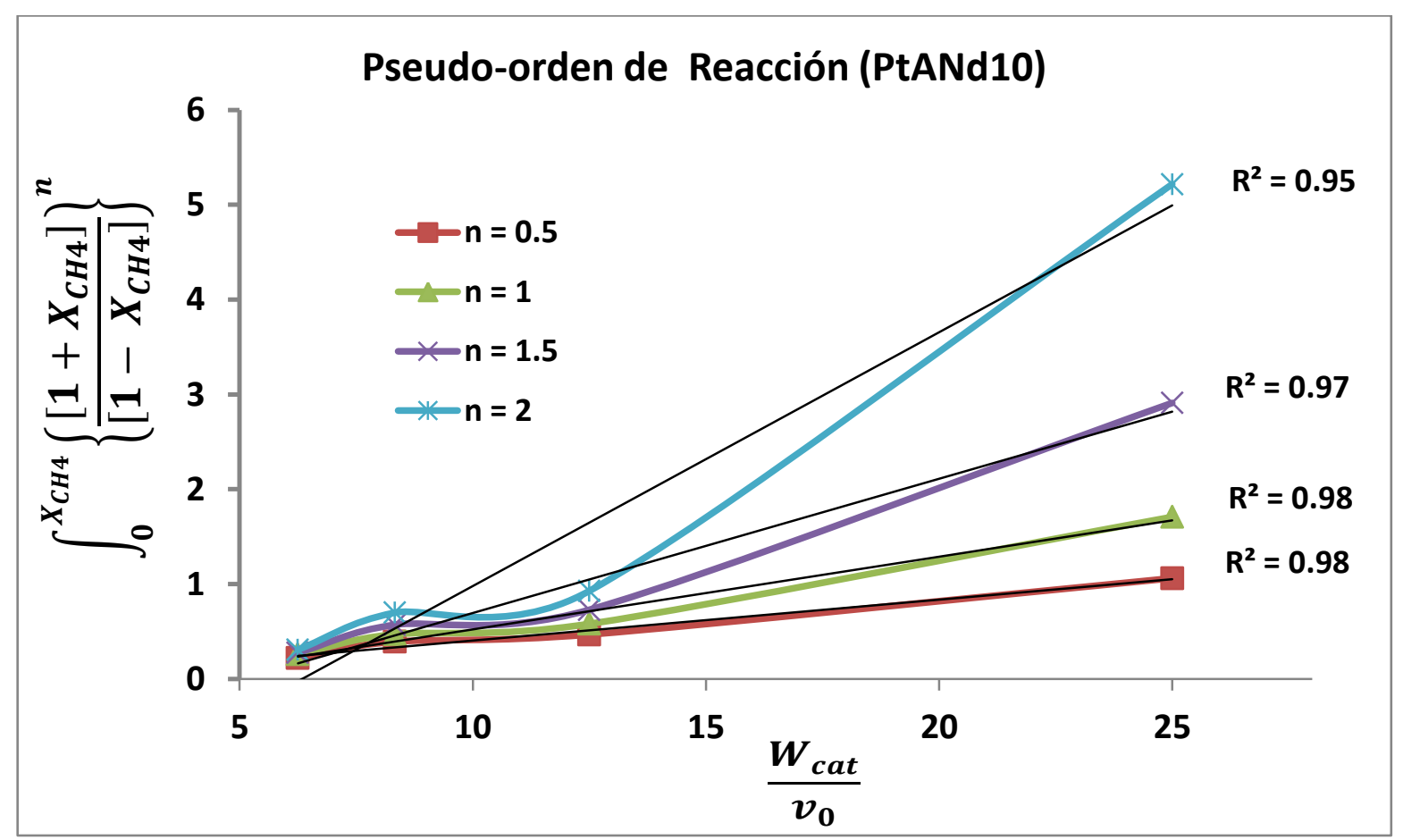

Figuras 40 f. Pseudo orden de reacción a T y masa del catalizador constantes y vo variable para PtANd10. 
Con el fin de encontrar k a temperaturas de $400,500,600,700$ y $750{ }^{\circ} \mathrm{C}$, se encontró el valor de la integral de la ecuación (10) según los datos de cada experimento y luego se calculó el valor de $\mathrm{k}$.

La energía de activación fue calculada usando un gráfico de Arrhenius de ln k contra 1/T y la pendiente de el gráfico lineal es (-Ea/R) (fig. 41). La energía de activación, el valor del factor preexponencial y la ecuación de Arrhenius aparecen en la (tabla 21):

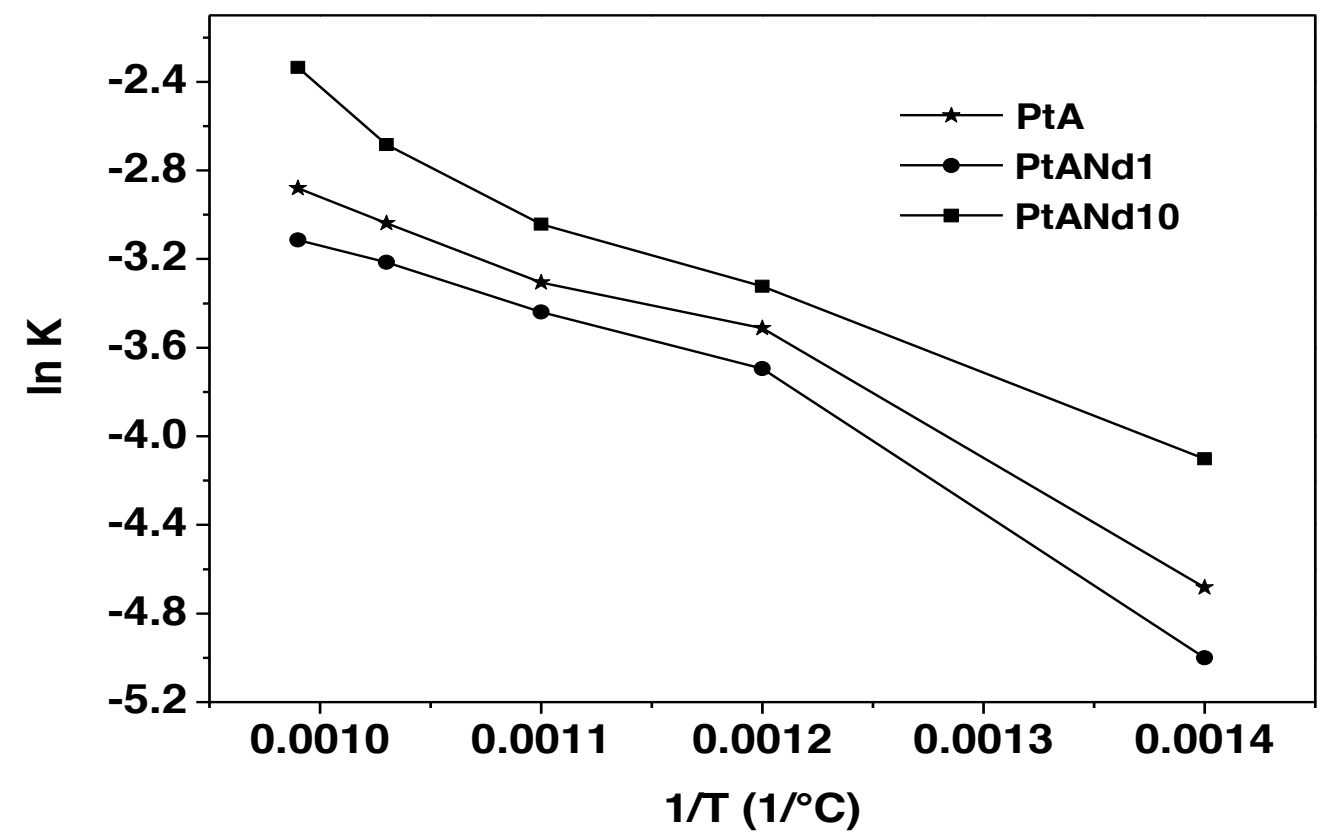

Figura 41. Gráfico de Arrhenius ln k vs. (1/T).

Tabla 21. Energía de activación, valor del factor preexponencial y ecuación de Arrhenius.

\begin{tabular}{cccc}
\hline Catalizador & $\begin{array}{c}\text { Energía de } \\
\text { activación } \\
(\mathrm{KJ} / \mathrm{mol})\end{array}$ & $\begin{array}{c}\text { Valor del factor } \\
\text { preexponencial } \\
\text { (L/gcat min) }\end{array}$ & Ecuación de Arrhenius \\
\hline Pt/A & 35.5 & 4.1 & $\mathrm{k}=4.131745678 \mathrm{e}^{\left(\frac{-4285}{\mathrm{~T}}\right)}$ \\
Pt/ANd1 & 37.9 & 4.6 & $\mathrm{k}=4.614022333 \mathrm{e}^{\left(\frac{-4564.2}{\mathrm{~T}}\right)}$ \\
Pt/ANd10 & 33 & 4.75 & $\mathrm{k}=4.753114085 \mathrm{e}^{\left(\frac{-4070}{\mathrm{~T}}\right)}$ \\
\hline
\end{tabular}




\section{CONCLUSIONES}


En el presente trabajo se estudió el efecto de la adición de $\mathrm{Nd}_{2} \mathrm{O}_{3}$ (1 y $10 \%$ en peso) al $\mathrm{RhA}$ para la producción de hidrógeno en la descomposición de metano en el intervalo de temperatura de $400-750^{\circ} \mathrm{C}$. Los soportes y catalizadores RhANd y PtANd se prepararon por impregnación del nitrato de $\mathrm{Nd}, \mathrm{RhCl}_{3} \mathrm{y}_{2} \mathrm{PtCl}_{6}$ como precursores. Los catalizadores con un tamaño de partícula de $\mathrm{Rh} \geq 2,1 \mathrm{~nm}$ fueron más activos (TOF) y selectivos para hidrógeno en la descomposición de metano a $700^{\circ} \mathrm{C}$. El catalizador RhANd10 presentó la mayor selectividad al hidrógeno, 100\%. El catalizador RhA y RhANd1 produjo 89 y $65 \%$ de selectividad hacia hidrógeno respectivamente y el resto fue etano y productos de etileno. El comportamiento del catalizador RhANd10 se explicó por una fuerte interacción entre el Rh y el soporte alumina- $\mathrm{Nd}_{2} \mathrm{O}_{3}$, detectado por los estudios RTP- $\mathrm{H}_{2}$ y EFRX. La producción de etano y etileno proviene de la movilidad de las especies $\mathrm{CHx}$ en la superficie del $\mathrm{Rh}$ formadas durante la degradación del metano en los catalizadores de RhANd1. El tipo de carbono producido durante la reacción fue carbono amorfo que se deposita principalmente sobre el soporte.

Mientras que con los catalizadores de platino, un mayor tamaño de partícula metálica, una menor acidez beneficiaron una mayor conversión de metano y actividad por sitio activo del catalizador PtANd10, obteniendo también una mayor producción de hidrógeno y por lo tanto una menor energía de activación.

Los resultados de los experimentos de descomposición de metano usando catalizadores de $\mathrm{Rh}$ y Pt en un reactor de lecho fijo a temperaturas de $400-750{ }^{\circ} \mathrm{C}$ y diferentes tiempos de residencia de metano, el primer experimento consistió en cambiar el peso del catalizador a un caudal de metano constante y en el segundo experimento se cambió el flujo de metano, manteniendo el peso del catalizador constante, dichos experimentos se utilizaron para evaluar la cinética aparente. La cinética aparente para los catalizadores de rodio mostró que el orden de reacción fue de 1.5 y la energía de activación fue de $38.9 \mathrm{KJ} / \mathrm{mol}$ para el catalizador RhANd10, $40.4 \mathrm{KJ} / \mathrm{mol}$ para el catalizador RhANd1 y $39.2 \mathrm{KJ} / \mathrm{mol}$ para el catalizador RhA; concluyendo que el mejor catalizador fue RhANd10.

Mientras que la cinética aparente en los catalizadores de platino mostró que el orden de reacción es 1 y la energía de activación fue $33 \mathrm{KJ} / \mathrm{mol}$ para el catalizador PtANd10, 37.9 $\mathrm{KJ} / \mathrm{mol}$ para el catalizador PtANd1 y 35,5 KJ/mol para el catalizador PtA; concluyendo que el mejor catalizador fue PtANd10. 


\section{PERSPECTIVAS}


Ya que la demanda de hidrógeno puro está aumentando cada año, ya sea en cantidad o en número de aplicaciones que requieren hidrógeno libre de monóxido de carbono. Mejorar la economía de la descomposición catalítica del metano, requiere una amplia investigación para mejorar los diferentes parámetros del proceso. El uso de un catalizador muy activo y estable, la optimización de las condiciones de funcionamiento, y el desarrollo de reactores adecuados están entre las diferentes áreas que necesitan ser abordadas en la descomposición del metano.

Por lo anterior se podrían sintetizar catalizadores bimetálicos, de metales nobles tales como Rodio-platino, rodio-paladio o platino -paladio, para llevar a cabo la reacción y conseguir mayores conversiones del metano, con selectividades del 100\% a hidrógeno. 


\section{BIBLIOGRAFÍA}

[1] Malaika A., Krzyzynska B., Kozlowski M., Int J Hydrogen Energy (2010); 35:7470-5.

[2] Muradov N., Int J Hydrogen Energy (1993); 18:211-5.

[3] Abbas H., Daud W., Int J Hydrogen Energy (2010); 35:12268-76.

[4] Ponelis A., Van Z., PGS. Stud Surf Sci Catal (1997); 107:555-60.

[5] Galuszka J., Pandey R., Ahmed S., Catal Today (1998); 46:83-9.

[6] Prabhu A., Oyama S., J Membr Sci (2000); 176:233-48.

[7] Prabhu A., Liu A., Lovell L., Oyama S., J Membr Sci (2000); 177:83-95.

[8] Raybold T., Huff M., AIChE J (2002); 48:1051-60.

[9] Ferreira P., Rodríguez I., Guerrero A., Appl Catal A Gen (2002);237:239-52.

[10] Muradov N., Baltimore, Maryland, USA (2001); p. 271-96.

[11] ABS energy-research., The hydrogen economy hydrogenand fuel cells (2006).

[12] Ermakova M., Ermakov D., Catal Today (2002);77:225-35.

[13] Catón N., Villacampa J., Royo C., Romeo E., Monzón A., Stud SurfSci Catalysis (2001); 391-8.

[14] Bartholomew C., Robert J., 2nded. New Jersey: Wiley-AIChE (2005).

[15] Otsuka K., Takenaka S., Ohtsuki H., Appl Catalysis (2004); 273:113-24.

[16] Rodat S., Abanades S., Sans J., Flamant G., Int J Hydrogen Energy (2010); 35:7748-58.

[17] Takenaka S., Ogihara H., Yamanaka I., Otsuka K., J Synchrotron Radiat (2001); 8:587-9.

[18] Dunker A., Kumar S., Mulawa P., Int J Hydrogen Energy (2006); 31:473-84.

[19] Muradov N., Int J Hydrogen Energy (2001); 26:1165-75.

[20] Abbas H., Wan D., Int J Hydrogen Energy (2010); 35:1160-90.

[21] Ashraf M., Croiset E., William E., Int. J. Hydrogen Energy 36 (2011); 2904-2935.

[22] Shah N., Panjala D., Huffman G., Energy Fuels (2001);15, 1528-1534.

[23] Wang Y., Shah N., Huffman G., Catalysis Today (2005); 99, 359-364.

[24] Pohlenz J, Scott N.. In: Ed. Universal Oil Prod, U.S. Patent No 3,284,161 (UOP); (1966).

[25] Rostrup-Nielsen J.R. J. Catal. (1972); 27: 343-356.

[26] De Bokx P.K., Kock A.J.H.M., Boellaard E., Klop W., Geus J.W. J. Catal. (1985); 96: 454467.

[27] Steinberg M, Cheng HC., Int J Hydrogen Energy (1989);14:797 - 820. 
[28] Muradov N.. Int J Hydrogen Energy (2001);26:1165-75.

[29] Makoa M, Coville N, Sokolovskii V. Catal Today (1999);49:11-16.

[30] Avdeeva L. Reshetenko T. Ismagilov Z, Likholobov V. Appl Catal A (2002);228:53-63.

[31] Lee K, Han G, Yoon K, Lee B. Catal Today (2004);93-95:81-86.

[32] Ibrahim AA, Fakeeha AH, Al Fatesh AS, Abasaeed AE, Khan WU. Int J Hydrogen Energy (2015);40:7593-600.

[33] ChesnokovVV, ChiChkan AS. Int J Hydrogen Energy (2009);34:2979-85.

[34] Muradov N Energy Fuels (1998);12:41-48.

[35] Moiliner R, Suelves I, Lázaro M J, Moreno O. Int J Hydrogen Energy (2005); 30:293-300.

[36] Rostrup-Nielsen JR, Sehested J Norskov JK. Adv Catal (2002);47:65-139.

[37] Muradov, N. Energy Fuels, (1998);12: 41-48

[38] Moliner R., Suelves I., Lázaro M.J., Moreno O. Int. J. Hydrogen Energy, (2005);30: 293300 ,

[39] Muradov, N. Catal. Comm, (2001);2: 89-94,

[40] Lee E E.K., Lee S.Y., Han G.Y., Lee B.K., Lee T.J., Jun J.H., Yoon K.J., Carbon, (2004); 42:2641-2648.

[41] Kim M.H., Lee E.K., Jun J.H., Kong S.J., Han G.Y., Lee B.K., Lee T.J., Yoon K.J., Int. J. Hydrogen Energy (2004); 29:187-193.

[42] Muradov N., F. Smith, A. T-Raissi, Catal. Today (2005); 102-103:225-233.

[43] Dufour A., Celzard A., Ouartassi B., Broust F., Fierro V., Zoulalian A., Appl. Catal. A: Gen. (2009);360:120-125.

[44] Serrano D.P., J.A. Botasa, R. Guil-Lopeza, Int. J. Hydrogen Energy (2009);34:44884494.

[45] Serrano D.P., Botas J.A., Pizarro P., Guil-Lopez R., Gomez G., Chem. Commun. (2008); 6585-6587.

[46] Lee K.K., Han G.Y., Yoon K.J., Lee B.K., Catal. Today (2004); 93-95:81-86.

[47] Dunker A.M., Kumar S., Mulawa P.A., Int. J. Hydrogen Energy (2006); 31:473-484.

[48] Ryu B.H., Lee S.Y., Lee D.H., Han G.Y., Lee T.J., Yoon K.J., Catal. Today (2007); 123:303309.

[49] Serrano D.P., Botas J.A., Fierro J.L.G., Guil-Lopez R., Pizarro P., Gomez G., Fuel (2010); 89: $1241-1248$. 
[50] Bond G., Moyes, R.B., Whan, D.A. Catal. Today, (1993);17:427-437.

[51] Domínguez, A., Fernández, Y., Fidalgo, B., Pis, J.J. Menéndez, J.A. Energy Fuels, (2007);21:2066-2071,

[52] Durka T., Van Gerven T., Stankiewiciz A. Chem. Eng. Technol., (2009);32: 1301-1312.

[53] Fidalgo B., Domínguez A., Pis J.J., Menéndez J.A. Int. J. Hydrogen Energy, (2008);33: 4337-4344,

[54] Shah N., D. Panjala, G.P. Huffman, Energy Fuels (2001); 15 (6):1528-1534.

[55] Shah N., Y. Wang, D. Panjala, G.P. Huffman, Energy Fuels (2004);18(3): 727-735.

[56] Hazzim F. Abbas*, W.M.A. Wan Daud, international journal of hydrogen energy (2010); 35:12268-12276.

[57] Bjørn Christian Enger a, Rune Lødeng b, Anders Holmen, international journal of hydrogen energy (2012); 37:10418-10424.

[58] Ferro S. Int J Electrochemistry (2011);2011:1-17.

[59] Fakeeha AH, Khan Wl-Fatesh AS, Ibrahim AA, Abasaeed AE. Int J Hydrogen Energy (2016);41:8193-98.

[60] Manoj Pudukudy, Zahira Yaakob, Mohd Sobri Takriff, Energy Conversion and Management (2016);126:302-315.

[61] Ahmed Sadeq Al-Fatesh, Ashraf Amin, Ahmed Aidid Ibrahim, Wasim Ullah Khan, Mostafa Aly Soliman, Raja Lafi AL-Otaibi and Anis Hamza Fakeeha, Catalysts (2016);6:40.

[62] Tang, L.; Yamaguchi, D.; Burke, N.; Trimm, D.; Chiang, K. Catal. Commun. (2010);11: 1215-1219.

[63] López-Vinasco AM, Favier I, Pradey C, Huerta L, Guerrero-Rios I, Teuma E, Gómez M, Martin E. Dalton Trans (2014);43: 9038-44.

[64] Rangel-V. I, Del Angel G, Bertin V, Gonzalez F, Vazquez-Zavala A, Arrieta A, Padilla J.M, Barrera A, Ramos-Ramírez E. J Alloys Comp (2015);643:144-49.

[65] Tanabe T, Morikawa A, Hatanaka M, Takahashi N, Nagai Y, Soto A, Kuno O, Suzuki H, Shinjoh H. Catal Today (2012);184:219-26

[66] Ojeda M, López-Granados M, Rojas S, Terreros P, García-García FJ, Fierro JLG. Applied Catal (2004);261:47-55.

[67] Hwang CP, Yeh CT, ZhuQ. Catal Today (1999);51:93-101.

[68] Ferrandon M, Krause T. Appl Catal A: General (2006);311:135-145. 
[69] Burch R, Loader PK, Cruise NA. Appl Catal A General (1996);147:375-94.

[70] Taniguchi T, Lizuka W, Nagata Y, Uchida T, Samanta H. J Alloys Compd (2003); 350: 2429.

[71] Borg H, Vanden Oetelaar LCA, Niemantsverdriet JW. Catal Lett (1993);17:81-95.

[72] Lafaye G, Mihut C, Specel C, Marecot P, Armiridis MD. Langmuir (2004);20: 10612-16.

[73] Yates JT, Duncan TM, Vaughan RW. The J of Chemical Physics. (1979);70:1219-24.

[74] Ma J, Reng S, Pan D, Li R, Xie K. Reactive \& Functional Polymers (2005);62:31-39.

[75] Liang C, Ma Z, Lin H, Ding H, Qiu J, Frandsen W, Su D. J Mater Chem (2009); 19:1417-24.

[76] Perez-Alonso FJ, López-Granados M, Ojeda M, Terreros P, Rojas S, Herranz T, Fierro JLG. Chem Mater (2005);17:2329-39.

[77] Del Angel G. A, Coq B, Ferrat G, Figueras F. Surface Science (1985);156:943-51.

[78] Sheu LL, Knszinger H, Sachtler WMH. Center for Catalysis and Surface Science (1989);111:8125-31.

[79] Lin YZ, Sun J, Yi J, Lin JD, Chen HB, Liao DW. J. Molecular structure: Theochem (2002);587:63-71.

[80] Dong GC, Baarle DWV, Rost MJ, Frenken JWM. New Journal of Physics (2012);14:15.

[81] DeLouise LA, Winogran N. Surface Science (1984);138:417-31.

[82] Al Fatesh AS, Amin A, Ibrahim AA, Khan WV, Soliman MA, Otaibi RL, Fakeeha AH. Catalysts (2016);6:40-55.

[83] Otaa A, Kunkesa EL, Krohnerta J, Schmalb M, Behrensa M. Applied Catalysis A General (2013);452:203-13.

[84] Rangel-V. I, Del Angel G, Bertin V, Gonzalez F, Vazquez-Zavala A, Arrieta A, Padilla J.M, Barrera A, Ramos-Ramírez, J Alloys Comp (2015);643:144-49.

[85] Borgna A, Garetto T. F, Apesteguia C. R, Le Normand F, and Moraweck B J of Catalysis (1999);186:433-441

[86] Meephoka, C. Chaisuk, C. Samparnpiboon, P.; Praserthdam, P. Catal. Commun. (2008);9:546-550.

[87] Santos, A. C. S. F. Damyanova, S. Teixeira, G. N. R. Mattos, L. V. Noronha, F. B. Passos, F. B. Bueno, J. M. C. Appl. Catal., A (2005); 290:123-132.

[88] Pitchon, V. Zins, J. F. Hilaire, L. \& Maire, G. Reaction Kinetics and Catalysis Letters. (1996); 59(2): 203-209. 
[89] Yu, C.; Ge, Q. Xu, H. \& Li, W. Applied Catalysis A: General. (2006); 315: 58-67.

[90] Tankov I, Arishtirova K, Bueno J.M.C, DAmyanova S, Applied cataltsis A: General (2014);474:135-148.

[91] Serrano -Ruiz J. C, Huber G. W, Sánchez-Castillo M. A, Dumesic J. A, Rodriguez-Reinoso

F, Sepulveda-Escribano A, Journal of Catalysis, (2006);241:378-388.

[92] Ivanova A.S, Slavinskaya E.M, Gulyaev R. V, Zaikovskii V. j, Stonkus O.A, Danilova I.G,

Plyasova L.M, Polukhina I.A, Boronin A.I, Applied Catalysis B: Environmental, (2010);97:5771.

[93] Muradov NZ, Veziroglu TN. International Journal of Hydrogen Energy (2005);30(3):225-37.

[94] Farhad S, Hamdullahpur F. Journal of Power Sources (2009);191(2):407-16.

[95] Farhad S, Hamdullahpur F. Journal of Power Sources (2009);193(2):632-8.

[96] Farhad S, Yoo Y, Hamdullahpur F. International Journal of Hydrogen Energy (2010);35(8):3758-68.

[97] Farhad S, Yoo Y, Hamdullahpur F. Journal of Power Sources (2010);195(5):1446-53.

[98] Louis-Charles de M. Abdellah Ch. Bernard C. and Figueras F., J. Chem. Soc., Faraday T rans., (1997); 93:3715-3720

[99] Olivier D, Daniel B., Applied Catalysis A: General (2000);196:271-280.

[100] Nelly H, Lilian O, Laurence P, Catherine E, María A. V, Carlos L, Florence E, Applied Catalysis A: General (2016); 517: 81-90.

[101] James A. Anderson, Fai Kait Chong, Colin H. Rochester, Journal of Molecular Catalysis A: Chemical (1999);140: 65-80.

[102] Viktor J. C, Jun W, Jorge H. P, Fabio H. R, W. Nicholas D., Journal of Catalysis (2016);339:163-172

[103] Karpinski Z, Gandhi S N, Sachtler W H M., J Catal,(1993);141(2):337.

[104] Oudet F., P. Courtine, and A. Vejux, Appl of Catalysis, (1989);50: 79-86.

[105] Tanabe T, Morikawa A, Hatanaka M, Takahashi N, Nagai Y, Soto A, Kuno O, Suzuki H, Shinjoh H. Catal Today (2012);184:219-26.

[106] Ma J, Reng S, Pan D, Li R, Xie K. Reactive \& Functional Polymers (2005);62:31-39.

[107] Kaila RK, Krause AOI. Int J Hydrogen Energy (2006);31: 1934-41.

[108] Guisnet M, Magnoux P. Appl Catal A; (2001);212: 83-96. 
[109] Srihiranpullop S, Catal Today (2004); 93-95: 723-7.

[110] Martın N, Viniegra M, Lima E, Espinosa G. Ind Eng Chem Res (2004); 43: 1206-10.

[111] Shamsi A, Baltrus JP, Spivey JJ. Appl Catal A (2005); 293: 145-52.

[112] Trimm DL. In: Ertl G, Knozinger H, Weitkamp J, editors. Handbook of heterogeneous catalysis, vol. 3. Wiley-VCH; (1997). p. 1263-80.

[113] Pinilla JL, Suelves I, Lázaro MJ, Moliner R. Chem Eng J, (2007);138(1-3):301-6.

[114] Lázaro MJ, Pinilla JL, Suelves I, Moliner R. Int J Hydrogen Energy (2008);33(15):410411. 